Supporting Information

\title{
Visible-light Promoted Selective Imination of Unactivated C-H Bonds via Copper-nitrene Intermediates for the Synthesis of 2H-Azirines
}

\author{
Liyan Feng, Chao Yang and Wujiong Xia*
}

\begin{abstract}
State Key Lab of Urban Water Resource and Environment, Harbin Institute of Technology (Shenzhen), Shenzhen 518055, China
\end{abstract}

E-mail:xiawj@hit.edu.cn 


\section{Table of Contents}

General Considerations .1

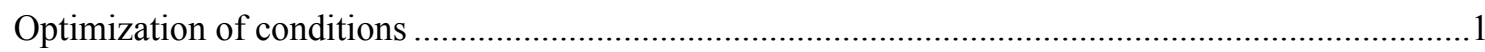

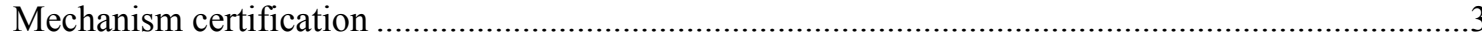

General procedure

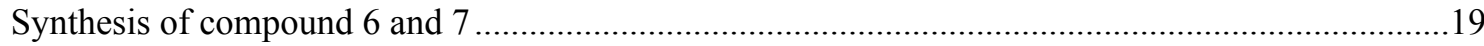

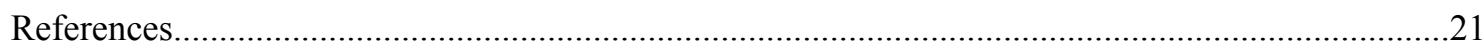

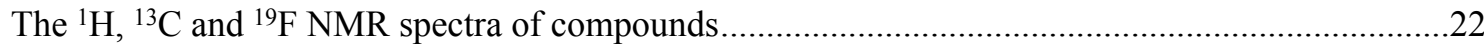




\section{General Considerations}

All reagents were purchased from commercial suppliers and used without further purification. Oxime derivatives $\mathbf{1 a - 1 z}$ and 3a-3o, $\mathbf{3 t}$ and $\mathbf{3 s}$ were prepared according to literature procedures. ${ }^{1} \mathrm{CuBr}$ was purchased in $99.99 \%$ purity as white power. Reactions were monitored by thin-layer chromatography (TLC) on commercial silica gel plates (GF254) using UV light as a visualizing agent. Flash chromatography was performed on silica gel 60 (200-300 mesh). ${ }^{1} \mathrm{H}$ and ${ }^{13} \mathrm{C}$ NMR spectra were recorded in $\mathrm{CDCl}_{3}$ on Bruker AV-400, 500 or 600 instrument with an internal tetramethylsilane (TMS) standard. Chemical shift in parts per million relatives to the chemical shift of $\mathrm{CDCl}_{3}$ at $7.26 \mathrm{ppm}$ integration and for ${ }^{13} \mathrm{C}$ NMR spectra were reported in parts per million relative to the center line signal of the $\mathrm{CDCl}_{3}$ triplet at $77.0 \mathrm{ppm}$. Abbreviations for signal couplings are: s, singlet; $\mathrm{d}$, doublet; $\mathrm{t}$, triplet; q, quartet; m, multiplet. Coupling constants $(J)$ are reported in $\mathrm{Hz}$ and refer to apparent peak multiplications. High resolution mass spectra were obtained using a Bruker Esquire LC mass spectrometer using electrospray ionization.

\section{Optimization of conditions}

Table S1. Screen of various solvents.

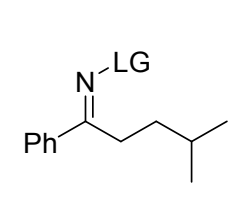

$1 a$

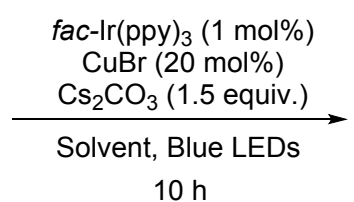

$10 \mathrm{~h}$

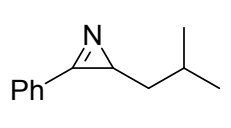

$2 a$

\begin{tabular}{ccc}
\hline Entry & solvent & Yield (\%) \\
\hline 1 & DMF & 53 \\
2 & DMA & 66 \\
3 & $\mathrm{CH}_{3} \mathrm{CN}$ & 23 \\
4 & THF & 15 \\
5 & Tolune & $<10$ \\
6 & MeOH & 0 \\
7 & $1,4-$ dioxane & 0 \\
8 & DCM & 0 \\
9 & DMSO & $<10$ \\
10 & NMP & $<10$ \\
11 & DMI & $<10$ \\
\hline
\end{tabular}

Table S2. Screen of various bases

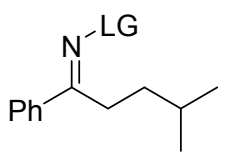

$1 a$

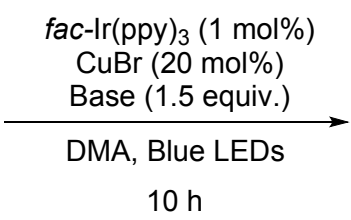

$10 \mathrm{~h}$

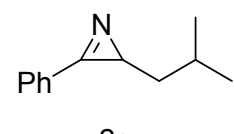

$2 a$ 


\begin{tabular}{ccc}
\hline Entry & base & Yield (\%) \\
\hline 1 & $\mathrm{Cs}_{2} \mathrm{CO}_{3}$ & 66 \\
2 & $\mathrm{Na}_{2} \mathrm{CO}_{3}$ & 30 \\
3 & $\mathrm{CsF}$ & $<10$ \\
4 & $\mathrm{~K}_{2} \mathrm{HPO}_{4}$ & 35 \\
5 & $\mathrm{CsHCO}_{3}$ & 20 \\
6 & $\mathrm{DBU}$ & $<10$ \\
7 & $2,6-$ Lutidine & $<10$ \\
\hline
\end{tabular}

Table S3. Screen of transition metals

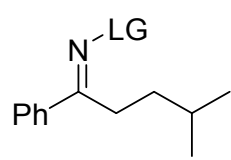

$1 \mathrm{a}$ fac- $-\operatorname{lr}(\mathrm{ppy})_{3}(1 \mathrm{~mol} \%)$ Transition metal (20 mol\%) $\mathrm{Cs}_{2} \mathrm{CO}_{3}$ (1.5 equiv.)

DMA, Blue LEDs

$10 \mathrm{~h}$

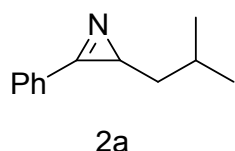

$2 a$

\begin{tabular}{ccc}
\hline Entry & Transition metal & Yield (\%) \\
\hline 1 & $\mathrm{CuBr}$ & 66 \\
2 & $\mathrm{CuBr}_{2}$ & 42 \\
3 & $\mathrm{Cu}(\mathrm{CN})_{4} \mathrm{PF}_{6}$ & 35 \\
4 & $\mathrm{CuCl}$ & 50 \\
5 & $\mathrm{CuSO}_{4}$ & $<10$ \\
6 & $\mathrm{Cu}_{4}\left(\mathrm{CF}_{3} \mathrm{SO}_{3}\right)_{2}$ & $<10$ \\
7 & $\mathrm{CuCN}_{2}$ & 23 \\
8 & $\mathrm{Cu}(\mathrm{OAc})_{2}$ & $<10$ \\
9 & $\mathrm{CuO}$ & $<10$ \\
10 & $\mathrm{Pd}(\mathrm{OAc})_{2}$ & 0 \\
11 & $\mathrm{Rh}(\mathrm{OAc})_{4}$ & 0 \\
\hline
\end{tabular}

Table S6. Effect of acid for ring-expansion reaction.<smiles>O=C(ON=C(c1ccccc1)c1ccc(C(F)(F)F)cc1)C1CCC1</smiles>

$3 a$<smiles>O=C(O)c1ccc(C(F)(F)F)cc1</smiles>

$5 a(1.5$ equiv.)

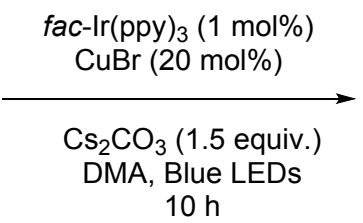

$10 \mathrm{~h}$

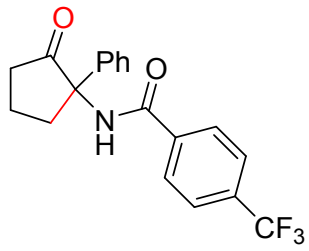

$4 a$

\begin{tabular}{ccc}
\hline Entry & 5a (equiv.) & Yield (\%) \\
\hline 1 & 0 & 40 \\
2 & 1 & 62 \\
3 & 1.5 & 75 \\
4 & 2 & 80 \\
\hline
\end{tabular}




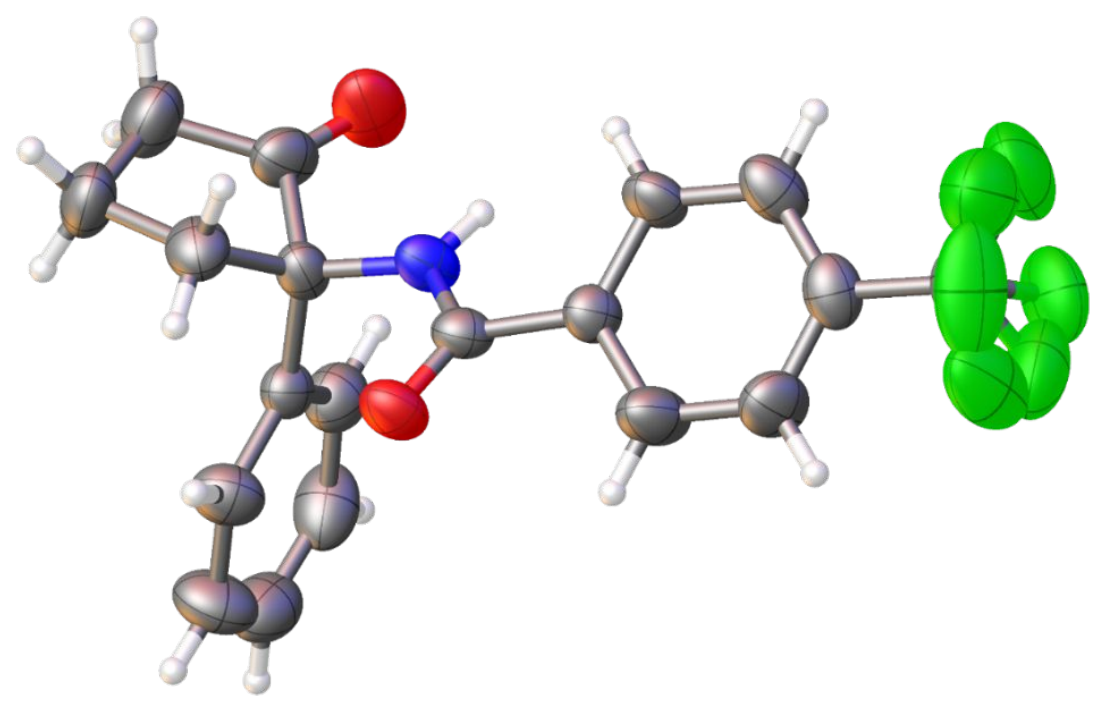

The X-ray structure of 4a. The ellipsoid contour percent probability level is 50\%. CCDC number: 1936471.

\section{Mechanism certification}

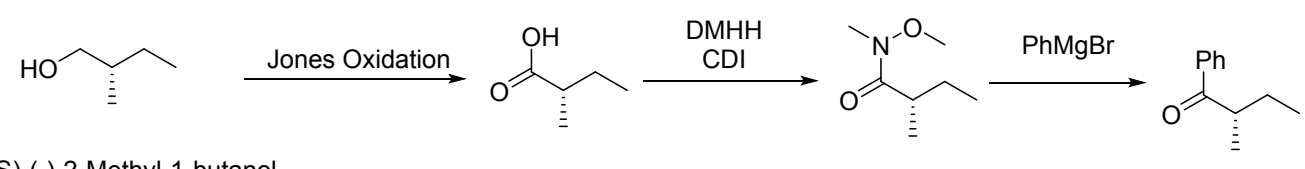

(S)-(-)-2-Methyl-1-butanol

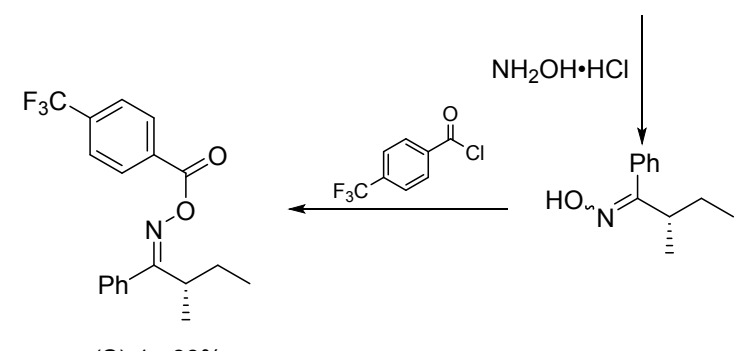

(S)-1e $88 \%$ ee

(s)-1e was prepared from (S)-(-)-2-Methyl-1-butanol through all known processes and the ee was $88 \%$ determined on chiral column HPLC: AD-H, $n$-hexane $/ i-\mathrm{PrOH}(96 / 4), 0.5 \mathrm{~mL} / \mathrm{min}$, detected at $245 \mathrm{~nm}$. Retention times: 21.5 min [minor enantiomer (R)], 22.5 min [major enantiomer (S)].

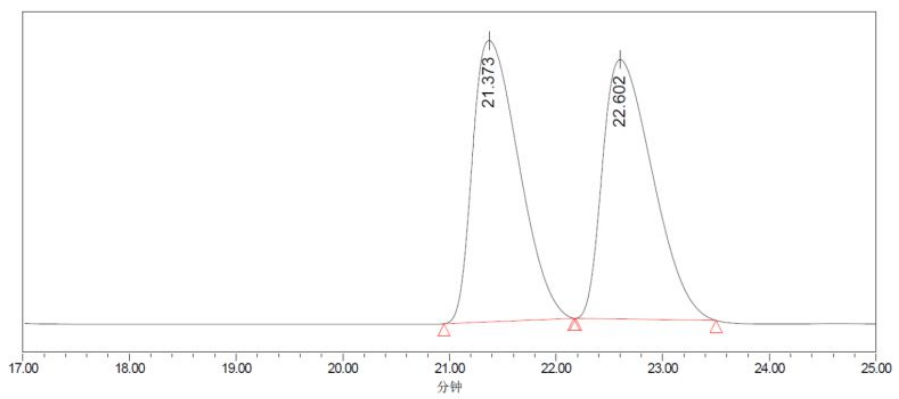

\begin{tabular}{|c|c|c|c|c|c|}
\hline \multicolumn{3}{|r|}{ RetTime } & Area & Area & Height \\
\hline & 进样 & $\begin{array}{c}\text { 保留时间 } \\
\text { (分钟) }\end{array}$ & $\begin{array}{c}\text { 面积 } \\
\text { (微伏*秒) }\end{array}$ & $\%$ 面积 & 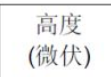 \\
\hline 1 & 1 & 22.602 & 83147797 & 50.01 & 2546005 \\
\hline 2 & 1 & 21.373 & 83114835 & 49.99 & 2762195 \\
\hline
\end{tabular}




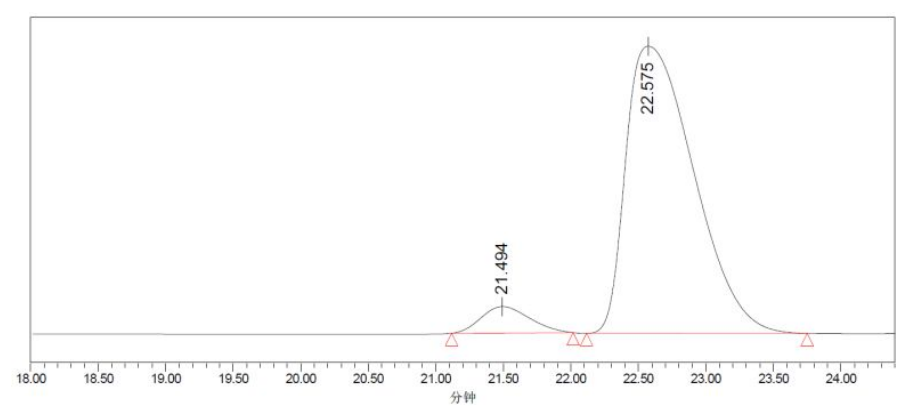

\begin{tabular}{l}
\multicolumn{9}{c}{ RetTime Area } & Area & Height \\
\begin{tabular}{|r|r|r|r|r|r|}
\hline & 进样 & $\begin{array}{c}\text { 保留时间 } \\
\text { (分钟) }\end{array}$ & $\begin{array}{c}\text { 面积 } \\
\text { (微伏*秒) }\end{array}$ & $\%$ 面积 & $\begin{array}{c}\text { 高度 } \\
\text { (微伏) }\end{array}$ \\
\hline 1 & 1 & 22.575 & 104671574 & 93.87 & 2987476 \\
\hline 2 & 1 & 21.494 & 6835376 & 6.13 & 275395 \\
\hline
\end{tabular}
\end{tabular}<smiles>CC[C@H](C)/C(=N\OC(=O)c1ccc(C(F)(F)F)cc1)c1ccccc1</smiles>

(S)-1e $88 \%$ ee

standard conditions

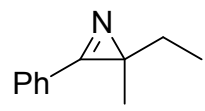

2 e $80 \%$

racemic

Following similar conditions as general procedure A, (S)-1e was transformed to 2e with very poor ee determined on chiral column HPLC: AD-H, $n$-hexane $/ i$-PrOH (99/1), $0.5 \mathrm{~mL} / \mathrm{min}$, detected at $245 \mathrm{~nm}$.

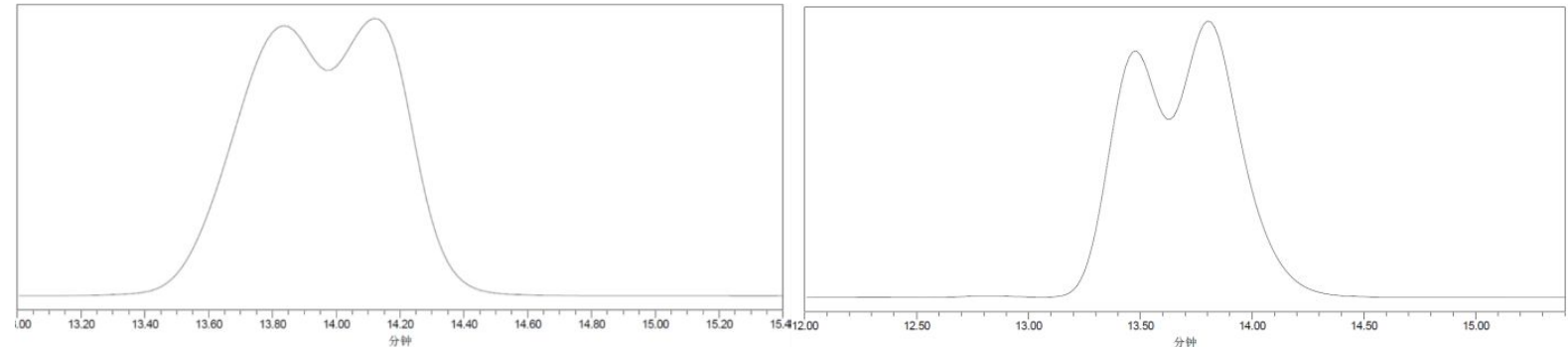

Figure 1 Starting from $1 e$

Figure 2 Starting from $(S)-1 e$

Although we can't determine an explicit value, the two figures showed the chirality corrosion obviously.

Figure 1 Stem-Volmer fluorescence quenching experiments.

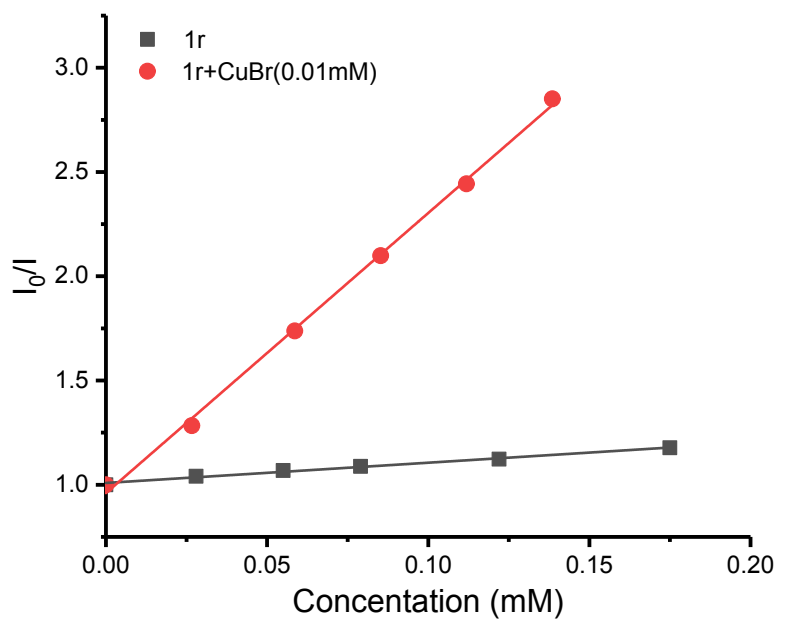

The experiments were carried out in a DMA solution of $f a c-\operatorname{Ir}(\mathrm{ppy})_{3}(0.001 \mathrm{mM})$ and variable concentrations of $1 \mathbf{r}$ with or without $\mathrm{CuBr}(0.01 \mathrm{mM})$ were added. $\lambda_{\mathrm{ex}}=420 \mathrm{~nm}$. 


\section{General procedure}

General procedure A:

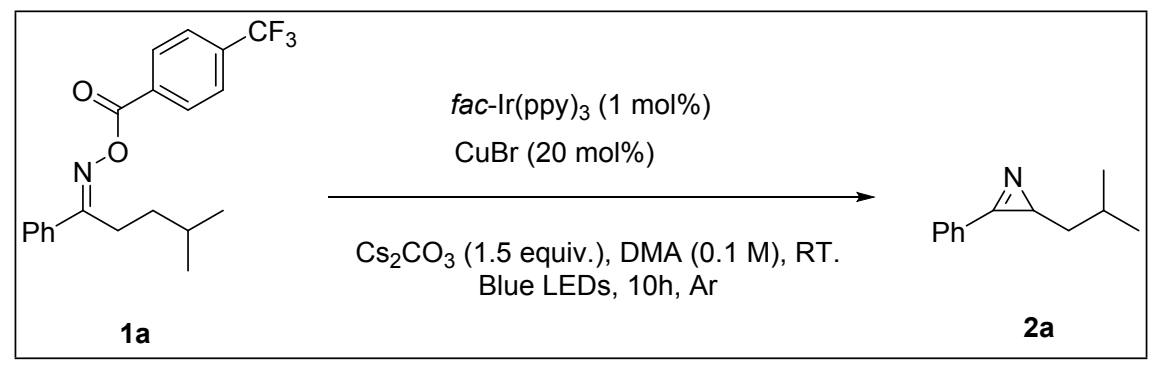

Under argon, an oven-dried glass tube equipped with a magnetic stir bar was charged with urea substrate 1a (0.2 mmol, 1.0 equiv.), fac- $\operatorname{Ir}($ ppy) 3 (1.3 mg, $1 \mathrm{~mol} \%), \mathrm{CuBr}(5.7 \mathrm{mg}, 20 \mathrm{~mol} \%), \mathrm{Cs}_{2} \mathrm{CO}_{3}$ (98.2 mg, 1.5 equiv.) and N,N-dimethylacetamide ( $2 \mathrm{ml})$, the tube was evacuated and backfilled with argon for 3 times then stirred at room temperature with a fan under the irradiation of $5 \mathrm{~W}$ blue LEDs for 10 hours. Upon completion, the reaction was quenched by cold water and extracted by ethyl acetate $(10 \mathrm{ml} \times 3)$ then filtered through celite to remove the undissolved copper salt if necessary. The organic phase was washed with brine, dried over $\mathrm{Na}_{2} \mathrm{SO}_{4}$ and concentrated in vacuo. The residue was purified by flash chromatography eluted with $\mathrm{PE} / \mathrm{EA}=100 / 1-50 / 1$ to afford the product $\mathbf{2 a}$. $2 \mathbf{a}-\mathbf{2} \mathbf{z}$ were prepared according to this procedure.

General procedure B:

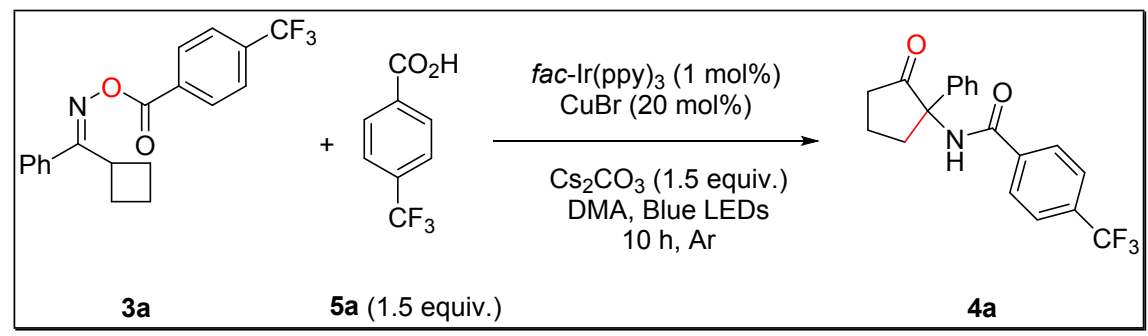

Under argon, an oven-dried glass tube equipped with a magnetic stir bar was charged with urea substrate 3a (0.3 mmol, 1.0 equiv.), 5a (85.8 mg, 1.5 equiv.), $f a c-\operatorname{Ir}(\mathrm{ppy})_{3}(2.0 \mathrm{mg}, 1 \mathrm{~mol} \%), \mathrm{CuBr}(8.6 \mathrm{mg}, 20 \mathrm{~mol} \%$ ), $\mathrm{Cs}_{2} \mathrm{CO}_{3}$ (147.0 mg, 1.5 equiv.) and $\mathrm{N}, \mathrm{N}$-dimethylacetamide $(2 \mathrm{ml})$, the tube was evacuated and backfilled with argon for 3 times then stirred at room temperature with a fan under the irradiation of $5 \mathrm{~W}$ blue LEDs for 10 hours. Upon completion, the reaction was quenched by cold water and extracted by ethyl acetate $(10 \mathrm{ml} \times$ 3) then filtered through celite to remove the undissolved copper salt if necessary. The organic phase was washed with brine, dried over $\mathrm{Na}_{2} \mathrm{SO}_{4}$ and concentrated in vacuo. The residue was purified by flash chromatography eluted with PE/EA/MTBE $=20 / 1 / 2$ to afford the product $\mathbf{4 a}$. 4a-4o and $4 \mathbf{s}$ were prepared according to this procedure.

General procedure $\mathbf{C}$ :

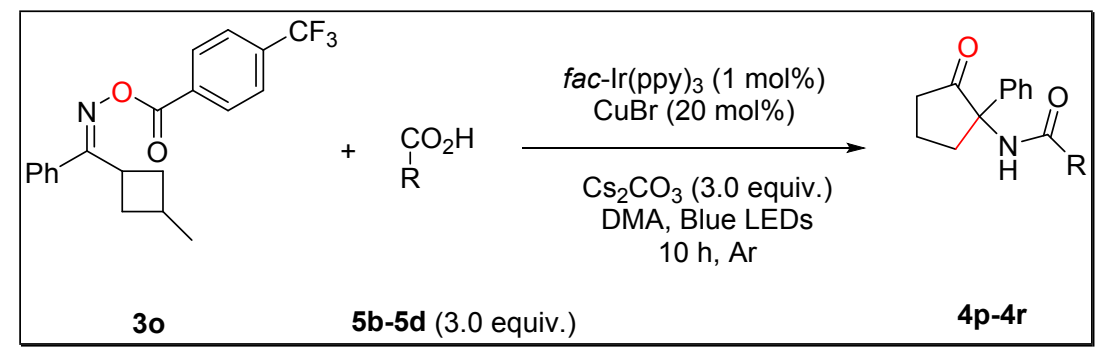


Under argon, an oven-dried glass tube equipped with a magnetic stir bar was charged with urea substrate 30 ( 0.3 mmol, 1.0 equiv.), 5b-5d (3.0 equiv.), fac- $\operatorname{Ir}(\mathrm{ppy})_{3}(2.0 \mathrm{mg}, 1 \mathrm{~mol} \%), \mathrm{CuBr}(8.6 \mathrm{mg}, 20 \mathrm{~mol} \%)$, $\mathrm{Cs}_{2} \mathrm{CO}_{3}$ (300.0 mg, 3.0 equiv.) and $\mathrm{N}$,N-dimethylacetamide $(2 \mathrm{ml})$, the tube was evacuated and backfilled with argon for 3 times then stirred at room temperature with a fan under the irradiation of 5 W blue LEDs for 10 hours. Upon completion, the reaction was quenched by cold water and extracted by ethyl acetate $(10 \mathrm{ml} \times 3)$ then filtered through celite to remove the undissolved copper salt if necessary. The organic phase was washed with brine, dried over $\mathrm{Na}_{2} \mathrm{SO}_{4}$ and concentrated in vacuo. The residue was purified by flash chromatography eluted with $\mathrm{PE} / \mathrm{EA} / \mathrm{MTBE}=20 / 1 / 2$ to afford the product $\mathbf{4 p - 4 r}$.

\section{Procedure for 3 mmol-scale reaction:}
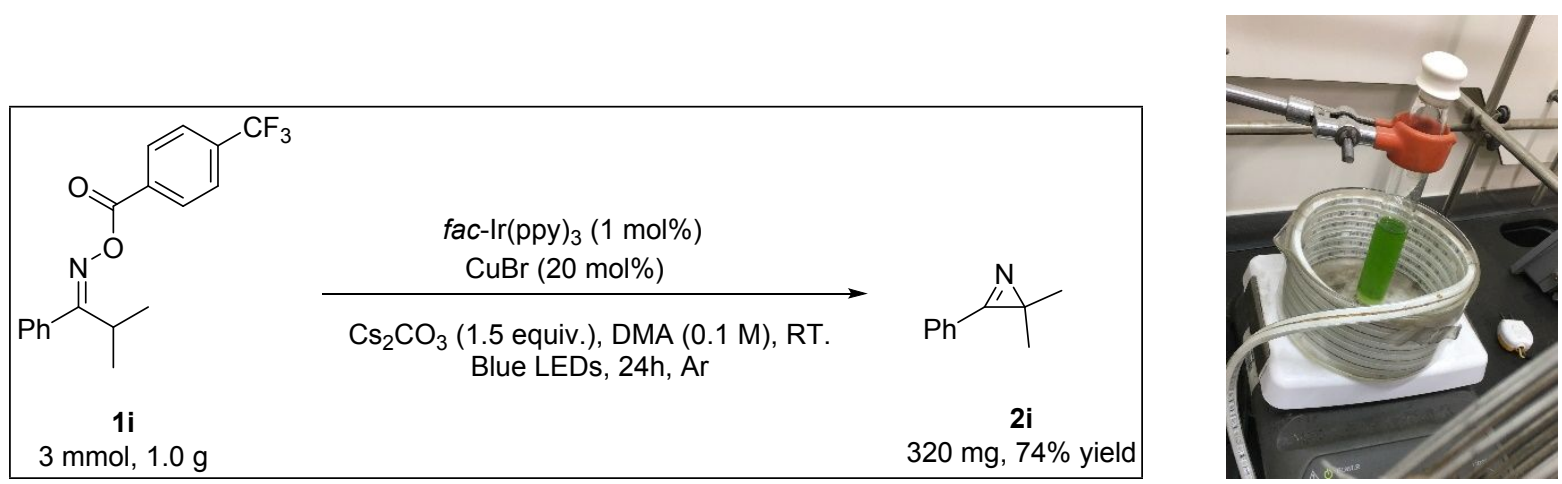

Under argon, an oven-dried glass tube equipped with a magnetic stir bar was charged with urea substrate 1i (3 mmol, 1.0 equiv.), $f a c-\operatorname{Ir}\left(\right.$ ppy) ${ }_{3}(19.5 \mathrm{mg}, 1 \mathrm{~mol} \%), \mathrm{CuBr}(85.5 \mathrm{mg}, 20 \mathrm{~mol} \%), \mathrm{Cs}_{2} \mathrm{CO}_{3}(2.9 \mathrm{~g}, 1.5$ equiv.) and $\mathrm{N}, \mathrm{N}$-dimethylacetamide $(30 \mathrm{ml})$, the tube was evacuated and backfilled with argon for 3 times then stirred at room temperature with a fan under the irradiation of $5 \mathrm{~W}$ blue LEDs for 24 hours. Upon completion, the reaction was quenched by cold water and ethyl acetate then filtered through celite to remove the undissolved copper salt. The filtrate was extracted by ethyl acetate and then the organic phase was washed with brine, dried over $\mathrm{Na}_{2} \mathrm{SO}_{4}$ and concentrated in vacuo. The residue was purified by flash chromatography eluted with PE/EA = 100/1-50/1 to afford the product $2 \mathbf{i}$ (320 $\mathrm{mg}, 74 \%$ yield).

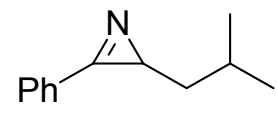

2-isobutyl-3-phenyl-2H-azirine (2a): colorless oil, purified by flash chromatography eluted with PE/EA $=100 / 1-50 / 1.66 \%$ yield $(23 \mathrm{mg}) .{ }^{1} \mathrm{H}$ NMR $(400 \mathrm{MHz}$, Chloroform- $d) \delta 7.86(\mathrm{~d}, J=7.0 \mathrm{~Hz}, 2 \mathrm{H}), 7.61-7.51(\mathrm{~m}$, $3 \mathrm{H}), 2.27(\mathrm{t}, J=5.5 \mathrm{~Hz}, 1 \mathrm{H}), 1.85(\mathrm{dp}, J=13.4,6.7 \mathrm{~Hz}, 1 \mathrm{H}), 1.55-1.38(\mathrm{~m}, 1 \mathrm{H}) 1.03(\mathrm{t}, J=6.1 \mathrm{~Hz}, 6 \mathrm{H}) .{ }^{13} \mathrm{C}$ NMR $\left(151 \mathrm{MHz}, \mathrm{CDCl}_{3}\right) \delta 171.90,132.64,129.14,129.04,125.90,42.66,31.41,27.45,22.75,22.71$. HRMS (ESI) $\mathrm{m} / \mathrm{z}$ calculated for $\mathrm{C}_{12} \mathrm{H}_{16} \mathrm{~N}(\mathrm{M}+\mathrm{H})^{+}$174.1283, found 174.1278.<smiles>CCCC1N=C1c1ccccc1</smiles>

3-phenyl-2-propyl-2H-azirine (2b): colorless oil, purified by flash chromatography eluted with PE/EA = 100/1-50/1. 60\% yield (20 mg). ${ }^{1} \mathrm{H}$ NMR (400 MHz, Chloroform- $d$ ) $\delta 7.89-7.83(\mathrm{~m}, 2 \mathrm{H}), 7.61-7.51(\mathrm{~m}, 3 \mathrm{H})$, $2.28(\mathrm{t}, J=4.8 \mathrm{~Hz}, 1 \mathrm{H}), 1.60(\mathrm{ddd}, J=11.9,7.1,3.3 \mathrm{~Hz}, 3 \mathrm{H}), 1.47$ (dddd, $J=14.7,11.2,7.0,2.8 \mathrm{~Hz}, 2 \mathrm{H}), 0.97(\mathrm{t}, J=$ 
$7.3 \mathrm{~Hz}, 3 \mathrm{H}) .{ }^{13} \mathrm{C} \mathrm{NMR}\left(101 \mathrm{MHz}, \mathrm{CDCl}_{3}\right) \delta 171.97,132.64,129.20,129.04,126.04,35.24,32.38,20.81,13.99 . \mathrm{HRMS}$ (ESI) $m / z$ calculated for $\mathrm{C}_{11} \mathrm{H}_{14} \mathrm{~N}(\mathrm{M}+\mathrm{H})^{+} 160.1126$, found 160.1120 .<smiles>c1ccc(CCC2N=C2c2ccccc2)cc1</smiles>

2-phenethyl-3-phenyl-2H-azirine (2c): colorless oil, purified by flash chromatography eluted with $\mathrm{PE} / \mathrm{EA}=100 / 1-50 / 1.44 \%$ yield $(22 \mathrm{mg}){ }^{1} \mathrm{H}$ NMR (600 MHz, Chloroform- $d$ ) $\delta 7.73-7.67(\mathrm{~m}, 2 \mathrm{H}), 7.58-7.52(\mathrm{~m}$, 1H), $7.51-7.46(\mathrm{~m}, 2 \mathrm{H}), 7.27(\mathrm{t}, J=7.5 \mathrm{~Hz}, 2 \mathrm{H}), 7.23-7.16(\mathrm{~m}, 3 \mathrm{H}), 2.85-2.72(\mathrm{~m}, 2 \mathrm{H}), 2.29(\mathrm{t}, J=4.9 \mathrm{~Hz}, 1 \mathrm{H})$, $2.04-1.89$ (m, $2 \mathrm{H}) .{ }^{13} \mathrm{C}$ NMR $\left(151 \mathrm{MHz}, \mathrm{CDCl}_{3}\right) \delta 171.74,141.57,132.67,129.18,128.95,128.44,128.34,125.82$, 125.58, 34.81, 33.60, 33.59, 31.93. HRMS (ESI) $\mathrm{m} / z$ calculated for $\mathrm{C}_{16} \mathrm{H}_{16} \mathrm{~N}(\mathrm{M}+\mathrm{H})^{+} 222.1283$, found 222.1280 .<smiles>C=CCCC1N=C1c1ccccc1</smiles>

2-(but-3-en-1-yl)-3-phenyl-2H-azirine (2d): colorless oil, purified by flash chromatography eluted with $\mathrm{PE} / \mathrm{EA}=100 / 1-50 / 1.64 \%$ yield $(22 \mathrm{mg}){ }^{1} \mathrm{H}$ NMR $(400 \mathrm{MHz}$, Chloroform- $d) \delta 7.86(\mathrm{~d}, J=7.5 \mathrm{~Hz}, 2 \mathrm{H}), 7.55(\mathrm{q}, J$ $=6.7,6.0 \mathrm{~Hz}, 3 \mathrm{H}), 5.86(\mathrm{ddt}, J=17.0,11.0,6.6 \mathrm{~Hz}, 1 \mathrm{H}), 5.02(\mathrm{dd}, J=31.4,13.6 \mathrm{~Hz}, 2 \mathrm{H}), 2.29(\mathrm{t}, J=4.9 \mathrm{~Hz}, 1 \mathrm{H}), 2.20$ $(\mathrm{q}, J=7.4 \mathrm{~Hz}, 2 \mathrm{H}), 1.73(\mathrm{q}, J=7.3 \mathrm{~Hz}, 2 \mathrm{H}) .{ }^{13} \mathrm{C} \mathrm{NMR}\left(101 \mathrm{MHz}, \mathrm{CDCl}_{3}\right) \delta 171.72,138.02,132.71,129.24,129.04$, 125.83, 114.89, 32.40, 31.99, 31.60. HRMS (ESI) $m / z$ calculated for $\mathrm{C}_{12} \mathrm{H}_{14} \mathrm{~N}(\mathrm{M}+\mathrm{H})^{+} 172.1126$, found 172.1123 .

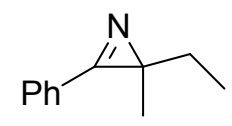

2-ethyl-2-methyl-3-phenyl-2H-azirine (2e): colorless oil, purified by flash chromatography eluted with $\mathrm{PE} / \mathrm{EA}=100 / 1-50 / 1.81 \%$ yield $(26 \mathrm{mg}){ }^{1} \mathrm{H}$ NMR $(600 \mathrm{MHz}$, Chloroform- $d) \delta 7.74(\mathrm{~d}, J=7.3 \mathrm{~Hz}, 2 \mathrm{H}), 7.50-$ $7.40(\mathrm{~m}, 3 \mathrm{H}), 1.78(\mathrm{q}, J=7.6 \mathrm{~Hz}, 1 \mathrm{H}), 1.66(\mathrm{q}, J=7.6 \mathrm{~Hz}, 1 \mathrm{H}), 1.31(\mathrm{~s}, 3 \mathrm{H}), 0.74(\mathrm{t}, J=7.6 \mathrm{~Hz}, 2 \mathrm{H}) .{ }^{13} \mathrm{C} \mathrm{NMR}(151$ $\left.\mathrm{MHz}, \mathrm{CDCl}_{3}\right) \delta 176.86,132.19,128.79,128.58,126.04,38.39,30.02,22.59,22.54,10.47$. HRMS (ESI) $m / z$ calculated for $\mathrm{C}_{11} \mathrm{H}_{14} \mathrm{~N}(\mathrm{M}+\mathrm{H})^{+} 160.1126$, found 160.1124 .

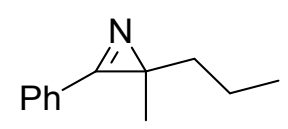

2-methyl-3-phenyl-2-propyl-2H-azirine (2f): colorless oil, purified by flash chromatography eluted with $\mathrm{PE} / \mathrm{EA}=100 / 1-50 / 1.83 \%$ yield $(29 \mathrm{mg}){ }^{1} \mathrm{H}$ NMR (400 MHz, Chloroform- $\left.d\right) \delta 7.81(\mathrm{~d}, J=7.3 \mathrm{~Hz}, 2 \mathrm{H}), 7.53(\mathrm{~d}, J$ $=6.4 \mathrm{~Hz}, 3 \mathrm{H}), 1.79(\mathrm{dt}, J=15.0,8.1 \mathrm{~Hz}, 1 \mathrm{H}), 1.65(\mathrm{dt}, J=14.5,8.0 \mathrm{~Hz}, 1 \mathrm{H}), 1.39(\mathrm{~s}, 3 \mathrm{H}), 1.27(\mathrm{~h}, J=7.4 \mathrm{~Hz}, 2 \mathrm{H})$, $0.88(\mathrm{t}, J=7.3 \mathrm{~Hz}, 3 \mathrm{H}) .{ }^{13} \mathrm{C} \mathrm{NMR}\left(101 \mathrm{MHz}, \mathrm{CDCl}_{3}\right) \delta 176.94,132.38,129.01,128.82,126.28,39.91,37.75,23.16$, 19.76, 14.13. HRMS (ESI) $m / z$ calculated for $\mathrm{C}_{12} \mathrm{H}_{16} \mathrm{~N}(\mathrm{M}+\mathrm{H})^{+} 174.1283$, found 174.1280.

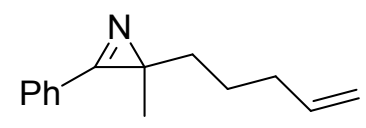

2-methyl-2-(pent-4-en-1-yl)-3-phenyl-2H-azirine (2g): colorless oil, purified by flash chromatography eluted with PE/EA = 100/1-50/1. 75\% yield $(30 \mathrm{mg}){ }^{1} \mathrm{H}$ NMR $(600 \mathrm{MHz}$, Chloroform- $d$ ) $\delta 7.80$ (dd, $J=7.9,1.7$ $\mathrm{Hz}, 2 \mathrm{H}), 7.59-7.47$ (m, 3H), $5.73(\mathrm{ddt}, J=16.9,10.2,6.7 \mathrm{~Hz}, 1 \mathrm{H}), 4.94(\mathrm{dq}, J=17.1,1.7 \mathrm{~Hz}, 1 \mathrm{H}), 4.90$ (ddt, $J=10.2$, 2.2, $1.3 \mathrm{~Hz}, 1 \mathrm{H}), 2.01$ (q, $J=7.1 \mathrm{~Hz}, 3 \mathrm{H}), 1.80$ (ddd, $J=14.2,9.6,6.9 \mathrm{~Hz}, 1 \mathrm{H}), 1.70$ (ddd, $J=14.2,9.7,6.7 \mathrm{~Hz}, 1 \mathrm{H}$ ), $1.38(\mathrm{~s}, 3 \mathrm{H}), 1.37-1.30(\mathrm{~m}, 2 \mathrm{H}) .{ }^{13} \mathrm{C}$ NMR $\left(151 \mathrm{MHz}, \mathrm{CDCl}_{3}\right) \delta 176.81,138.46,132.42,129.00,128.80,126.09$, $114.51,37.55,37.02,33.62,25.69,23.13$. HRMS (ESI) $m / z$ calculated for $\mathrm{C}_{14} \mathrm{H}_{18} \mathrm{~N}(\mathrm{M}+\mathrm{H})^{+} 200.1439$, found 200.1434. 


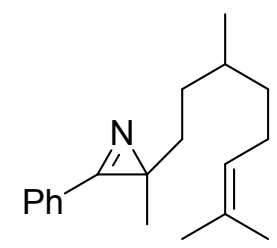

2-(3, 7-dimethyloct-6-en-1-yl)-2-methyl-3-phenyl-2H-azirine (2h): colorless oil, purified by flash chromatography eluted with $\mathrm{PE} / \mathrm{EA}=100 / 1-50 / 1.82 \%$ yield $(44 \mathrm{mg}, \mathrm{dr}=1: 1)^{1} \mathrm{H} \mathrm{NMR}(600 \mathrm{MHz}$, Chloroform- $d$ ) $\delta 7.80-7.75(\mathrm{~m}, 2 \mathrm{H}), 7.55-7.47(\mathrm{~m}, 3 \mathrm{H}), 5.02(\mathrm{dddt}, J=8.6,7.1,5.7,1.4 \mathrm{~Hz}, 1 \mathrm{H}), 1.96-1.89(\mathrm{~m}$, $1 \mathrm{H}), 1.88-1.83(\mathrm{~m}, 1 \mathrm{H}), 1.82-1.78(\mathrm{~m}, 0.5 \mathrm{H}), 1.76-1.66(\mathrm{~m}, 1 \mathrm{H}), 1.62(\mathrm{~d}, J=1.6 \mathrm{~Hz}, 3 \mathrm{H}), 1.61-1.56(\mathrm{~m}, 0.5 \mathrm{H})$, $1.52(\mathrm{~d}, J=5.2 \mathrm{~Hz}, 3 \mathrm{H}), 1.35(\mathrm{~s}, 3 \mathrm{H}), 1.34-1.30(\mathrm{~m}, 1 \mathrm{H}), 1.28-1.20(\mathrm{~m}, 2 \mathrm{H}), 1.11-1.01(\mathrm{~m}, 2 \mathrm{H}), 0.79(\mathrm{~d}, J=3.4 \mathrm{~Hz}$, 3H). ${ }^{13} \mathrm{C}$ NMR (151 MHz, $\mathrm{CDCl}_{3}$ ) $\delta$ 177.07, 132.36, 130.94, 128.97, 128.79, 126.19, 124.79, 37.86, 36.89, 35.02, 33.47, 32.27, 25.63, 25.40, 23.14, 19.40, 17.51. HRMS (ESI) $\mathrm{m} / z$ calculated for $\mathrm{C}_{19} \mathrm{H}_{28} \mathrm{~N}(\mathrm{M}+\mathrm{H})^{+} 270.2222$, found 270.2225.<smiles>CC1(C)N=C1c1ccccc1</smiles>

2, 2-dimethyl-3-phenyl-2H-azirine ${ }^{2}$ (2i): colorless oil, purified by flash chromatography eluted with PE/EA $=100 / 1-50 / 1.75 \%$ yield $(22 \mathrm{mg}){ }^{1} \mathrm{H}$ NMR (400 MHz, Chloroform- $d$ ) $\delta 7.92-7.75(\mathrm{~m}, 2 \mathrm{H}), 7.64-7.46(\mathrm{~m}$, $3 \mathrm{H}), 1.42(\mathrm{~s}, 6 \mathrm{H}) .{ }^{13} \mathrm{C} \mathrm{NMR}\left(101 \mathrm{MHz}, \mathrm{CDCl}_{3}\right) \delta 177.73,132.48,129.05,128.91,125.89,33.87,24.59$.<smiles>CC1(C)N=C1c1ccc(C(F)(F)F)cc1</smiles>

2, 2-dimethyl-3-(4-(trifluoromethyl) phenyl)-2H-azirine (2j): colorless oil, purified by flash chromatography eluted with PE/EA $=100 / 1-50 / 1.70 \%$ yield $(30 \mathrm{mg}){ }^{1} \mathrm{H}$ NMR $(500 \mathrm{MHz}$, Chloroform- $d$ ) $\delta 7.92$ $(\mathrm{d}, J=7.9 \mathrm{~Hz}, 2 \mathrm{H}), 7.80(\mathrm{~d}, J=7.9 \mathrm{~Hz}, 2 \mathrm{H}), 1.43(\mathrm{~s}, 6 \mathrm{H}) \cdot{ }^{13} \mathrm{C} \mathrm{NMR}\left(126 \mathrm{MHz}, \mathrm{CDCl}_{3}\right) \delta 177.67,134.00(\mathrm{q}, J=32.7$ $\mathrm{Hz}), 129.17,129.07,126.10(\mathrm{q}, J=3.8 \mathrm{~Hz}), 123.55$ (q, $J=272.6 \mathrm{~Hz}), 34.92,24.52 .{ }^{19} \mathrm{~F} \mathrm{NMR}\left(376 \mathrm{MHz}, \mathrm{CDCl}_{3}\right) \delta$ -63.03. HRMS (ESI) $m / z$ calculated for $\mathrm{C}_{11} \mathrm{H}_{11} \mathrm{~F}_{3} \mathrm{~N}(\mathrm{M}+\mathrm{H})^{+} 214.2112$, found 214.2110.<smiles>CC(=O)c1ccc(C2NC2(C)C)cc1</smiles>

methyl 4-(2, 2-dimethyl-2H-azirin-3-yl)benzoate (2k): colorless oil, purified by flash chromatography eluted with PE/EA $=100 / 1-50 / 1.76 \%$ yield $(31 \mathrm{mg}){ }^{1} \mathrm{H}$ NMR $(500 \mathrm{MHz}$, Chloroform- $d$ ) $\delta 8.17(\mathrm{~d}, J=8.1 \mathrm{~Hz}$, 2H), 7.85 (d, $J=7.9 \mathrm{~Hz}, 2 \mathrm{H}), 3.94$ (s, 3H), 1.41 (s, 6H). ${ }^{13} \mathrm{C}$ NMR $\left(126 \mathrm{MHz}, \mathrm{CDCl}_{3}\right) \delta$ 177.74, 166.04, 133.42, 130.16, 129.62, 128.62, 52.41, 34.67, 24.52. HRMS (ESI) $m / z$ calculated for $\mathrm{C}_{12} \mathrm{H}_{14} \mathrm{NO}_{2}(\mathrm{M}+\mathrm{H})^{+} 204.1025$, found 204.1027.<smiles>CC1(Cc2ccccc2)N=C1c1ccccc1</smiles>

2-benzyl-2-methyl-3-phenyl-2H-azirine ${ }^{3}$ (21): colorless oil, purified by flash chromatography eluted with PE/EA $=100 / 1-50 / 1.60 \%$ yield $(27 \mathrm{mg}){ }^{1} \mathrm{H}$ NMR $(600 \mathrm{MHz}$, Chloroform- $d$ ) $\delta 7.72-7.68(\mathrm{~m}, 2 \mathrm{H}), 7.56-$ $7.51(\mathrm{~m}, 1 \mathrm{H}), 7.50-7.46(\mathrm{~m}, 2 \mathrm{H}), 7.27-7.24(\mathrm{~m}, 2 \mathrm{H}), 7.22-7.15(\mathrm{~m}, 3 \mathrm{H}), 3.14(\mathrm{~d}, J=14.2 \mathrm{~Hz}, 1 \mathrm{H}), 2.85(\mathrm{~d}, J=14.2$ $\mathrm{Hz}, 1 \mathrm{H}), 1.39$ (s, 3H). ${ }^{13} \mathrm{C}$ NMR $\left(151 \mathrm{MHz}, \mathrm{CDCl}_{3}\right) \delta 176.84,138.66,132.51,129.49,128.96,128.92,128.26,126.22$, 125.75, 45.28, 38.48, 22.57. HRMS (ESI) $m / z$ calculated for $\mathrm{C}_{13} \mathrm{H}_{18} \mathrm{~N}(\mathrm{M}+\mathrm{H})^{+}$188.1434, found 188.1431. 


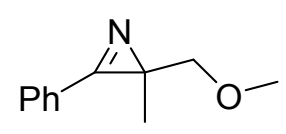

2-(methoxymethyl)-2-methyl-3-phenyl-2H-azirine (2m): colorless oil, purified by flash chromatography eluted with PE/EA $=100 / 1-50 / 1.80 \%$ yield $(28 \mathrm{mg}){ }^{1} \mathrm{H}$ NMR $(600 \mathrm{MHz}$, Chloroform- $d$ ) $\delta 7.84$ - $7.81(\mathrm{~m}, 2 \mathrm{H}), 7.57-7.50(\mathrm{~m}, 3 \mathrm{H}), 3.60(\mathrm{~d}, J=10.9 \mathrm{~Hz}, 1 \mathrm{H}), 3.51(\mathrm{~d}, J=10.9 \mathrm{~Hz}, 1 \mathrm{H}), 3.33(\mathrm{~s}, 3 \mathrm{H}), 1.39(\mathrm{~s}, 3 \mathrm{H}) .{ }^{13} \mathrm{C}$ NMR $\left(151 \mathrm{MHz}, \mathrm{CDCl}_{3}\right) \delta 174.13,132.66,129.16,128.98,125.40,76.79,58.77,36.52,19.85$. HRMS (ESI) $\mathrm{m} / \mathrm{z}$ calculated for $\mathrm{C}_{11} \mathrm{H}_{14} \mathrm{NO}(\mathrm{M}+\mathrm{H})^{+} 176.1075$, found 176.1078 .<smiles>c1ccccc1</smiles>

2-phenyl-6-oxa-1-azaspiro[2.5]oct-1-ene (2n): colorless oil, purified by flash chromatography eluted with PE/EA $=100 / 1-50 / 1.48 \%$ yield $(18 \mathrm{mg}){ }^{1} \mathrm{H}$ NMR (400 MHz, Chloroform- $d$ ) $\delta 7.86-7.82(\mathrm{~m}, 2 \mathrm{H}), 7.60-$ $7.52(\mathrm{~m}, 3 \mathrm{H}), 4.06$ (ddd, $J=11.1,7.1,3.9 \mathrm{~Hz}, 2 \mathrm{H}), 3.83(\mathrm{ddd}, J=11.1,6.9,4.0 \mathrm{~Hz}, 2 \mathrm{H}), 1.79$ (ddd, $J=13.8,7.1,4.0$ $\mathrm{Hz}, 2 \mathrm{H}), 1.68$ (ddd, $J=13.8,6.9,4.0 \mathrm{~Hz}, 2 \mathrm{H}) .{ }^{13} \mathrm{C} \mathrm{NMR}\left(101 \mathrm{MHz}, \mathrm{CDCl}_{3}\right) \delta 177.61,132.92,129.19,129.04,125.33$, 68.01, 37.20, 35.42. HRMS (ESI) $m / z$ calculated for $\mathrm{C}_{12} \mathrm{H}_{14} \mathrm{NO}(\mathrm{M}+\mathrm{H})^{+} 188.1075$, found 188.1080 .<smiles>c1ccc([C@@H]2NC23CCSCC3)cc1</smiles>

2-phenyl-6-thia-1-azaspiro[2.5]oct-1-ene (2o): colorless oil, purified by flash chromatography eluted with PE/EA $=100 / 1-50 / 1.51 \%$ yield $(21 \mathrm{mg}){ }^{1} \mathrm{H}$ NMR (400 MHz, Chloroform- $d$ ) $\delta 7.85-7.79(\mathrm{~m}, 2 \mathrm{H}), 7.63-$ $7.52(\mathrm{~m}, 3 \mathrm{H}), 3.03$ (dddd, $J=13.0,8.4,3.2,0.9 \mathrm{~Hz}, 2 \mathrm{H}$ ), 2.72 (dddd, $J=13.2,7.2,3.4,1.0 \mathrm{~Hz}, 2 \mathrm{H}$ ), 2.02 (ddd, $J=13.8$, 8.6, 3.4 Hz, 2H), 1.84 (ddd, $J=13.8,7.7,3.3 \mathrm{~Hz}, 2 \mathrm{H}) .{ }^{13} \mathrm{C} \mathrm{NMR}\left(101 \mathrm{MHz}, \mathrm{CDCl}_{3}\right) \delta$ 178.17, 132.94, 129.19, 129.10, 125.28, 38.51, 37.00, 28.42. HRMS (ESI) $m / z$ calculated for $\mathrm{C}_{12} \mathrm{H}_{14} \mathrm{NS}(\mathrm{M}+\mathrm{H})^{+} 204.0847$, found 204.0842.

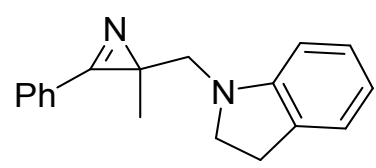

1-((2-methyl-3-phenyl-2H-azirin-2-yl)methyl)indoline (2p): yellow solid, purified by flash chromatography eluted with PE/EA $=100 / 1-10 / 1.61 \%$ yield $(32 \mathrm{mg}){ }^{1} \mathrm{H}$ NMR $(500 \mathrm{MHz}$, Chloroform- $d$ ) $\delta$ $7.82(\mathrm{~d}, J=6.2 \mathrm{~Hz}, 2 \mathrm{H}), 7.54(\mathrm{dt}, J=14.2,7.0 \mathrm{~Hz}, 3 \mathrm{H}), 7.04(\mathrm{t}, J=7.3 \mathrm{~Hz}, 2 \mathrm{H}), 6.62(\mathrm{t}, J=7.3 \mathrm{~Hz}, 1 \mathrm{H}), 6.51(\mathrm{~d}, J=$ $7.9 \mathrm{~Hz}, 1 \mathrm{H}), 3.52(\mathrm{q}, J=8.4 \mathrm{~Hz}, 1 \mathrm{H}), 3.46-3.36(\mathrm{~m}, 2 \mathrm{H}), 3.20(\mathrm{~d}, J=14.6 \mathrm{~Hz}, 1 \mathrm{H}), 2.94(\mathrm{t}, J=8.4 \mathrm{~Hz}, 2 \mathrm{H}), 1.48(\mathrm{~s}$, 3H). ${ }^{13} \mathrm{C}$ NMR $\left(126 \mathrm{MHz}, \mathrm{CDCl}_{3}\right) \delta 174.78,152.47,132.66,129.41,129.06,129.00,127.22,125.65,124.33,117.25$, 106.60, 56.75, 54.46, 37.41, 28.66, 20.84. HRMS (ESI) $m / z$ calculated for $\mathrm{C}_{18} \mathrm{H}_{19} \mathrm{~N}_{2}(\mathrm{M}+\mathrm{H})^{+} 263.1548$, found 263.1553 .

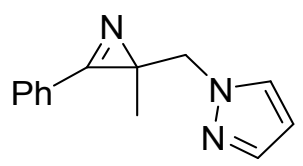

1-((2-methyl-3-phenyl-2H-azirin-2-yl)methyl)-1H-pyrazole (2q): yellow oil, purified by flash chromatography eluted with PE/EA $=100 / 1-5 / 1.32 \%$ yield $(14 \mathrm{mg}){ }^{1} \mathrm{H}$ NMR $(400 \mathrm{MHz}$, Chloroform- $d$ ) $\delta 7.80$ $-7.75(\mathrm{~m}, 2 \mathrm{H}), 7.58-7.52(\mathrm{~m}, 1 \mathrm{H}), 7.52-7.46(\mathrm{~m}, 2 \mathrm{H}), 7.44-7.40(\mathrm{~m}, 1 \mathrm{H}), 7.38(\mathrm{dd}, J=2.4,0.7 \mathrm{~Hz}, 1 \mathrm{H}), 6.19(\mathrm{t}, J$ $=2.1 \mathrm{~Hz}, 1 \mathrm{H}), 4.52(\mathrm{~d}, J=14.6 \mathrm{~Hz}, 1 \mathrm{H}), 4.28(\mathrm{~d}, J=14.5 \mathrm{~Hz}, 1 \mathrm{H}), 1.38(\mathrm{~s}, 3 \mathrm{H}) \cdot{ }^{13} \mathrm{C} \mathrm{NMR}\left(101 \mathrm{MHz}, \mathrm{CDCl}_{3}\right) \delta 173.96$, 
$139.45,132.95,129.88,129.39,128.96,124.66,105.80,58.99,37.03,20.48$. HRMS (ESI) $m / z$ calculated for $\mathrm{C}_{13} \mathrm{H}_{14} \mathrm{~N}_{3}$ $(\mathrm{M}+\mathrm{H})^{+} 212.1188$, found 212.1182 .<smiles>c1ccc(C2NC23CCCCC3)cc1</smiles>

2-phenyl-1-azaspiro[2.5]oct-1-ene ${ }^{4}$ (2r): colorless oil, purified by flash chromatography eluted with $\mathrm{PE} / \mathrm{EA}=100 / 1-50 / 1.74 \%$ yield $(28 \mathrm{mg}){ }^{1} \mathrm{H}$ NMR (400 MHz, Chloroform- $d$ ) $\delta 7.84(\mathrm{~d}, J=6.5 \mathrm{~Hz}, 2 \mathrm{H}), 7.60-$ $7.51(\mathrm{~m}, 3 \mathrm{H}), 2.00-1.84(\mathrm{~m}, 2 \mathrm{H}), 1.76-1.48(\mathrm{~m}, 8 \mathrm{H}) .{ }^{13} \mathrm{C} \mathrm{NMR}\left(101 \mathrm{MHz}, \mathrm{CDCl}_{3}\right) \delta$ 179.13, 132.51, 129.08, 129.01, $126.11,40.48,35.51,26.57,26.09$.<smiles>FC(F)(F)c1ccc(C2NC23CCCCC3)cc1</smiles>

2-(4-(trifluoromethyl)phenyl)-1-azaspiro[2.5]oct-1-ene (2s): colorless oil, purified by flash chromatography eluted with PE/EA = 100/1-50/1. 63\% yield (32 mg) ${ }^{1} \mathrm{H}$ NMR (500 MHz, Chloroform- $d$ ) $\delta 7.95$ $(\mathrm{d}, J=7.9 \mathrm{~Hz}, 2 \mathrm{H}), 7.80(\mathrm{~d}, J=8.0 \mathrm{~Hz}, 2 \mathrm{H}), 1.96-1.88(\mathrm{~m}, 2 \mathrm{H}), 1.74-1.54(\mathrm{~m}, 8 \mathrm{H}) .{ }^{13} \mathrm{C} \mathrm{NMR}\left(126 \mathrm{MHz}, \mathrm{CDCl}_{3}\right) \delta$ 179.04, 134.00 (q, $J=32.5 \mathrm{~Hz}), 129.35,129.13,126.12$ (q, $J=3.8 \mathrm{~Hz}), 123.55$ (q, $J=271.25 \mathrm{~Hz}), 41.49,35.36,26.41$, 25.96. ${ }^{19} \mathrm{~F}$ NMR (376 MHz, $\left.\mathrm{CDCl}_{3}\right) \delta-63.02$. HRMS (ESI) $m / z$ calculated for $\mathrm{C}_{14} \mathrm{H}_{15} \mathrm{~F}_{3} \mathrm{~N}(\mathrm{M}+\mathrm{H})^{+} 254.1157$, found 254.1158 .<smiles>Cc1ccc(C2NC23CCCCC3)cc1</smiles>

2-(p-tolyl)-1-azaspiro[2.5]oct-1-ene (2t): colorless oil, purified by flash chromatography eluted with $\mathrm{PE} / \mathrm{EA}=100 / 1-50 / 1.80 \%$ yield $(32 \mathrm{mg}){ }^{1} \mathrm{H}$ NMR $(500 \mathrm{MHz}$, Chloroform- $d$ ) $\delta 7.71(\mathrm{~d}, J=7.8 \mathrm{~Hz}, 2 \mathrm{H}), 7.32(\mathrm{~d}, J$ $=7.8 \mathrm{~Hz}, 2 \mathrm{H}), 2.42(\mathrm{~s}, 3 \mathrm{H}), 1.94-1.84(\mathrm{~m}, 2 \mathrm{H}), 1.72-1.49(\mathrm{~m}, 8 \mathrm{H}) .{ }^{13} \mathrm{C} \mathrm{NMR}\left(126 \mathrm{MHz}, \mathrm{CDCl}_{3}\right) \delta 178.46,143.12$, $129.69,128.91,123.23,39.94,35.43,26.50,26.01,21.68$. HRMS (ESI) $m / z$ calculated for $\mathrm{C}_{14} \mathrm{H}_{18} \mathrm{~N}(\mathrm{M}+\mathrm{H})^{+} 200.1439$, found 200.1428 .<smiles>C=Cc1ccc(C2NC23CCCCC3)cc1</smiles>

2-(4-vinylphenyl)-1-azaspiro[2.5]oct-1-ene (2u): colorless oil, purified by flash chromatography eluted with PE/EA = 100/1-50/1. 55\% yield (23 mg) ${ }^{1} \mathrm{H}$ NMR (500 MHz, Chloroform- $d$ ) $\delta 7.79(\mathrm{~d}, J=8.0 \mathrm{~Hz}, 2 \mathrm{H}), 7.56$ $(\mathrm{d}, J=7.9 \mathrm{~Hz}, 2 \mathrm{H}), 6.77(\mathrm{dd}, J=17.6,10.9 \mathrm{~Hz}, 1 \mathrm{H}), 5.89(\mathrm{~d}, J=17.6 \mathrm{~Hz}, 1 \mathrm{H}), 5.40(\mathrm{~d}, J=10.9 \mathrm{~Hz}, 1 \mathrm{H}), 1.96-1.86$ $(\mathrm{m}, 2 \mathrm{H}), 1.73-1.48(\mathrm{~m}, 8 \mathrm{H}) .{ }^{13} \mathrm{C}$ NMR $\left(126 \mathrm{MHz}, \mathrm{CDCl}_{3}\right) \delta 178.63,141.66,135.99,129.28,126.82,125.23,116.51$, 40.42, 35.51, 26.57, 26.09. HRMS (ESI) $m / z$ calculated for $\mathrm{C}_{15} \mathrm{H}_{18} \mathrm{~N}(\mathrm{M}+\mathrm{H})^{+} 212.1439$, found 212.1440. 
<smiles>Fc1ccc(C2NC23CCCCC3)cc1</smiles>

2-(4-fluorophenyl)-1-azaspiro[2.5]oct-1-ene (2v): colorless oil, purified by flash chromatography eluted with PE/EA $=100 / 1-50 / 1.64 \%$ yield $(26 \mathrm{mg}){ }^{1} \mathrm{H}$ NMR (400 MHz, Chloroform- $d$ ) $\delta 7.86-7.80(\mathrm{~m}, 2 \mathrm{H}), 7.25-$ $7.19(\mathrm{~m}, 2 \mathrm{H}), 1.96-1.84(\mathrm{~m}, 2 \mathrm{H}), 1.72-1.48(\mathrm{~m}, 8 \mathrm{H}) .{ }^{13} \mathrm{C} \mathrm{NMR}\left(101 \mathrm{MHz}, \mathrm{CDCl}_{3}\right) \delta 178.04,165.18(\mathrm{~d}, J=254.4$ $\mathrm{Hz}), 131.22$ (d, $J=9.2 \mathrm{~Hz}), 122.43$ (d, $J=3.2 \mathrm{~Hz}), 116.45$ (d, $J=22.3 \mathrm{~Hz}), 40.63,35.37,26.53,25.98 .{ }^{19} \mathrm{~F}$ NMR $(376$ $\left.\mathrm{MHz}, \mathrm{CDCl}_{3}\right) \delta$-105.38. HRMS (ESI) $\mathrm{m} / z$ calculated for $\mathrm{C}_{13} \mathrm{H}_{15} \mathrm{~F}_{3} \mathrm{~N}(\mathrm{M}+\mathrm{H})^{+}$204.1189, found 204.11178.<smiles>Clc1ccc(C2NC23CCCCC3)cc1</smiles>

2-(4-chlorophenyl)-1-azaspiro[2.5]oct-1-ene ${ }^{5}$ (2w): colorless oil, purified by flash chromatography eluted with PE/EA $=100 / 1-50 / 1.75 \%$ yield $(33 \mathrm{mg}){ }^{1} \mathrm{H}$ NMR $(500 \mathrm{MHz}$, Chloroform- $d$ ) $\delta 7.75(\mathrm{~d}, J=8.1 \mathrm{~Hz}$, 2H), 7.50 (d, $J=8.2 \mathrm{~Hz}, 2 \mathrm{H}), 1.96-1.84$ (m, 2H), $1.75-1.49$ (m, 8H). ${ }^{13} \mathrm{C}$ NMR (126 MHz, $\mathrm{CDCl}_{3}$ ) $\delta 178.40,138.73$, $130.14,129.52,124.59,40.88,35.41,26.52,26.02$.

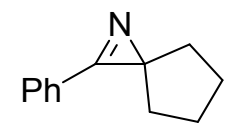

2-phenyl-1-azaspiro[2.4]hept-1-ene $\mathbf{3}^{\mathbf{3}} \mathbf{2 x}$ ): colorless oil, purified by flash chromatography eluted with $\mathrm{PE} / \mathrm{EA}=100 / 1-50 / 1.61 \%$ yield $(21 \mathrm{mg}){ }^{1} \mathrm{H}$ NMR $(600 \mathrm{MHz}$, Chloroform- $d) \delta 7.82(\mathrm{~d}, J=7.1 \mathrm{~Hz}, 2 \mathrm{H}), 7.59-$ $7.50(\mathrm{~m}, 3 \mathrm{H}), 2.08-1.93(\mathrm{~m}, 2 \mathrm{H}), 1.89(\mathrm{dt}, J=13.6,6.6 \mathrm{~Hz}, 2 \mathrm{H}), 1.82-1.72(\mathrm{~m}, 2 \mathrm{H}), 1.52(\mathrm{dt}, J=13.2,6.2 \mathrm{~Hz}, 2 \mathrm{H})$. ${ }^{13} \mathrm{C}$ NMR $\left(151 \mathrm{MHz}, \mathrm{CDCl}_{3}\right) \delta 171.93,132.42,129.00,128.93,125.60,44.12,34.11,26.18$.

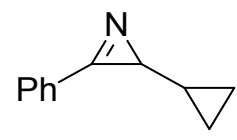

2-cyclopropyl-3-phenyl-2H-azirine ${ }^{6}$ (2y): colorless oil, purified by flash chromatography eluted with $\mathrm{PE} / \mathrm{EA}=100 / 1-50 / 1.53 \%$ yield $(17 \mathrm{mg}){ }^{1} \mathrm{H}$ NMR (500 MHz, Chloroform- $d$ ) $\delta 7.84(\mathrm{~d}, J=7.3 \mathrm{~Hz}, 2 \mathrm{H}), 7.56$ (dd, $J=11.1,7.0 \mathrm{~Hz}, 3 \mathrm{H}), 2.35(\mathrm{~d}, J=3.7 \mathrm{~Hz}, 1 \mathrm{H}), 1.08$ (tq, $J=8.8,4.6 \mathrm{~Hz}, 1 \mathrm{H}), 0.52(\mathrm{tt}, J=8.8,4.7 \mathrm{~Hz}, 1 \mathrm{H}), 0.45(\mathrm{tt}, J=$ $8.8,4.8 \mathrm{~Hz}, 1 \mathrm{H}), 0.29(\mathrm{dq}, J=9.6,4.9 \mathrm{~Hz}, 1 \mathrm{H}), 0.22(\mathrm{dq}, J=10.0,5.0 \mathrm{~Hz}, 1 \mathrm{H}) .{ }^{13} \mathrm{C}$ NMR $\left(126 \mathrm{MHz}, \mathrm{CDCl}_{3}\right) \delta 170.08$, $132.74,129.18,129.07,125.85,34.80,12.84,4.03,3.11$. HRMS (ESI) $\mathrm{m} / z$ calculated for $\mathrm{C}_{13} \mathrm{H}_{18} \mathrm{~N}(\mathrm{M}+\mathrm{H})^{+} 188.1434$, found 188.1431 .<smiles></smiles>

3-(2-phenyl-2H-azirin-3-yl)butyl benzoate (2z): colorless oil, purified by flash chromatography eluted with PE/EA = 100/1-50/1. 70\% yield (41 mg, dr=1:1) ${ }^{1} \mathrm{H}$ NMR $\left(600 \mathrm{MHz}, \mathrm{CDCl}_{3}\right) \delta 8.03(\mathrm{~d}, J=7.8 \mathrm{~Hz}, 2 \mathrm{H}), 7.55$ (q, $J=7.0,6.3 \mathrm{~Hz}, 1 \mathrm{H}), 7.43(\mathrm{q}, J=7.1 \mathrm{~Hz}, 2 \mathrm{H}), 7.24(\mathrm{dt}, J=35.5,7.2 \mathrm{~Hz}, 3 \mathrm{H}), 7.07$ (t, $J=6.9 \mathrm{~Hz}, 2 \mathrm{H}), 4.55-4.41(\mathrm{~m}$, 
2H), 3.23 (dh, $J=14.2,7.5 \mathrm{~Hz}, 1 \mathrm{H}), 2.98$ (s, 1H), 2.31 (dq, $J=13.4,6.5 \mathrm{~Hz}, 1 \mathrm{H}), 2.06$ (tq, $J=13.1,6.5 \mathrm{~Hz}, 1 \mathrm{H}), 1.40$ $(\mathrm{d}, J=7.5 \mathrm{~Hz}, 3 \mathrm{H}) .{ }^{13} \mathrm{C}$ NMR $\left(151 \mathrm{MHz}, \mathrm{CDCl}_{3}\right) \delta 170.12,169.76,166.27,141.14,141.07,132.99,132.96,129.88$, 129.85, 129.47, 129.45, 128.32, 128.30, 128.17, 128.14, 126.72, 126.70, 125.36, 77.21, 77.00, 76.79, 62.10, 61.98, $34.40,33.87,31.59,29.95,29.88,15.95,15.73$. HRMS (ESI) $\mathrm{m} / z$ calculated for $\mathrm{C}_{19} \mathrm{H}_{19} \mathrm{NNaO}_{2}(\mathrm{M}+\mathrm{Na})^{+} 316.1304$, found 316.1301

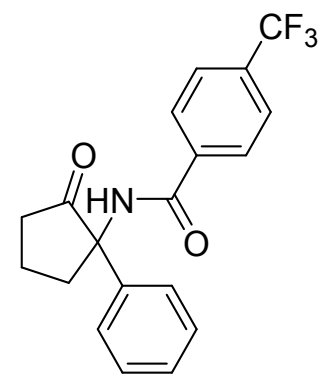

N-(2-oxo-1-phenylcyclopentyl)-4-(trifluoromethyl)benzamide (4a): colorless solid, purified by flash chromatography eluted with PE/EA/MTBE $=20 / 1 / 2.80 \%$ yield $(84 \mathrm{mg}){ }^{1} \mathrm{H}$ NMR $(400 \mathrm{MHz}$, Chloroform- $d) \delta$ $7.82(\mathrm{~d}, J=8.0 \mathrm{~Hz}, 2 \mathrm{H}), 7.64$ (d, $J=8.1 \mathrm{~Hz}, 2 \mathrm{H}), 7.57$ (d, $J=7.7 \mathrm{~Hz}, 2 \mathrm{H}), 7.45-7.30$ (m, 3H), 6.98 (s, 1H), 3.14 (dd, $J$ $=13.6,6.6 \mathrm{~Hz}, 1 \mathrm{H}), 2.65(\mathrm{td}, J=13.1,7.5 \mathrm{~Hz}, 1 \mathrm{H}), 2.58-2.48(\mathrm{~m}, 1 \mathrm{H}), 2.39(\mathrm{ddd}, J=19.6,9.5,2.0 \mathrm{~Hz}, 1 \mathrm{H}), 2.14(\mathrm{dt}$, $J=16.8,8.7 \mathrm{~Hz}, 1 \mathrm{H}), 1.94-1.76(\mathrm{~m}, 1 \mathrm{H}) .{ }^{13} \mathrm{C} \mathrm{NMR}\left(101 \mathrm{MHz}, \mathrm{CDCl}_{3}\right) \delta 213.58,164.82,137.16,136.26,133.30$ (q, $J$ $=33.9,33.3 \mathrm{~Hz}), 129.11,128.68,127.46,126.86,125.52$ (q, $J=3.7 \mathrm{~Hz}), 123.57$ (q, $J=272.4 \mathrm{~Hz}), 66.77,34.73,33.13$, 17.81. ${ }^{19} \mathrm{~F}$ NMR (376 MHz, $\left.\mathrm{CDCl}_{3}\right) \delta-62.91$. HRMS (ESI) $m / z$ calculated for $\mathrm{C}_{19} \mathrm{H}_{17} \mathrm{~F}_{3} \mathrm{NO}_{2}(\mathrm{M}+\mathrm{H})^{+} 348.1206$, found 348.1206 .

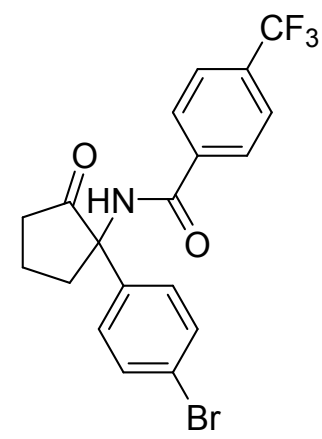

N-(1-(4-bromophenyl)-2-oxocyclopentyl)-4-(trifluoromethyl)benzamide (4b): colorless solid, purified by flash chromatography eluted with PE/EA/MTBE $=20 / 1 / 2.73 \%$ yield $(94 \mathrm{mg}){ }^{1} \mathrm{H}$ NMR $(400 \mathrm{MHz}$, Chloroform- $d$ ) $\delta 7.80$ (d, $J=8.1 \mathrm{~Hz}, 2 \mathrm{H}), 7.64(\mathrm{~d}, J=8.1 \mathrm{~Hz}, 2 \mathrm{H}), 7.49(\mathrm{~d}, J=8.7 \mathrm{~Hz}, 2 \mathrm{H}), 7.43(\mathrm{~d}, J=8.8 \mathrm{~Hz}, 2 \mathrm{H})$, 7.06 (s, 1H), 3.17 (dd, $J=13.9,6.5 \mathrm{~Hz}, 1 \mathrm{H}), 2.63-2.45$ (m, 2H), 2.38 (dd, $J=19.6,9.4 \mathrm{~Hz}, 1 \mathrm{H}), 2.14$ (ddd, $J=18.3$, 10.5, $4.9 \mathrm{~Hz}, 1 \mathrm{H}), 1.82(\mathrm{ttd}, J=12.6,9.7,6.4 \mathrm{~Hz}, 1 \mathrm{H}) .{ }^{13} \mathrm{C} \mathrm{NMR}\left(101 \mathrm{MHz}, \mathrm{CDCl}_{3}\right) \delta 213.27,164.86,136.84,134.97$, 133.36 (q, $J=32.8 \mathrm{~Hz}), 132.16,128.69,127.44,125.54$ (q, $J=3.7 \mathrm{~Hz}), 123.51$ (d, $J=272.5 \mathrm{~Hz}), 123.02,66.15,34.45$, 33.04, 17.74. ${ }^{19} \mathrm{~F}$ NMR (376 MHz, $\left.\mathrm{CDCl}_{3}\right) \delta$-62.91. HRMS (ESI) $\mathrm{m} / z$ calculated for $\mathrm{C}_{19} \mathrm{H}_{16} \mathrm{BrF}_{3} \mathrm{NO}_{2}(\mathrm{M}+\mathrm{H})^{+} 426.0317$, found 426.0317 . 


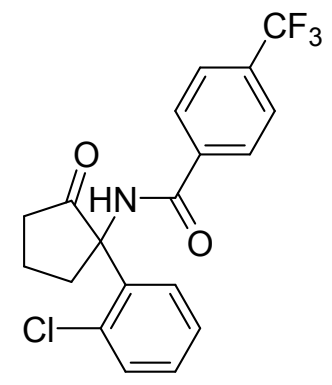

N-(1-(2-chlorophenyl)-2-oxocyclopentyl)-4-(trifluoromethyl)benzamide (4c): colorless solid, purified by flash chromatography eluted with PE/EA/MTBE $=20 / 1 / 2.70 \%$ yield $(81 \mathrm{mg}){ }^{1} \mathrm{H}$ NMR $(600 \mathrm{MHz}$, Chloroform- $d$ ) $\delta 7.87(\mathrm{~d}, J=8.1 \mathrm{~Hz}, 2 \mathrm{H}), 7.67(\mathrm{~d}, J=8.1 \mathrm{~Hz}, 2 \mathrm{H}), 7.50(\mathrm{dd}, J=7.9,1.3 \mathrm{~Hz}, 1 \mathrm{H}), 7.33(\mathrm{td}, J=7.5,2.1$ Hz, 1H), $7.30-7.22$ (m, 2H), 7.11 (s, 1H), $2.97-2.88$ (m, 2H), 2.76 (dt, $J=19.4,9.9 \mathrm{~Hz}, 1 \mathrm{H}), 2.59-2.46(\mathrm{~m}, 1 \mathrm{H})$, 2.15 (dddt, $J=12.6,9.6,6.1,2.8 \mathrm{~Hz}, 1 \mathrm{H}), 1.77-1.64(\mathrm{~m}, 1 \mathrm{H}) .{ }^{13} \mathrm{C} \mathrm{NMR}\left(151 \mathrm{MHz}, \mathrm{CDCl}_{3}\right) \delta 214.05,164.78,137.05$, 134.99, 133.32 (q, $J=32.9 \mathrm{~Hz}), 133.13,132.43,130.03,129.36,127.51,127.18,125.58$ (q, $J=3.8 \mathrm{~Hz}), 123.57$ (q, $J=$ $272.7 \mathrm{~Hz}$ ), 68.19, 36.34, 33.77, 18.02. ${ }^{19} \mathrm{~F}$ NMR (376 MHz, $\left.\mathrm{CDCl}_{3}\right) \delta-62.90$. HRMS (ESI) $\mathrm{m} / z$ calculated for $\mathrm{C}_{19} \mathrm{H}_{15} \mathrm{ClF}_{3} \mathrm{NNaO}_{2}(\mathrm{M}+\mathrm{Na})^{+} 404.0641$, found 404.0641 .

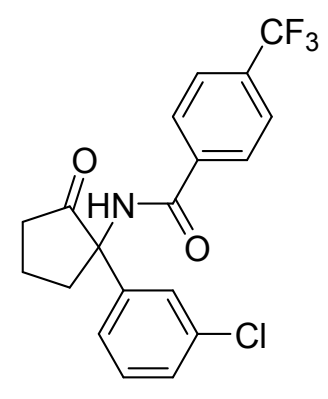

N-(1-(3-chlorophenyl)-2-oxocyclopentyl)-4-(trifluoromethyl)benzamide (4d): colorless solid, purified by flash chromatography eluted with PE/EA/MTBE $=20 / 1 / 2.75 \%$ yield $(87 \mathrm{mg}){ }^{1} \mathrm{H}$ NMR $(400 \mathrm{MHz}$, Chloroform- $d$ ) $\delta 7.81$ (d, $J=8.2 \mathrm{~Hz}, 2 \mathrm{H}), 7.64(\mathrm{~d}, J=8.2 \mathrm{~Hz}, 2 \mathrm{H}), 7.55-7.51(\mathrm{~m}, 1 \mathrm{H}), 7.50-7.39$ (m, 1H), 7.30 (dd, $J$ $=4.9,2.1 \mathrm{~Hz}, 2 \mathrm{H}), 7.07(\mathrm{~s}, 1 \mathrm{H}), 3.16(\mathrm{dd}, J=13.9,7.0 \mathrm{~Hz}, 1 \mathrm{H}), 2.63-2.46(\mathrm{~m}, 2 \mathrm{H}), 2.40(\mathrm{ddt}, J=19.6,9.3,2.1 \mathrm{~Hz}$, 1H), $2.19-2.10(\mathrm{~m}, 1 \mathrm{H}), 1.94-1.77(\mathrm{~m}, 1 \mathrm{H}) .{ }^{13} \mathrm{C} \mathrm{NMR}\left(101 \mathrm{MHz}, \mathrm{CDCl}_{3}\right) \delta 213.24,164.96,138.17,136.91,135.11$, 133.45 (q, $J=32.7 \mathrm{~Hz}), 130.33,128.96,127.66,127.55,127.29,125.62$ (q, $J=3.8 \mathrm{~Hz}), 125.18,123.59$ (q, $J=272.7$ $\mathrm{Hz}), 66.36,34.60,33.23,17.84 .{ }^{19} \mathrm{~F}$ NMR $\left(376 \mathrm{MHz}, \mathrm{CDCl}_{3}\right) \delta$-62.92. HRMS (ESI) $m / z$ calculated for $\mathrm{C}_{19} \mathrm{H}_{16} \mathrm{ClF}_{3} \mathrm{NO}_{2}$ $(\mathrm{M}+\mathrm{H})^{+} 382.0816$, found 382.0820 .

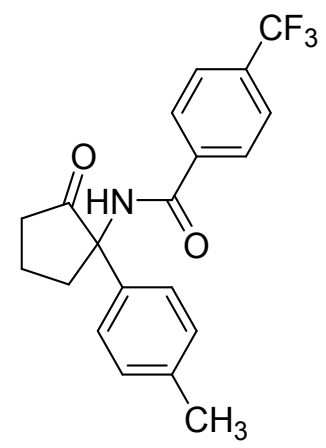

N-(2-oxo-1-(p-tolyl)cyclopentyl)-4-(trifluoromethyl)benzamide (4e): colorless solid, purified by flash chromatography eluted with PE/EA/MTBE $=20 / 1 / 2.68 \%$ yield $(75 \mathrm{mg}){ }^{1} \mathrm{H}$ NMR $(400 \mathrm{MHz}$, Chloroform- $d$ ) $\delta$ $7.82(\mathrm{~d}, J=8.1 \mathrm{~Hz}, 3 \mathrm{H}), 7.64(\mathrm{~d}, J=8.2 \mathrm{~Hz}, 3 \mathrm{H}), 7.45(\mathrm{~d}, J=8.3 \mathrm{~Hz}, 2 \mathrm{H}), 7.20$ (d, $J=8.0 \mathrm{~Hz}, 2 \mathrm{H}), 6.95(\mathrm{~s}, 1 \mathrm{H}), 3.11$ $(\mathrm{dd}, J=13.4,6.8 \mathrm{~Hz}, 1 \mathrm{H}), 2.70-2.58(\mathrm{~m}, 1 \mathrm{H}), 2.58-2.46(\mathrm{~m}, 1 \mathrm{H}), 2.39(\mathrm{tt}, J=10.4,2.1 \mathrm{~Hz}, 1 \mathrm{H}), 2.33(\mathrm{~s}, 3 \mathrm{H}), 2.19-$ 
$2.07(\mathrm{~m}, 1 \mathrm{H}), 1.93-1.76(\mathrm{~m}, 1 \mathrm{H}) .{ }^{13} \mathrm{C} \mathrm{NMR}\left(101 \mathrm{MHz}, \mathrm{CDCl}_{3}\right) \delta 213.67,164.77,138.67,137.14,133.23(\mathrm{q}, J=32.8$ Hz), 133.05, 129.79, 127.45, 126.79, 125.49 (q, $J=3.7 \mathrm{~Hz}), 123.56$ (q, $J=272.6 \mathrm{~Hz}$ ), 66.51, 34.67, 32.96, 20.98, 17.80 . ${ }^{19} \mathrm{~F}$ NMR (376 MHz, $\left.\mathrm{CDCl}_{3}\right) \delta-62.89$. HRMS (ESI) $m / z$ calculated for $\mathrm{C}_{20} \mathrm{H}_{19} \mathrm{~F}_{3} \mathrm{NO}_{2}(\mathrm{M}+\mathrm{H})^{+}$362.1362, found 362.1361 .

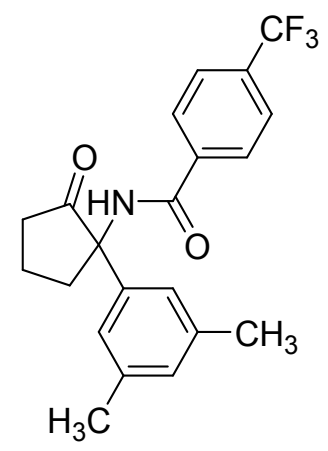

N-(1-(3, 5-dimethylphenyl)-2-oxocyclopentyl)-4-(trifluoromethyl)benzamide (4f): colorless solid, purified by flash chromatography eluted with PE/EA/MTBE $=20 / 1 / 2.65 \%$ yield $(74 \mathrm{mg}){ }^{1} \mathrm{H} \mathrm{NMR}(400 \mathrm{MHz}$, Chloroform- $d$ ) $\delta 7.84(\mathrm{~d}, J=8.2 \mathrm{~Hz}, 2 \mathrm{H}), 7.65(\mathrm{~d}, J=8.3 \mathrm{~Hz}, 2 \mathrm{H}), 7.16(\mathrm{~s}, 2 \mathrm{H}), 6.98(\mathrm{~s}, 1 \mathrm{H}), 6.88(\mathrm{~s}, 1 \mathrm{H}), 3.07(\mathrm{dd}, J=$ 13.5, 6.6 Hz, 1H), $2.68(\mathrm{td}, J=13.1,7.5 \mathrm{~Hz}, 1 \mathrm{H}), 2.55$ (dt, $J=19.9,10.0 \mathrm{~Hz}, 1 \mathrm{H}), 2.40$ (ddt, $J=19.4,9.2,2.1 \mathrm{~Hz}, 1 \mathrm{H})$, $2.19-2.07(\mathrm{~m}, 1 \mathrm{H}), 1.84$ (tddd, $J=13.0,10.6,9.4,6.6 \mathrm{~Hz}, 1 \mathrm{H}) .{ }^{13} \mathrm{C} \mathrm{NMR}\left(101 \mathrm{MHz}, \mathrm{CDCl}_{3}\right) \delta 213.77,164.73,138.73$, 137.18, 136.09, 133.22 (d, $J=32.7 \mathrm{~Hz}), 130.39,127.46,125.49$ (q, $J=3.6 \mathrm{~Hz}), 124.52,123.57$ (q, $J=272.5 \mathrm{~Hz}), 66.82$, 34.85, 33.02, 21.41, 17.84. ${ }^{19} \mathrm{~F}$ NMR $\left(376 \mathrm{MHz}, \mathrm{CDCl}_{3}\right) \delta-62.89$. HRMS (ESI) $\mathrm{m} / z$ calculated for $\mathrm{C}_{21} \mathrm{H}_{20} \mathrm{~F}_{3} \mathrm{NNaO}_{2}$ $(\mathrm{M}+\mathrm{Na})^{+}$398.1340, found 398.1328.

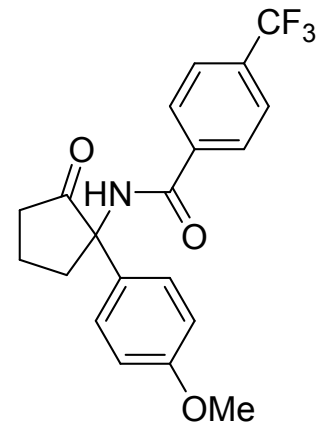

N-(1-(4-methoxyphenyl)-2-oxocyclopentyl)-4-(trifluoromethyl)benzamide $\quad \mathbf{( 4 g ) :}$ colorless solid, purified by flash chromatography eluted with $\mathrm{PE} / \mathrm{EA} / \mathrm{MTBE}=20 / 1 / 2.71 \%$ yield $(81 \mathrm{mg}){ }^{1} \mathrm{H}$ NMR $(400 \mathrm{MHz}$, Chloroform- $d$ ) $\delta 7.82$ (d, $J=8.1 \mathrm{~Hz}, 2 \mathrm{H}), 7.64(\mathrm{~d}, J=8.2 \mathrm{~Hz}, 2 \mathrm{H}), 7.55-7.44(\mathrm{~m}, 2 \mathrm{H}), 6.94-6.88$ (m, 3H), 3.79 (s, $3 \mathrm{H}), 3.11(\mathrm{dd}, J=13.6,6.6 \mathrm{~Hz}, 1 \mathrm{H}), 2.63(\mathrm{td}, J=13.1,7.5 \mathrm{~Hz}, 1 \mathrm{H}), 2.53(\mathrm{dt}, J=19.8,9.9 \mathrm{~Hz}, 1 \mathrm{H}), 2.38(\mathrm{ddt}, J=19.5$, 9.2, $2.1 \mathrm{~Hz}, 1 \mathrm{H}), 2.17-2.06(\mathrm{~m}, 1 \mathrm{H}), 1.82$ (tddd, $J=13.0,10.5,9.3,6.6 \mathrm{~Hz}, 1 \mathrm{H}) .{ }^{13} \mathrm{C} \mathrm{NMR}\left(101 \mathrm{MHz}, \mathrm{CDCl}_{3}\right) \delta$ $213.60,164.77,159.76,137.16,133.24(\mathrm{q}, J=32.6 \mathrm{~Hz}), 128.28,127.64,127.44,125.51$ (q, $J=3.8 \mathrm{~Hz}), 123.57(\mathrm{q}, J=$ $272.8 \mathrm{~Hz}), 114.43,66.19,55.25,34.61,32.95,17.77 .{ }^{19} \mathrm{~F} \mathrm{NMR}\left(376 \mathrm{MHz}, \mathrm{CDCl}_{3}\right) \delta-62.89 . \mathrm{HRMS}(\mathrm{ESI}) \mathrm{m} / z$ calculated for $\mathrm{C}_{20} \mathrm{H}_{19} \mathrm{~F}_{3} \mathrm{NO}_{3}(\mathrm{M}+\mathrm{H})^{+} 378.1317$, found 378.1311 . 


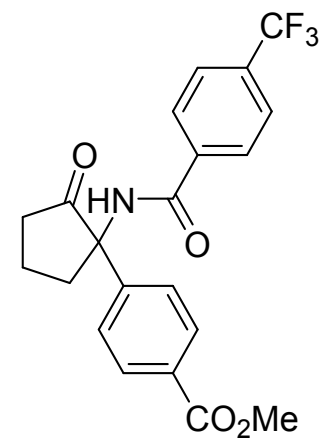

methyl 4-(2-oxo-1-(4-(trifluoromethyl)benzamido)cyclopentyl)benzoate (4h): colorless solid, purified by flash chromatography eluted with $\mathrm{PE} / \mathrm{EA} / \mathrm{MTBE}=20 / 1 / 2.75 \%$ yield $(92 \mathrm{mg}){ }^{1} \mathrm{H}$ NMR $(400 \mathrm{MHz}$, Chloroform- $d$ ) $\delta 8.05-8.00(\mathrm{~m}, 2 \mathrm{H}), 7.87-7.80(\mathrm{~m}, 2 \mathrm{H}), 7.69-7.62(\mathrm{~m}, 4 \mathrm{H}), 7.09(\mathrm{~s}, 1 \mathrm{H}), 3.90(\mathrm{~s}, 1 \mathrm{H}), 3.26(\mathrm{dd}, J=$ 13.9, 6.6 Hz, 1H), $2.64-2.49$ (m, 2H), 2.41 (ddt, $J=19.8,9.5,2.2 \mathrm{~Hz}, 1 \mathrm{H}), 2.24-2.12(\mathrm{~m}, 1 \mathrm{H}), 1.87$ (ttd, $J=13.1,9.9$, $6.6 \mathrm{~Hz}, 1 \mathrm{H}) .{ }^{13} \mathrm{C}$ NMR $\left(101 \mathrm{MHz}, \mathrm{CDCl}_{3}\right) \delta 213.27,166.35,164.89,140.98,136.87,133.45$ (q, $\left.J=32.6 \mathrm{~Hz}\right), 130.33$, 130.21, 127.48, 126.95, $125.60(\mathrm{q}, J=3.3 \mathrm{~Hz}), 123.52(\mathrm{q}, J=272.7 \mathrm{~Hz}), 66.58,52.26,34.53,33.27,17.80 .{ }^{19} \mathrm{~F}$ NMR (376 MHz, CDCl3) $\delta$-62.93. HRMS (ESI) $m / z$ calculated for $\mathrm{C}_{21} \mathrm{H}_{19} \mathrm{~F}_{3} \mathrm{NO}_{4}(\mathrm{M}+\mathrm{H})^{+} 406.1266$, found 406.1264 .<smiles>O=C(NC1(c2cc(C(F)(F)F)cc(C(F)(F)F)c2)CCCC1=O)c1ccc(C(F)(F)F)cc1</smiles>

N-(1-(3, 5-bis(trifluoromethyl)phenyl)-2-oxocyclopentyl)-4-(trifluoromethyl)benzamide (4i): colorless solid, purified by flash chromatography eluted with PE/EA/MTBE $=20 / 1 / 2.65 \%$ yield $(94 \mathrm{mg}){ }^{1} \mathrm{H}$ NMR (400 MHz, Chloroform- $d$ ) $\delta 8.05(\mathrm{~s}, 2 \mathrm{H}), 7.87(\mathrm{~s}, 1 \mathrm{H}), 7.82(\mathrm{~d}, J=8.1 \mathrm{~Hz}, 2 \mathrm{H}), 7.67$ (d, $J=8.2 \mathrm{~Hz}, 2 \mathrm{H}), 7.20$ (s, 1H), 3.48 (dd, $J=14.1,6.8 \mathrm{~Hz}, 1 \mathrm{H}), 2.66-2.39$ (m, 3H), 2.26 (qdd, $J=9.2,8.1,4.7,1.6 \mathrm{~Hz}, 1 \mathrm{H}), 1.88$ (ttd, $J=13.2$, 9.8, $6.5 \mathrm{~Hz}, 1 \mathrm{H}) .{ }^{13} \mathrm{C}$ NMR $\left(101 \mathrm{MHz}, \mathrm{CDCl}_{3}\right) \delta 212.75,165.13,138.76,136.53,133.76(\mathrm{q}, J=32.9 \mathrm{~Hz}), 132.43(\mathrm{q}, J=$ $33.6 \mathrm{~Hz}), 127.51,127.31,125.74(\mathrm{q}, J=3.8 \mathrm{~Hz}), 123.51$ (d, $J=272.6 \mathrm{~Hz}), 123.01$ (q, $J=272.9 \mathrm{~Hz}), 122.75(\mathrm{dt}, J=6.7$, $3.5 \mathrm{~Hz}), 65.90,34.30,33.41,17.85 .{ }^{19} \mathrm{~F}$ NMR $(376 \mathrm{MHz}$, Chloroform- $d$ ) $\delta-62.75,-63.06$. HRMS (ESI) $\mathrm{m} / \mathrm{z}$ calculated for $\mathrm{C}_{21} \mathrm{H}_{15} \mathrm{~F}_{9} \mathrm{NO}_{2}(\mathrm{M}+\mathrm{H})^{+} 484.0959$, found 484.0955 .

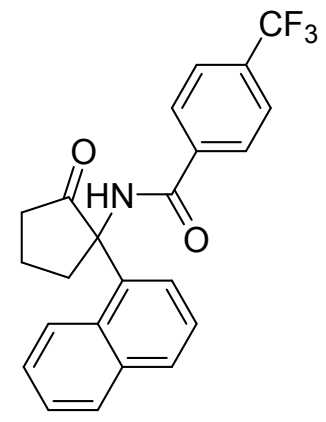

N-(1-(naphthalen-1-yl)-2-oxocyclopentyl)-4-(trifluoromethyl)benzamide (4j): colorless solid, purified by flash chromatography eluted with $\mathrm{PE} / \mathrm{EA} / \mathrm{MTBE}=20 / 1 / 2.82 \%$ yield $(98 \mathrm{mg}){ }^{1} \mathrm{H}$ NMR $(600 \mathrm{MHz}$, Chloroform- $d$ ) $\delta 8.43(\mathrm{~d}, J=8.6 \mathrm{~Hz}, 1 \mathrm{H}), 7.95(\mathrm{~d}, J=8.1 \mathrm{~Hz}, 1 \mathrm{H}), 7.87(\mathrm{~d}, J=8.2 \mathrm{~Hz}, 1 \mathrm{H}), 7.76(\mathrm{~d}, J=8.2 \mathrm{~Hz}, 2 \mathrm{H})$, $7.58(\mathrm{tt}, J=14.9,7.8 \mathrm{~Hz}, 4 \mathrm{H}), 7.38(\mathrm{t}, J=7.8 \mathrm{~Hz}, 1 \mathrm{H}), 7.25$ (d, $J=7.1 \mathrm{~Hz}, 1 \mathrm{H}), 7.05(\mathrm{~s}, 1 \mathrm{H}), 3.21$ (td, $J=12.4,7.4 \mathrm{~Hz}$, 
1H), $2.88(\mathrm{dd}, J=12.8,6.9 \mathrm{~Hz}, 1 \mathrm{H}), 2.73(\mathrm{dt}, J=19.9,10.2 \mathrm{~Hz}, 1 \mathrm{H}), 2.54$ (ddt, $J=19.3,9.0,2.0 \mathrm{~Hz}, 1 \mathrm{H}), 2.21-2.11$ $(\mathrm{m}, 1 \mathrm{H}), 1.64(\mathrm{dtd}, J=20.0,12.1,8.0 \mathrm{~Hz}, 1 \mathrm{H}) .{ }^{13} \mathrm{C} \mathrm{NMR}\left(151 \mathrm{MHz}, \mathrm{CDCl}_{3}\right) \delta 215.84,165.12,136.95,135.36,133.58$, 133.22 (q, $J=32.9 \mathrm{~Hz}), 130.16,130.02,130.00,127.48,126.61,125.96,125.82,125.48$ (q, $J=3.7 \mathrm{~Hz}), 125.02,124.82$, 123.52 (q, $J=272.4 \mathrm{~Hz}), 69.32,36.52,34.40,18.48 .{ }^{19} \mathrm{~F}$ NMR $\left(376 \mathrm{MHz}, \mathrm{CDCl}_{3}\right) \delta-62.94$. HRMS (ESI) $\mathrm{m} / z$ calculated for $\mathrm{C}_{23} \mathrm{H}_{18} \mathrm{~F}_{3} \mathrm{NNaO}_{2}(\mathrm{M}+\mathrm{Na})^{+} 420.1187$, found 420.1174 .<smiles>O=C(NC1(c2ccncc2)CCCC1=O)c1ccc(C(F)(F)F)cc1</smiles>

N-(2-oxo-1-(pyridin-4-yl)cyclopentyl)-4-(trifluoromethyl)benzamide (4k): slight yellow solid, purified by flash chromatography eluted with PE/EA/MTBE = 10/1/2-5/1/1. 60\% yield (63 mg) ${ }^{1} \mathrm{H} \mathrm{NMR}(600 \mathrm{MHz}$, Chloroform- $d$ ) $\delta 8.56(\mathrm{~d}, J=5.5 \mathrm{~Hz}, 2 \mathrm{H}), 7.84(\mathrm{~d}, J=8.2 \mathrm{~Hz}, 2 \mathrm{H}), 7.66(\mathrm{~d}, J=8.3 \mathrm{~Hz}, 2 \mathrm{H}), 7.44(\mathrm{~d}, J=6.1 \mathrm{~Hz}, 2 \mathrm{H})$, $7.22(\mathrm{~s}, 1 \mathrm{H}), 3.26(\mathrm{dd}, J=14.0,6.7 \mathrm{~Hz}, 1 \mathrm{H}), 2.62-2.47(\mathrm{~m}, 2 \mathrm{H}), 2.41(\mathrm{dd}, J=19.7,9.5 \mathrm{~Hz}, 1 \mathrm{H}), 2.26-2.15(\mathrm{~m}, 1 \mathrm{H})$, $1.87(\mathrm{ttd}, J=13.1,9.9,6.7 \mathrm{~Hz}, 1 \mathrm{H}) .{ }^{13} \mathrm{C} \mathrm{NMR}\left(151 \mathrm{MHz}, \mathrm{CDCl}_{3}\right) \delta 212.76,165.02,150.47,145.14,136.63,133.55(\mathrm{q}$, $J=32.9 \mathrm{~Hz}), 127.50,125.62(\mathrm{q}, J=3.8 \mathrm{~Hz}), 123.47$ (q, $J=272.6 \mathrm{~Hz}), 121.65,65.95,34.49,33.00,17.88$. HRMS (ESI) $m / z$ calculated for $\mathrm{C}_{18} \mathrm{H}_{15} \mathrm{~F}_{3} \mathrm{~N}_{2} \mathrm{NaO}_{2}(\mathrm{M}+\mathrm{Na})^{+} 371.0975$, found 371.0961 .<smiles>O=C(NC1(c2cccnc2)CCCC1=O)c1ccc(C(F)(F)F)cc1</smiles>

N-(2-oxo-1-(pyridin-3-yl)cyclopentyl)-4-(trifluoromethyl)benzamide (4I): slight yellow solid, purified by flash chromatography eluted with PE/EA/MTBE $=10 / 1 / 2-5 / 1 / 1.65 \%$ yield (68 mg) ${ }^{1} \mathrm{H} \mathrm{NMR}(400 \mathrm{MHz}$, Chloroform- $d$ ) $\delta 8.77(\mathrm{dd}, J=2.5,0.8 \mathrm{~Hz}, 1 \mathrm{H}), 8.53(\mathrm{dd}, J=4.8,1.6 \mathrm{~Hz}, 1 \mathrm{H}), 7.93(\mathrm{ddd}, J=8.1,2.5,1.6 \mathrm{~Hz}, 1 \mathrm{H}), 7.89$ $-7.84(\mathrm{~m}, 2 \mathrm{H}), 7.70-7.65(\mathrm{~m}, 2 \mathrm{H}), 7.32(\mathrm{ddd}, J=8.1,4.8,0.8 \mathrm{~Hz}, 1 \mathrm{H}), 7.28(\mathrm{~s}, 1 \mathrm{H}), 3.31(\mathrm{dd}, J=13.9,6.7 \mathrm{~Hz}, 1 \mathrm{H})$, $2.66-2.51(\mathrm{~m}, 2 \mathrm{H}), 2.44(\mathrm{ddt}, J=19.7,9.4,2.1 \mathrm{~Hz}, 1 \mathrm{H}), 2.27-2.14(\mathrm{~m}, 1 \mathrm{H}), 1.94-1.78(\mathrm{~m}, 1 \mathrm{H}) .{ }^{13} \mathrm{C} \mathrm{NMR}(101$ $\left.\mathrm{MHz}, \mathrm{CDCl}_{3}\right) \delta 213.07,165.04,149.70,148.40,136.74,134.90,133.49$ (q, $\left.J=32.7 \mathrm{~Hz}\right), 131.85,127.51,125.59(\mathrm{q}, J=$ $3.8 \mathrm{~Hz}), 123.74,123.50(\mathrm{q}, J=272.7 \mathrm{~Hz}) 65.23,34.50,32.99,17.75 .{ }^{19} \mathrm{~F} \mathrm{NMR}\left(376 \mathrm{MHz}, \mathrm{CDCl}_{3}\right) \delta-62.94 . \mathrm{HRMS}$ (ESI) $m / z$ calculated for $\mathrm{C}_{18} \mathrm{H}_{16} \mathrm{~F}_{3} \mathrm{~N}_{2} \mathrm{O}_{2}(\mathrm{M}+\mathrm{H})^{+} 349.1164$, found 349.1160 .<smiles>O=C(NC1(c2ccco2)CCCC1=O)c1ccc(C(F)(F)F)cc1</smiles>

N-(1-(furan-2-yl)-2-oxocyclopentyl)-4-(trifluoromethyl)benzamide (4m): colorless solid, purified by flash chromatography eluted with PE/EA/MTBE $=20 / 1 / 2.50 \%$ yield $(51 \mathrm{mg}){ }^{1} \mathrm{H}$ NMR (400 MHz, Chloroform- $d$ ) 
$\delta 7.85(\mathrm{~d}, J=8.1 \mathrm{~Hz}, 2 \mathrm{H}), 7.64(\mathrm{~d}, J=8.2 \mathrm{~Hz}, 2 \mathrm{H}), 7.42(\mathrm{dd}, J=1.8,0.8 \mathrm{~Hz}, 1 \mathrm{H}), 7.03(\mathrm{~s}, 1 \mathrm{H}), 6.41(\mathrm{dd}, J=3.4,0.7$ $\mathrm{Hz}, 1 \mathrm{H}), 6.36$ (dd, $J=3.4,1.8 \mathrm{~Hz}, 1 \mathrm{H}), 2.92$ (dd, $J=13.1,6.9 \mathrm{~Hz}, 1 \mathrm{H}), 2.73-2.54$ (m, 2H), 2.45 (ddt, $J=19.2,8.8,2.0$ $\mathrm{Hz}, 1 \mathrm{H}), 2.21-2.08(\mathrm{~m}, 1 \mathrm{H}), 1.95-1.78(\mathrm{~m}, 1 \mathrm{H}) .{ }^{13} \mathrm{C} \mathrm{NMR}\left(101 \mathrm{MHz}, \mathrm{CDCl}_{3}\right) \delta 210.58,165.01,148.74,143.75$, 136.70, 133.35 (q, $J=32.7 \mathrm{~Hz}), 127.55,125.50$ (q, $J=3.8 \mathrm{~Hz}), 123.53$ (q, $J=272.6 \mathrm{~Hz}), 110.85,109.52,63.86,35.06$, 33.09, 18.32. ${ }^{19} \mathrm{~F}$ NMR $\left(376 \mathrm{MHz}, \mathrm{CDCl}_{3}\right) \delta-62.92$. HRMS (ESI) $\mathrm{m} / z$ calculated for $\mathrm{C}_{17} \mathrm{H}_{15} \mathrm{~F}_{3} \mathrm{NO}_{3}(\mathrm{M}+\mathrm{H})^{+} 338.1004$, found 338.1002 .

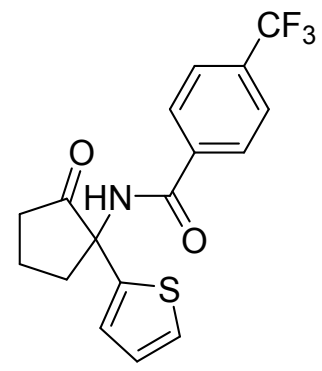

N-(2-oxo-1-(thiophen-2-yl)cyclopentyl)-4-(trifluoromethyl)benzamide (4n): colorless solid, purified by flash chromatography eluted with PE/EA/MTBE $=20 / 1 / 2.70 \%$ yield $(74 \mathrm{mg}){ }^{1} \mathrm{H}$ NMR $(400 \mathrm{MHz}$, Chloroform- $d$ ) $\delta 7.83(\mathrm{~d}, J=8.1 \mathrm{~Hz}, 2 \mathrm{H}), 7.65(\mathrm{~d}, J=8.2 \mathrm{~Hz}, 2 \mathrm{H}), 7.36(\mathrm{dd}, J=5.2,1.1 \mathrm{~Hz}, 1 \mathrm{H}), 7.14(\mathrm{dd}, J=3.7,1.2 \mathrm{~Hz}, 1 \mathrm{H}), 7.00$ (dd, $J=5.1,3.6 \mathrm{~Hz}, 1 \mathrm{H}), 6.87$ (s, 1H), $2.96(\mathrm{dd}, J=13.5,7.0 \mathrm{~Hz}, 1 \mathrm{H}), 2.81$ (td, $J=13.0,7.4 \mathrm{~Hz}, 1 \mathrm{H}), 2.63$ (ddd, $J=$ 20.1, 11.0, $9.5 \mathrm{~Hz}, 1 \mathrm{H}$ ), 2.47 (ddt, $J=19.4,8.9,1.9 \mathrm{~Hz}, 1 \mathrm{H}$ ), $2.22-2.10$ (m, 1H), 1.90 (tddd, $J=12.9,11.0,8.9,6.8 \mathrm{~Hz}$, 1H). ${ }^{13} \mathrm{C}$ NMR (101 MHz, $\left.\mathrm{CDCl}_{3}\right) \delta 211.74,164.77,139.99,136.76,133.40$ (q, $\left.J=32.8 \mathrm{~Hz}\right), 127.53,127.33,127.21$, 127.07, $125.55(\mathrm{q}, J=3.8 \mathrm{~Hz}), 123.54(\mathrm{q}, J=272.7 \mathrm{~Hz}), 64.60,35.65,34.96,18.36 .{ }^{19} \mathrm{~F}$ NMR $\left(376 \mathrm{MHz}, \mathrm{CDCl}_{3}\right) \delta$ -62.91. HRMS (ESI) $m / z$ calculated for $\mathrm{C}_{17} \mathrm{H}_{15} \mathrm{~F}_{3} \mathrm{NO}_{2} \mathrm{~S}(\mathrm{M}+\mathrm{H})^{+} 354.0776$, found 354.0774 .<smiles>CC1CC(=O)C(NC(=O)c2ccc(C(F)(F)F)cc2)(c2ccccc2)C1</smiles>

N-(4-methyl-2-oxo-1-phenylcyclopentyl)-4-(trifluoromethyl)benzamide (40): colorless solid, purified by flash chromatography eluted with PE/EA/MTBE $=20 / 1 / 2.67 \%$ yield $(73 \mathrm{mg})^{1} \mathrm{H}$ NMR $(600 \mathrm{MHz}$, Chloroform- $d$ ) $\delta 7.80(\mathrm{~d}, J=8.1 \mathrm{~Hz}, 2 \mathrm{H}), 7.62(\mathrm{~d}, J=8.3 \mathrm{~Hz}, 2 \mathrm{H}), 7.56(\mathrm{~d}, J=8.2 \mathrm{~Hz}, 2 \mathrm{H}), 7.37(\mathrm{~d}, J=8.3 \mathrm{~Hz}, 2 \mathrm{H})$, $7.36-7.29(\mathrm{~m}, 1 \mathrm{H}), 7.00(\mathrm{~s}, 1 \mathrm{H}), 3.11$ (ddd, $J=13.2,5.4,1.9 \mathrm{~Hz}, 1 \mathrm{H}), 2.69$ (dq, $J=14.9,7.4,6.9 \mathrm{~Hz}, 1 \mathrm{H}), 2.57-2.49$ (m, 1H), $2.40-2.32(\mathrm{~m}, 1 \mathrm{H}), 2.28-2.16(\mathrm{~m}, 1 \mathrm{H}), 1.21(\mathrm{~d}, J=4.4 \mathrm{~Hz}, 3 \mathrm{H}) .{ }^{13} \mathrm{C}$ NMR $\left(151 \mathrm{MHz}, \mathrm{CDCl}_{3}\right) \delta 213.23$, $164.77,139.61,136.44,133.15$ (q, $J=32.6 \mathrm{~Hz}), 129.00,128.60,127.43,126.93,125.42$ (q, $J=4.0 \mathrm{~Hz}), 123.52(\mathrm{q}, J=$ $272.6 \mathrm{~Hz}$ ), 68.24, 43.38, 41.44, 26.40, 20.18. HRMS (ESI) $\mathrm{m} / z$ calculated for $\mathrm{C}_{20} \mathrm{H}_{19} \mathrm{~F}_{3} \mathrm{NO}_{2}(\mathrm{M}+\mathrm{H})^{+} 362.1368$, found 362.1364 .<smiles>COc1ccc(C(=O)NC2(c3ccccc3)CC(C)CC2=O)cc1</smiles>

4-methoxy-N-(4-methyl-2-oxo-1-phenylcyclopentyl)benzamide (4p): colorless solid, purified by flash chromatography eluted with PE/EA/MTBE $=20 / 1 / 2.39 \%$ yield $(40 \mathrm{mg}){ }^{1} \mathrm{H}$ NMR $(600 \mathrm{MHz}$, Chloroform- $d$ ) $\delta$ 7.69 (d, $J=7.7 \mathrm{~Hz}, 2 \mathrm{H}), 7.59$ (d, $J=7.9 \mathrm{~Hz}, 2 \mathrm{H}), 7.39$ (t, $J=7.4 \mathrm{~Hz}, 2 \mathrm{H}), 7.34$ (d, $J=6.7 \mathrm{~Hz}, 1 \mathrm{H}), 6.88$ (d, $J=7.6 \mathrm{~Hz}$, 
2H), $6.71(\mathrm{~s}, 1 \mathrm{H}), 3.82(\mathrm{~s}, 3 \mathrm{H}), 3.10(\mathrm{ddd}, J=13.4,5.4,2.6 \mathrm{~Hz}, 1 \mathrm{H}), 2.55(\mathrm{dd}, J=18.3,7.2 \mathrm{~Hz}, 1 \mathrm{H}), 2.42(\mathrm{t}, J=12.3$ $\mathrm{Hz}, 1 \mathrm{H}), 2.31-2.15(\mathrm{~m}, 2 \mathrm{H}), 1.21(\mathrm{~d}, J=5.7 \mathrm{~Hz}, 3 \mathrm{H}) .{ }^{13} \mathrm{C} \mathrm{NMR}\left(151 \mathrm{MHz}, \mathrm{CDCl}_{3}\right) \delta 213.81,165.56,162.27,137.14$, $128.99,128.77,128.45,126.97,125.99,113.63,77.21,77.00,76.79,68.09,55.34,43.63,41.77,26.50,20.26$. HRMS (ESI) $m / z$ calculated for $\mathrm{C}_{20} \mathrm{H}_{22} \mathrm{NO}_{3}(\mathrm{M}+\mathrm{H})^{+} 324.1600$, found 324.1604 .<smiles>CC1CC(=O)C(NC(=O)c2ccccc2Br)(c2ccccc2)C1</smiles>

2-bromo-N-(4-methyl-2-oxo-1-phenylcyclopentyl)benzamide (4q): colorless solid, purified by flash chromatography eluted with PE/EA/MTBE $=20 / 1 / 2.45 \%$ yield $(52 \mathrm{mg}){ }^{1} \mathrm{H}$ NMR $(600 \mathrm{MHz}$, Chloroform- $d$ ) $\delta$ $7.58(\mathrm{~d}, J=7.8 \mathrm{~Hz}, 1 \mathrm{H}), 7.57-7.52(\mathrm{~m}, 2 \mathrm{H}), 7.51$ (t, $J=7.4 \mathrm{~Hz}, 1 \mathrm{H}), 7.39$ (t, $J=7.6 \mathrm{~Hz}, 2 \mathrm{H}), 7.36-7.29(\mathrm{~m}, 2 \mathrm{H})$, $7.28-7.22(\mathrm{~m}, 1 \mathrm{H}), 6.52(\mathrm{~s}, 1 \mathrm{H}), 3.14(\mathrm{dd}, J=13.9,7.4 \mathrm{~Hz}, 1 \mathrm{H}), 2.82(\mathrm{dd}, J=17.5,7.8 \mathrm{~Hz}, 1 \mathrm{H}), 2.64-2.51(\mathrm{~m}, 1 \mathrm{H})$, $2.31-2.18(\mathrm{~m}, 1 \mathrm{H}), 2.14(\mathrm{dd}, J=17.4,8.1 \mathrm{~Hz}, 1 \mathrm{H}), 1.10(\mathrm{~d}, J=6.7 \mathrm{~Hz}, 3 \mathrm{H}) .{ }^{13} \mathrm{C}$ NMR $\left(151 \mathrm{MHz}, \mathrm{CDCl}_{3}\right) \delta 213.37$, $213.09,166.35,166.17,139.82,136.92,136.86,136.68,133.28,131.40,131.33,129.71,129.68,128.96,128.93$, $128.55,128.23,127.52,127.46,127.00,126.57,119.31,119.30,68.54,67.41,45.33,43.52,43.00,41.56,26.81,26.57$, 21.56, 20.24.HRMS (ESI) $m / z$ calculated for $\mathrm{C}_{19} \mathrm{H}_{19} \mathrm{BrNO}_{2}(\mathrm{M}+\mathrm{H})^{+} 372.0600$, found 372.0604 .

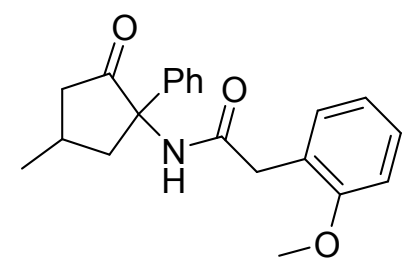

2-(2-methoxyphenyl)-N-(4-methyl-2-oxo-1-phenylcyclopentyl)acetamide (4r): colorless solid, purified by flash chromatography eluted with PE/EA/MTBE $=20 / 1 / 2.27 \%$ yield $(28 \mathrm{mg})^{1} \mathrm{H}$ NMR $(600 \mathrm{MHz}$, Chloroform- $d$ ) $\delta 7.40(\mathrm{~d}, J=8.1 \mathrm{~Hz}, 2 \mathrm{H}), 7.31(\mathrm{t}, J=7.5 \mathrm{~Hz}, 2 \mathrm{H}), 7.29-7.22(\mathrm{~m}, 2 \mathrm{H}), 7.19$ (d, $J=7.3 \mathrm{~Hz}, 1 \mathrm{H}), 6.91$ (t, $J=7.4 \mathrm{~Hz}, 1 \mathrm{H}), 6.87$ (d, $J=8.2 \mathrm{~Hz}, 1 \mathrm{H}), 6.60$ (s, 1H), 3.79 (s, 3H), 3.54 (d, $J=14.8 \mathrm{~Hz}, 1 \mathrm{H}), 3.46$ (d, $J=14.7 \mathrm{~Hz}, 1 \mathrm{H})$, $2.93(\mathrm{dd}, J=12.1,4.9 \mathrm{~Hz}, 1 \mathrm{H}), 2.45(\mathrm{q}, J=12.5 \mathrm{~Hz}, 1 \mathrm{H}), 2.24(\mathrm{t}, J=12.1 \mathrm{~Hz}, 1 \mathrm{H}), 2.19-2.11(\mathrm{~m}, 2 \mathrm{H}), 1.15(\mathrm{~d}, J=$ $5.3 \mathrm{~Hz}, 3 \mathrm{H}) .{ }^{13} \mathrm{C}$ NMR $\left(151 \mathrm{MHz}, \mathrm{CDCl}_{3}\right) \delta 213.72,170.23,156.84,137.42,131.13,128.75,128.68,128.20,126.67$, $123.47,121.01,110.40,77.21,77.00,76.79,67.75,55.19,43.65,41.80,38.99,26.55,20.26$. HRMS (ESI) $\mathrm{m} / \mathrm{z}$ calculated for $\mathrm{C}_{21} \mathrm{H}_{24} \mathrm{NO}_{3}(\mathrm{M}+\mathrm{H})^{+} 338.1756$, found 338.1747 .

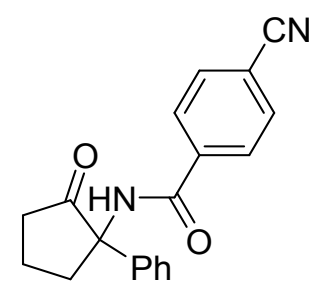

4-cyano-N-(2-oxo-1-phenylcyclopentyl)benzamide (4s): colorless solid, purified by flash chromatography eluted with PE/EA/MTBE $=20 / 1 / 2.80 \%$ yield $(72 \mathrm{mg}){ }^{1} \mathrm{H}$ NMR $(400 \mathrm{MHz}$, Chloroform- $d$ ) $\delta 7.85-7.77(\mathrm{~m}, 2 \mathrm{H})$, $7.72-7.64(\mathrm{~m}, 2 \mathrm{H}), 7.56(\mathrm{~d}, J=8.0 \mathrm{~Hz}, 2 \mathrm{H}), 7.45-7.30(\mathrm{~m}, 3 \mathrm{H}), 6.95(\mathrm{~s}, 1 \mathrm{H}), 3.15$ (dd, $J=13.6,6.6 \mathrm{~Hz}, 1 \mathrm{H}), 2.63(\mathrm{td}$, $J=13.3,7.7 \mathrm{~Hz}, 1 \mathrm{H}), 2.56-2.47$ (m, 1H), 2.39 (ddd, $J=19.6,9.4,2.0 \mathrm{~Hz}, 1 \mathrm{H}), 2.14(\mathrm{dt}, J=17.0,8.6 \mathrm{~Hz}, 1 \mathrm{H}), 1.92-$ $1.77(\mathrm{~m}, 1 \mathrm{H}) .{ }^{13} \mathrm{C}$ NMR $\left(101 \mathrm{MHz}, \mathrm{CDCl}_{3}\right) \delta 213.45,164.28,137.76,136.04,132.32,129.13,128.75,127.67,126.83$, $117.86,115.18,66.84,34.66,33.04,17.76$. HRMS (ESI) $m / z$ calculated for $\mathrm{C}_{19} \mathrm{H}_{17} \mathrm{~N}_{2} \mathrm{O}_{2}(\mathrm{M}+\mathrm{H})^{+} 305.1290$, found 305.1290 . 


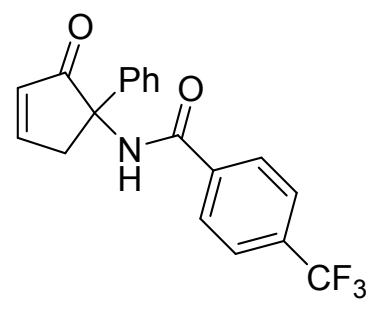

N-(2-oxo-1-phenylcyclopent-3-en-1-yl)-4-(trifluoromethyl)benzamide (4t): slight yellow solid, purified by flash chromatography eluted with PE/EA/MTBE $=20 / 1 / 2.50 \%$ yield $(57 \mathrm{mg}){ }^{1} \mathrm{H}$ NMR $(600 \mathrm{MHz}$, Chloroform- $d$ ) $\delta 7.93-7.85(\mathrm{~m}, 3 \mathrm{H}), 7.71-7.58(\mathrm{~m}, 2 \mathrm{H}), 7.37(\mathrm{~d}, J=7.9 \mathrm{~Hz}, 2 \mathrm{H}), 7.35-7.30(\mathrm{~m}, 2 \mathrm{H}), 7.29-7.19(\mathrm{~m}$, 2H), $6.26(\mathrm{~s}, 1 \mathrm{H}), 3.59$ (d, $J=19.5 \mathrm{~Hz}, 1 \mathrm{H}), 3.48(\mathrm{~d}, J=19.5 \mathrm{~Hz}, 1 \mathrm{H}) .{ }^{13} \mathrm{C}$ NMR $\left(151 \mathrm{MHz}, \mathrm{CDCl}_{3}\right) \delta 204.54,165.52$, 162.78, 137.91, 136.71, 133.44 (q, $J=32.8 \mathrm{~Hz}), 130.80,128.90,128.07,127.55,125.62$ (q, $J=3.3 \mathrm{~Hz}), 125.16,123.64$ (q, $J=272.7 \mathrm{~Hz}$ ), 65.26, 43.85. HRMS (ESI) $\mathrm{m} / z$ calculated for $\mathrm{C}_{19} \mathrm{H}_{14} \mathrm{~F}_{3} \mathrm{NNaO}_{2}(\mathrm{M}+\mathrm{Na})^{+}$368.0872, found 368.0866.

\section{Synthesis of compound 6 and 7}

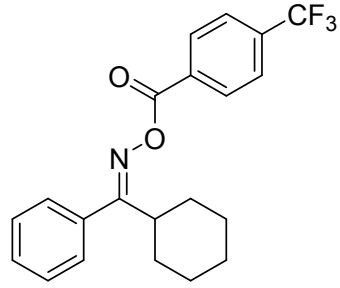

$1 \mathrm{r}$

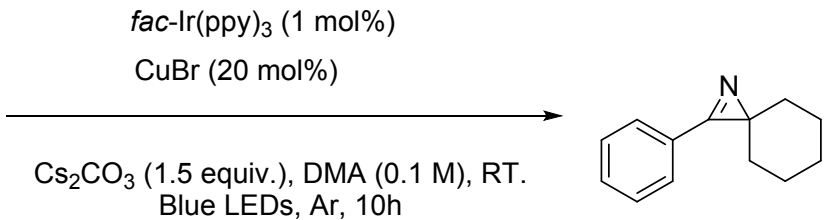

$2 r$

\section{Following general procedure A:}

Under argon, an oven-dried glass tube equipped with a magnetic stir bar was charged with urea substrate 1r (0.4 mmol, 1.0 equiv.), fac- $\operatorname{Ir}(\mathrm{ppy})_{3}(2.6 \mathrm{mg}, 1 \mathrm{~mol} \%), \mathrm{CuBr}(11.5 \mathrm{mg}, 20 \mathrm{~mol} \%), \mathrm{Cs}_{2} \mathrm{CO}_{3}(195 \mathrm{mg}$, 1.5 equiv.) and DMA ( $4 \mathrm{ml})$, the tube was evacuated and backfilled with argon for 3 times then stirred at room temperature with a fan under the irradiation of $5 \mathrm{~W}$ blue LEDs for 10 hours. Upon completion, the reaction was quenched by cold water and extracted by ethyl acetate $(10 \mathrm{ml} \times 3)$ then filtered through celite to remove the undissolved copper salt. The organic phase was washed with brine, dried over $\mathrm{Na}_{2} \mathrm{SO}_{4}$ and concentrated in vacuo. The residue was purified by flash chromatography to afford the crude product $\mathbf{2 r}$ which was used in next step without further purification.

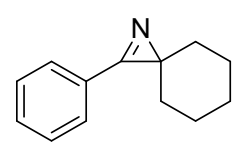

$2 r$

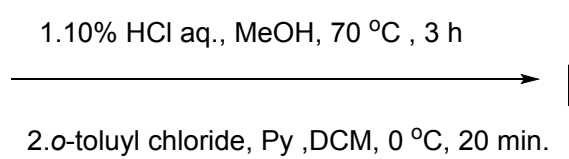

2.o-toluyl chloride, $\mathrm{Py}, \mathrm{DCM}, 0^{\circ} \mathrm{C}, 20 \mathrm{~min}$.

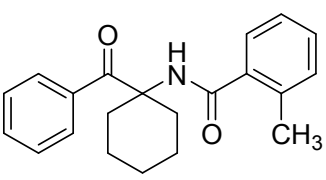

6

To a test tube with screw cap was added crude product $\mathbf{2 r}$, $\mathrm{MeOH}(3 \mathrm{~mL})$ and $10 \% \mathrm{HCl}$ aq. $(0.3 \mathrm{~mL})$. The reaction mixture was stirred at $70{ }^{\circ} \mathrm{C}$ for $3 \mathrm{~h}$, then cooled to rt. $\mathrm{MeOH}$ was removed by evaporation. The mixture was washed with petroleum ether $(5 \mathrm{~mL} \times 3)$ to remove the byproduct ketone and to the result white solid salt was added $\mathrm{CH}_{2} \mathrm{Cl}_{2}(3 \mathrm{~mL})$, pyridine (3 equiv.) and subsequently o-toluyl chloride was added dropwise at $0{ }^{\circ} \mathrm{C}$. After the reaction was complete in several minutes (judged by TLC), the mixture was concentrated under vacuum to remove DCM and dissolved in EA $(15 \mathrm{~mL})$. The organic phase was washed by brine and dried over $\mathrm{Na}_{2} \mathrm{SO}_{4}$, then filtered and concentrated under vacuum. The crude mixture was purified by flash chromatography to afford the product 6 . 
<smiles>Cc1ccccc1C(=O)NC1(C(=O)c2ccccc2)CCCCC1</smiles>

N-(1-benzoylcyclohexyl)-2-methylbenzamide (6): colorless solid, purified by flash chromatography eluted with PE/EA/MTBE $=20 / 1 / 2.42 \%$ yield $(54 \mathrm{mg}){ }^{1} \mathrm{H}$ NMR $(600 \mathrm{MHz}$, Chloroform- $d$ ) $\delta 7.93-7.85(\mathrm{~m}, 2 \mathrm{H}), 7.48-$ $7.42(\mathrm{~m}, 1 \mathrm{H}), 7.34$ (t, $J=7.8 \mathrm{~Hz}, 2 \mathrm{H}), 7.26$ (ddd, $J=9.1,5.0,1.8 \mathrm{~Hz}, 1 \mathrm{H}), 7.19-7.09$ (m, 3H), $6.42(\mathrm{~s}, 1 \mathrm{H}), 2.39-$ $2.35(\mathrm{~m}, 2 \mathrm{H}), 2.08-1.97(\mathrm{~m}, 5 \mathrm{H}), 1.80(\mathrm{dt}, J=14.0,3.8 \mathrm{~Hz}, 2 \mathrm{H}), 1.73(\mathrm{dt}, J=12.8,3.7 \mathrm{~Hz}, 1 \mathrm{H}), 1.54(\mathrm{qt}, J=13.2,3.5$ $\mathrm{Hz}, 2 \mathrm{H}), 1.36(\mathrm{qt}, J=12.5,3.8 \mathrm{~Hz}, 1 \mathrm{H}) .{ }^{13} \mathrm{C}$ NMR $\left(151 \mathrm{MHz}, \mathrm{CDCl}_{3}\right) \delta 202.72,168.76,137.10,136.53,135.64,131.32$, 130.99, 129.91, 128.01, 127.80, 126.36, 125.52, 63.87, 32.28, 25.06, 21.73, 19.05. HRMS (ESI) $\mathrm{m} / z$ calculated for $\mathrm{C}_{21} \mathrm{H}_{24} \mathrm{NO}_{2}(\mathrm{M}+\mathrm{H})^{+}$322.1807, found 322.1805.

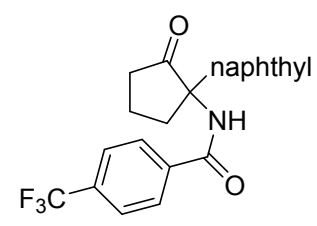

$4 \mathbf{j}$

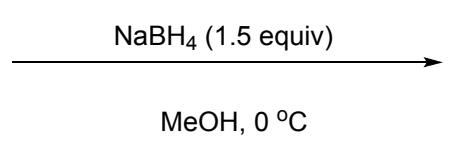

$\mathrm{MeOH}, 0^{\circ} \mathrm{C}$

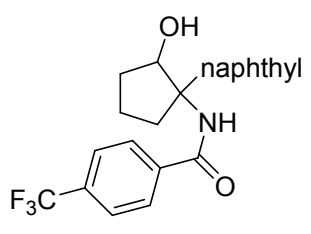

$790 \%$

To a $5 \mathrm{~mL}$ round-bottle flask was added $\mathbf{4 j}$ (100mg, $3.70 \mathrm{mmol}), \mathrm{NaBH}_{4}(21 \mathrm{mg}, 5.6 \mathrm{mmol})$ and $\mathrm{MeOH}$ $(3 \mathrm{~mL})$. The reaction mixture was stirred at $\mathrm{rt}$. for several hours and quenched by acetone $(1 \mathrm{~mL})$ and $\mathrm{H}_{2} \mathrm{O}(3 \mathrm{~mL})$ was added and the mixture was extracted with EA $(10 \mathrm{~mL} \times 3)$. The combined organic layer was washed with saturated $\mathrm{NaHCO}_{3}$ aq. $(15 \mathrm{~mL})$ and brine $(15 \mathrm{~mL})$, then dried over $\mathrm{MgSO}_{4}$, filtered and evaporated. The residue was subjected to silica gel column chromatography to afford compound 7 as a white solid.

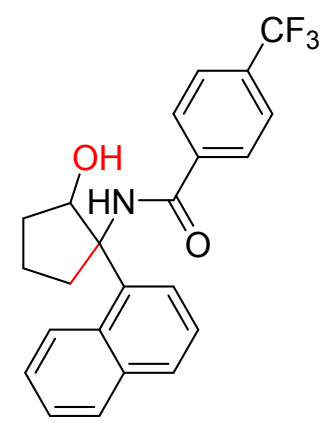

N-(2-hydroxy-1-(naphthalen-1-yl)cyclopentyl)-4-(trifluoromethyl)benzamide (7): colorless solid, purified by flash chromatography eluted with $\mathrm{PE} / \mathrm{EA} / \mathrm{DCM}=5 / 1 / 2.90 \%$ yield $(91 \mathrm{mg}){ }^{1} \mathrm{H} \mathrm{NMR}(600 \mathrm{MHz}$, Chloroform- $d$ ) $\delta 8.34$ (d, $J=8.6 \mathrm{~Hz}, 1 \mathrm{H}), 8.02(\mathrm{~d}, J=7.4 \mathrm{~Hz}, 1 \mathrm{H}), 7.89$ (dd, $J=8.1,1.5 \mathrm{~Hz}, 1 \mathrm{H}), 7.83(\mathrm{~d}, J=8.2 \mathrm{~Hz}$, $1 \mathrm{H}), 7.54(\mathrm{~d}, J=8.0 \mathrm{~Hz}, 2 \mathrm{H}), 7.50(\mathrm{t}, J=7.8 \mathrm{~Hz}, 1 \mathrm{H}), 7.48-7.38(\mathrm{~m}, 4 \mathrm{H}), 6.71(\mathrm{~s}, 1 \mathrm{H}), 5.07-5.02(\mathrm{~m}, 1 \mathrm{H}), 2.90-$ $2.73(\mathrm{~m}, 2 \mathrm{H}), 2.40(\mathrm{ddd}, J=17.3,9.8,5.2 \mathrm{~Hz}, 1 \mathrm{H}), 2.08-1.92(\mathrm{~m}, 3 \mathrm{H}), 1.82(\mathrm{ddtd}, J=16.1,13.0,7.8,4.0 \mathrm{~Hz}, 1 \mathrm{H}) .{ }^{13} \mathrm{C}$ NMR (151 MHz, $\left.\mathrm{CDCl}_{3}\right) \delta 165.58,138.14,134.84,134.56,132.92$ (q, $\left.J=32.6 \mathrm{~Hz}\right), 130.66,130.02,129.31,128.85$, 127.20, 125.95, 125.42 (q, $J=3.9 \mathrm{~Hz}), 125.24,124.13,123.92(\mathrm{q}, J=271.2 \mathrm{~Hz}) 78.67,71.53,33.88,31.78,20.19$. HRMS (ESI) $m / z$ calculated for $\mathrm{C}_{23} \mathrm{H}_{21} \mathrm{~F}_{3} \mathrm{NO}_{2}(\mathrm{M}+\mathrm{H})^{+} 400.1524$, found 400.1521 . 


\section{unsuccess}<smiles>CC(=NC(=O)c1ccc(C2CCCCC2)cc1)C1CCCCC1</smiles><smiles>c1ccc(C(=N[Ge]C2CC2)C2CC2)cc1</smiles><smiles>CN(C)c1ccc(C(=NC2CCCCC2)C2CCCCC2)cc1</smiles><smiles>COc1ccc(CC/C(=N/[O-])C(C)=O)cc1</smiles><smiles>CC(=NC1CCCCC1)C(C)Cc1ccc2ccccc2c1</smiles><smiles>CN(C)c1ccc(C(=NC(=O)[O-])C2CCC2)cc1</smiles><smiles>Cn1ccnc1C(=NC1CCCC1)C1CCC1</smiles><smiles>CCOC(=O)[C@H]1C2CCCC2[C@H]1/C(=N\[GeH2])c1ccccc1</smiles><smiles>CCOC(=O)[C@H]1C[C@@H](C)[C@H]1/C(=N\[Ge])c1ccccc1</smiles><smiles>C=C1CC(/C(=N/C2CCCCC2)c2ccccc2)C1</smiles><smiles>FC1(F)CC(/C(=N\[GeH2])c2ccccc2)C1</smiles>

\section{References}

(1) Jiang, H.; An, X.; Tong, K.; Zheng, T.; Zhang, Y.; Yu, S. Angew. Chem. Int. Edit. 2015, 54, 4055.

(2) Leonard, N. J.; Zwanenburg, B. J. Am. Chem. Soc. 1967, 89, 4456.

(3) Okamoto, K.; Shimbayashi, T.; Yoshida, M.; Nanya, A.; Ohe, K. Angew. Chem. Int. Edit. 2016, 55, 7199.

(4) Ben Cheikh, R.; Bouzouita, N.; Ghabi, H.; Chaabouni, R. Tetrahedron 1990, 46, 5155.

(5) Pfoertner, K.-H.; Montavon, F.; Bernauer, K. Helv. Chim. Acta 1985, 68, 600.

(6) Isomura, K.; Kawasaki, H.; Takehara, K.; Taniguchi, H. Heterocycles 1995, 40, 511. 
5. The ${ }^{1} \mathrm{H},{ }^{13} \mathrm{C}$ and ${ }^{19} \mathrm{~F}$ NMR spectra of compounds<smiles>CC(C)CC1N=C1Pc1ccccc1</smiles>

$2 a$

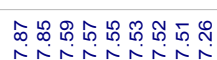

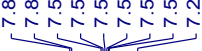

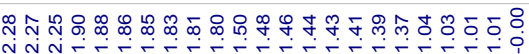

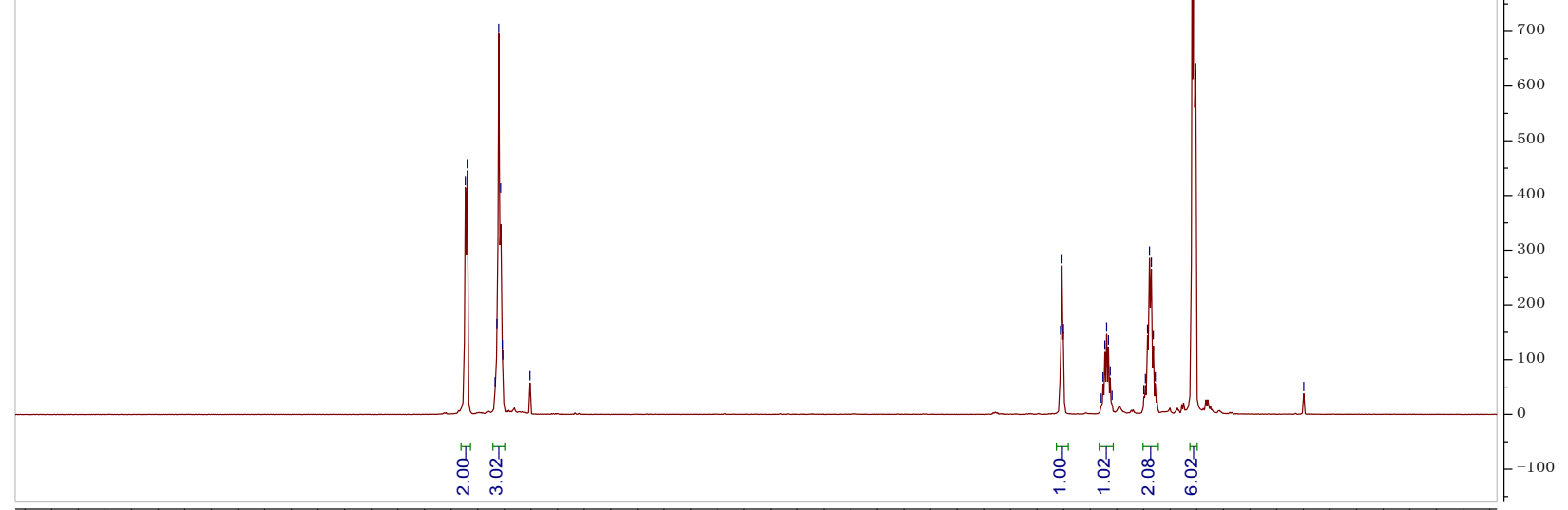

\begin{tabular}{llllllllllllllllllllllllllllllllllllllllllllll}
\hline 2.0 & 11.5 & 11.0 & 10.5 & 10.0 & 9.5 & 9.0 & 8.5 & 8.0 & 7.5 & 7.0 & 6.5 & 6.0 & 5.5 & 5.0 & 4.5 & 4.0 & 3.5 & 3.0 & 2.5 & 2.0 & 1.5 & 1.0 & 0.5 & 0.0 & -0.5 & -1.0 & -1.5
\end{tabular}

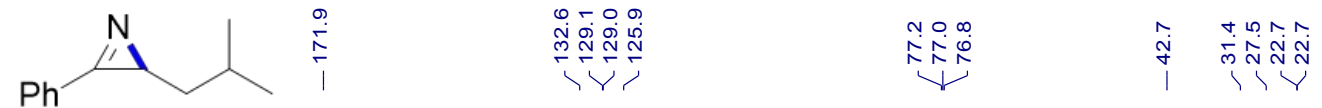

$2 a$

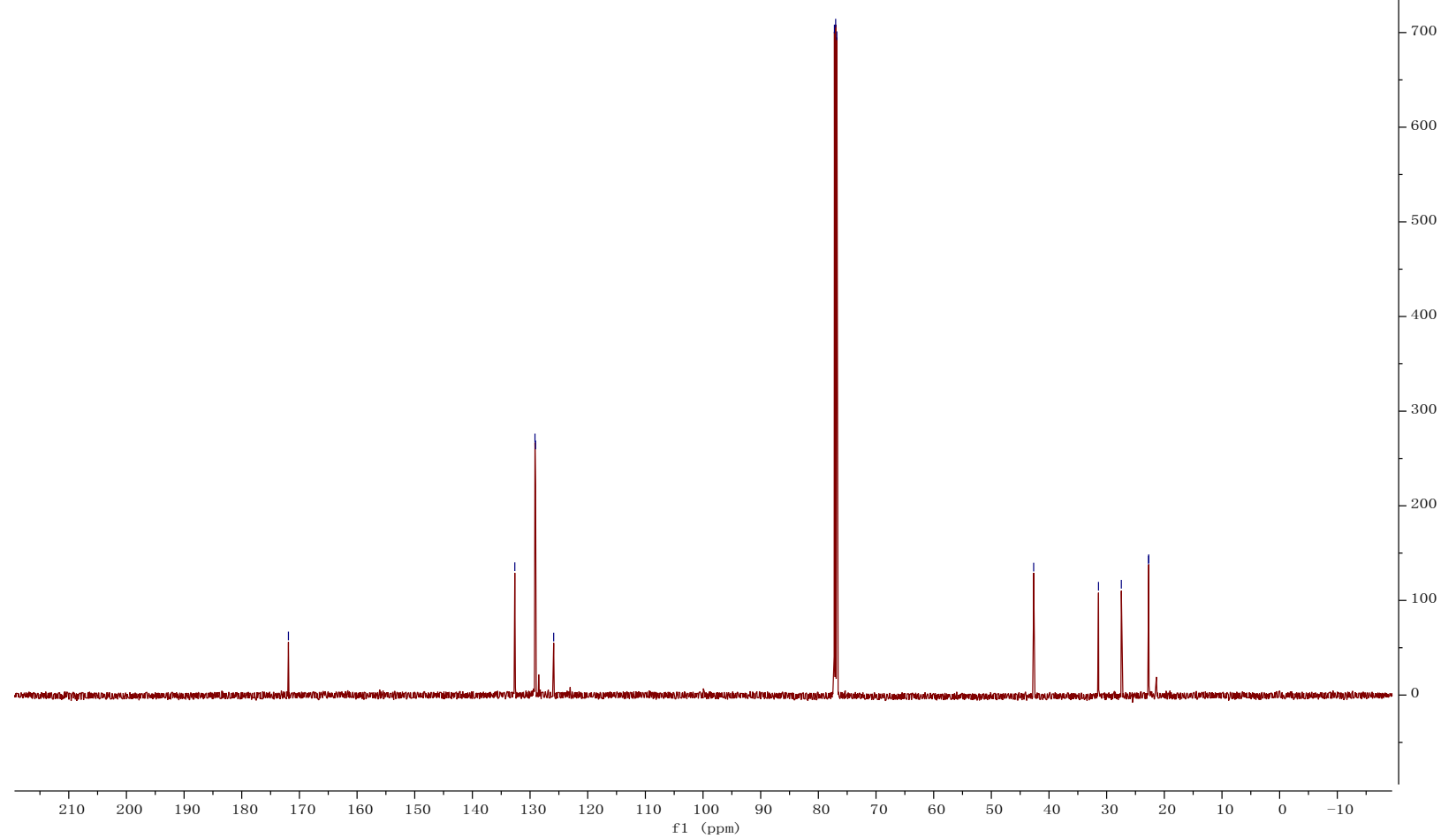


(N)

2b

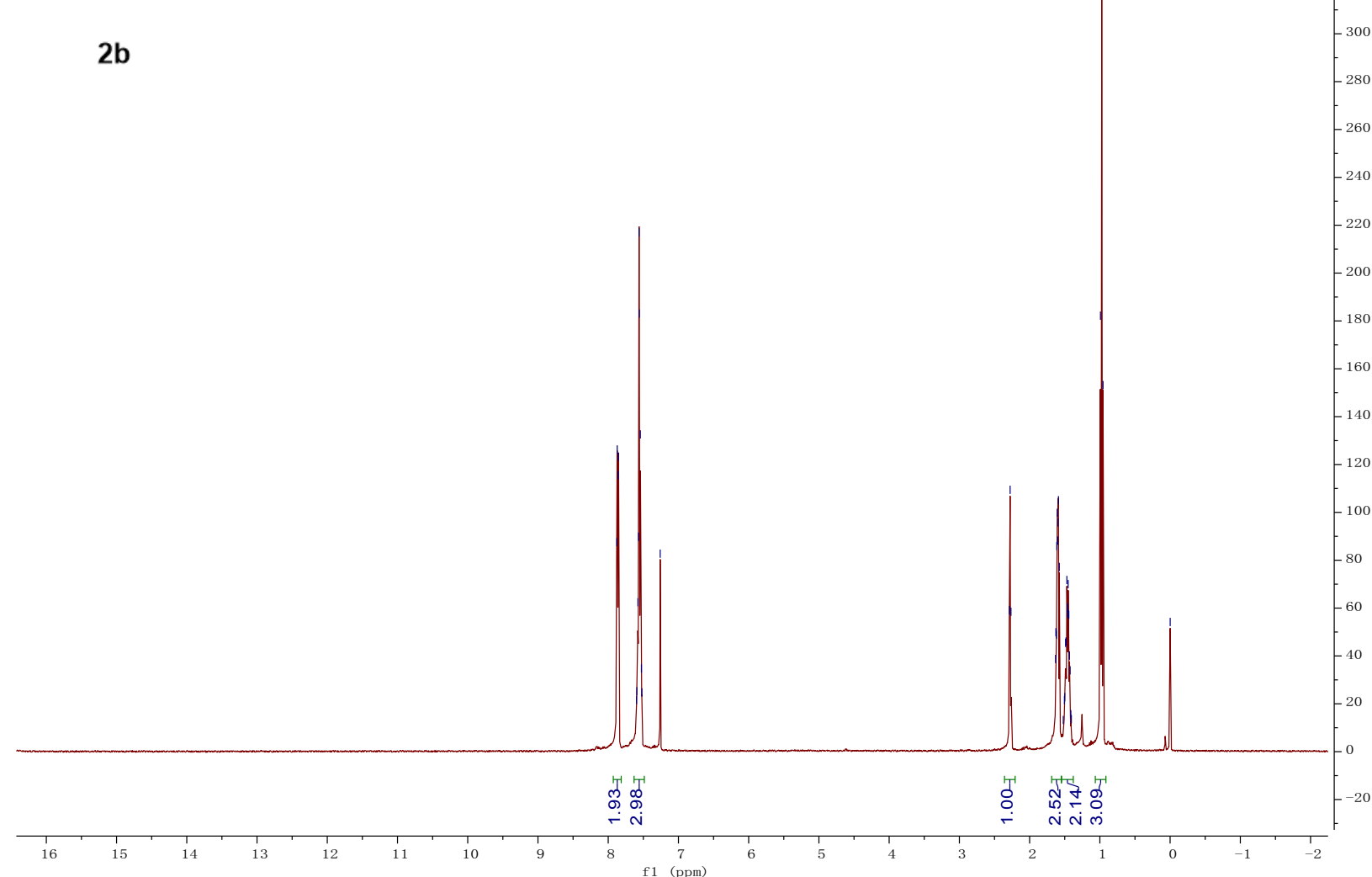

M

2b

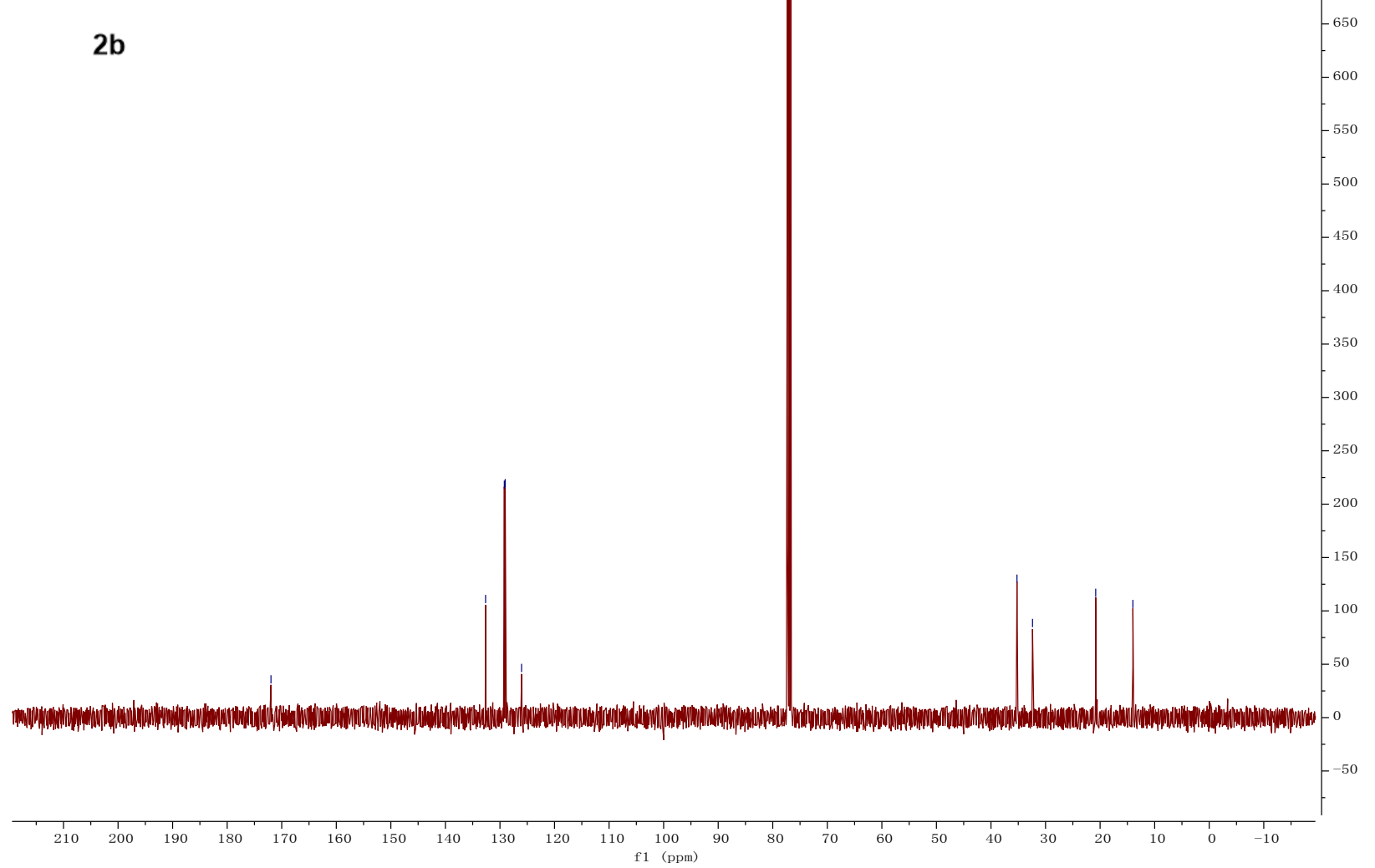



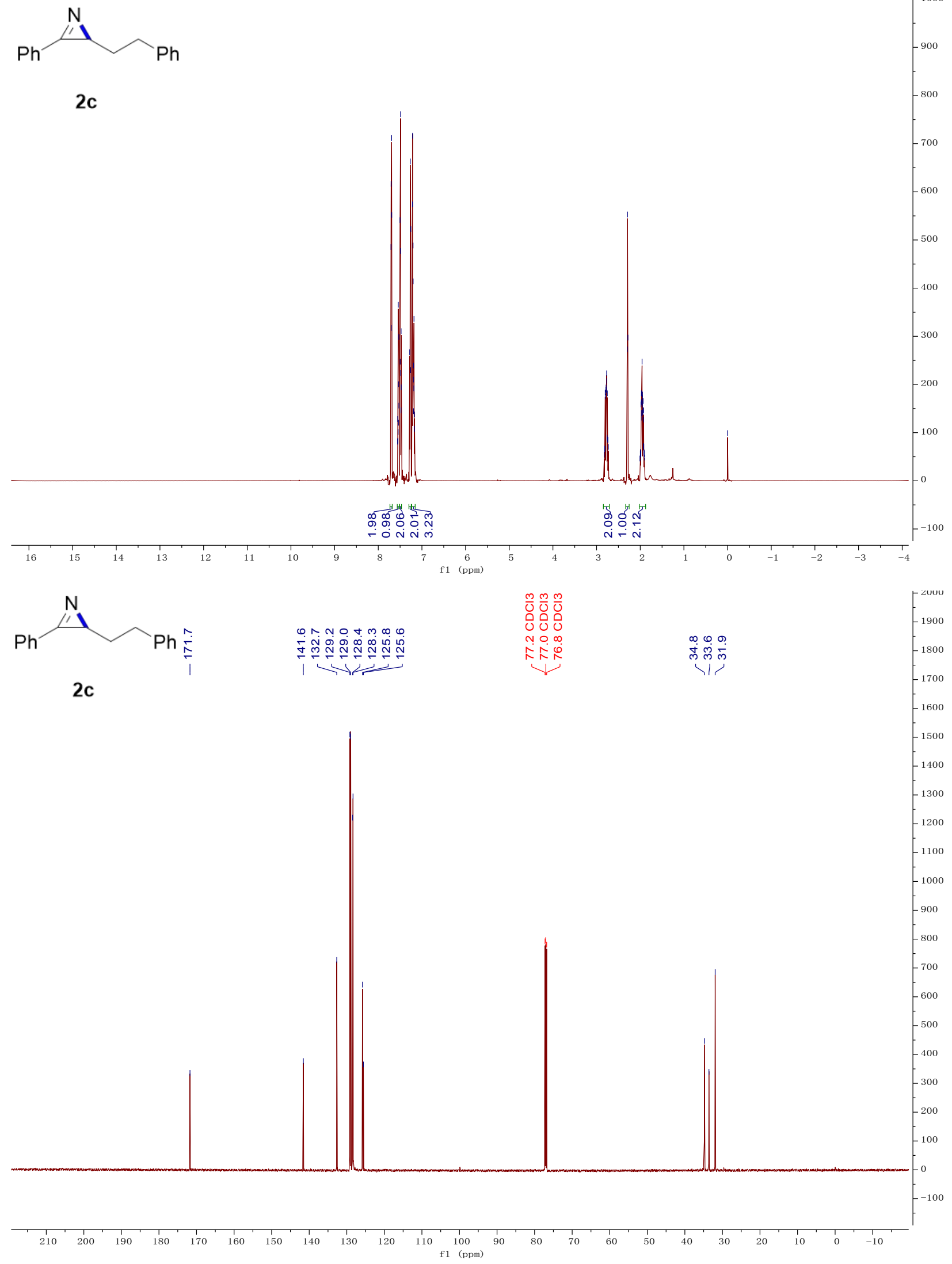
至

2d

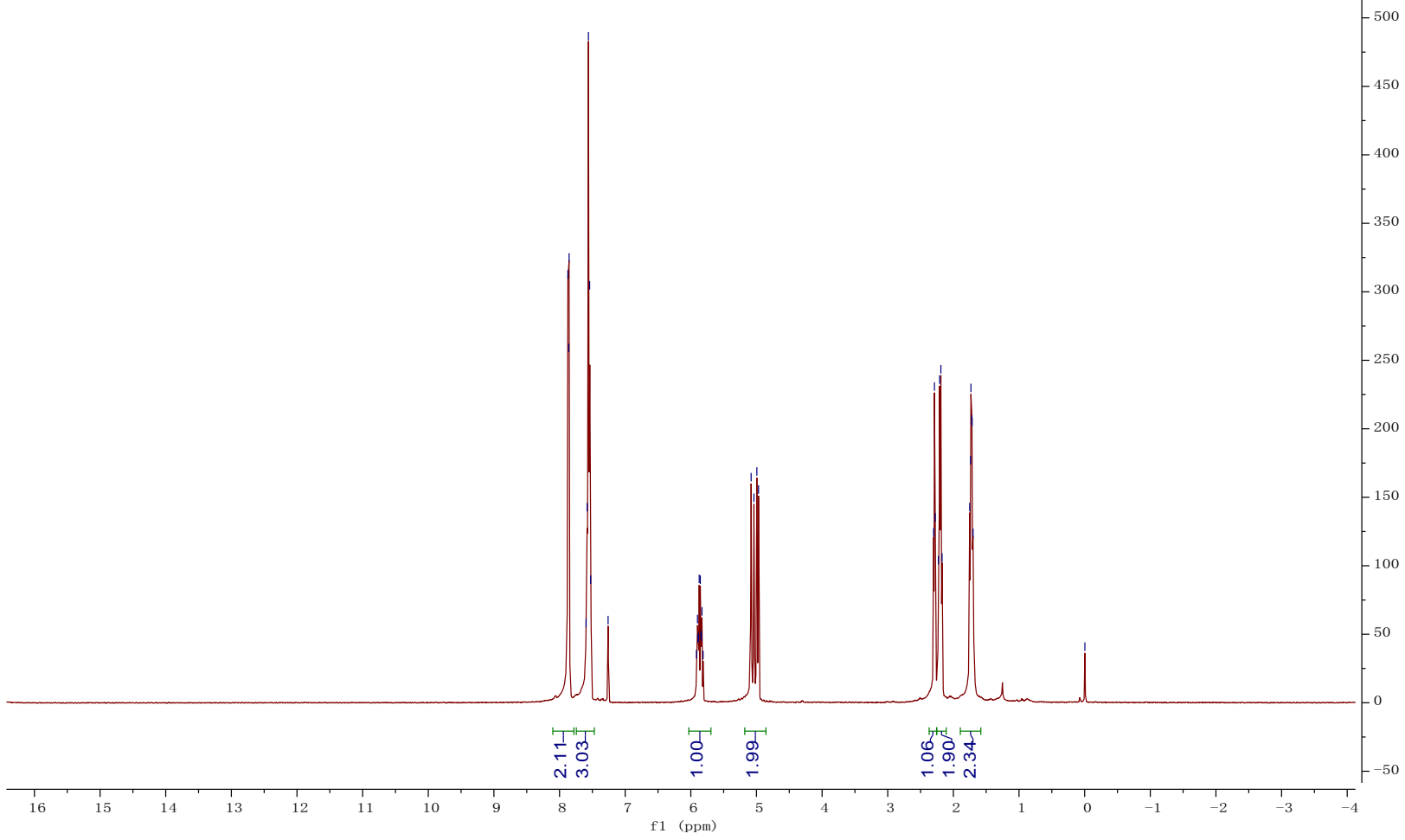<smiles>C/C=C/CCC1N=C1c1ccccc1</smiles>

2d

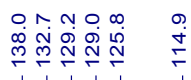

iरण i

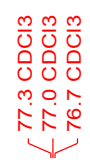

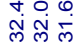

$\checkmark$

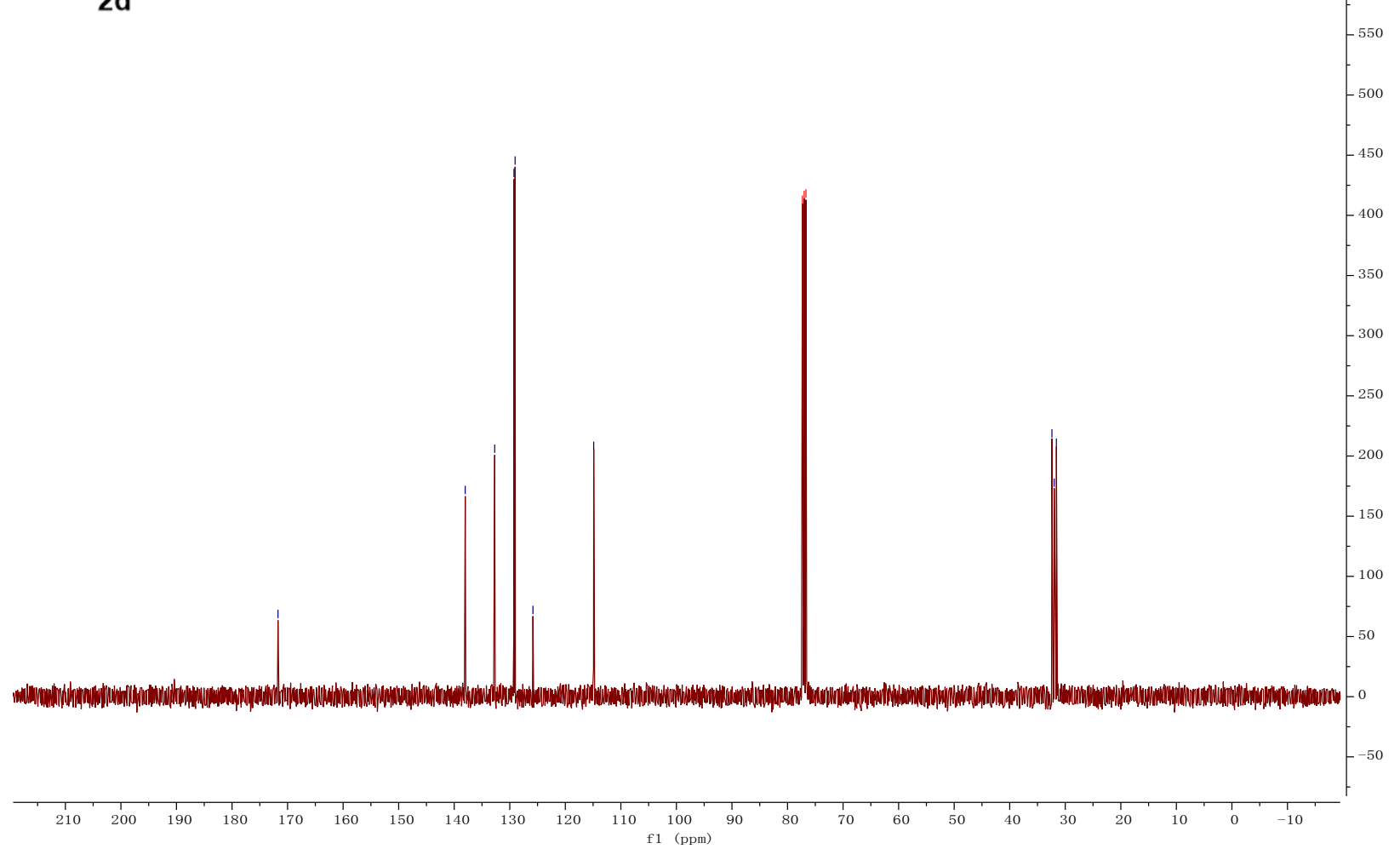




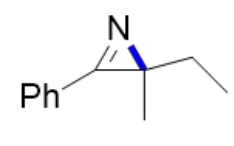

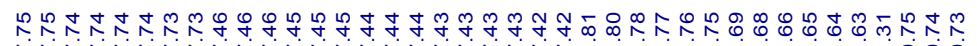

$2 \mathrm{e}$

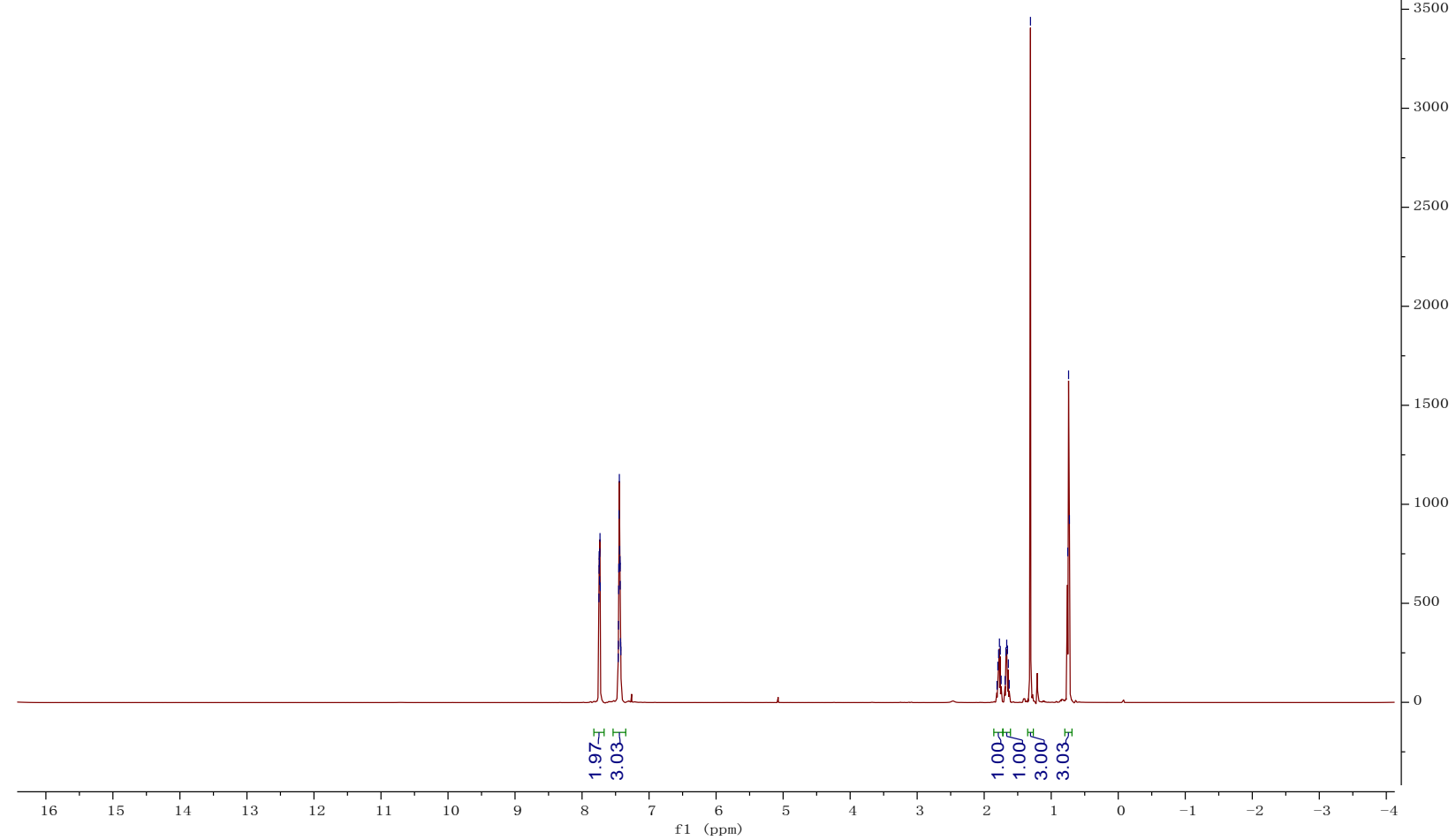

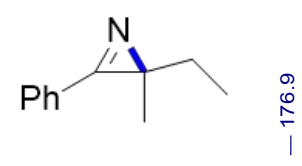

$2 e$ $\underset{\substack{0 \\ \stackrel{0}{i}}}{\stackrel{2}{i}}$

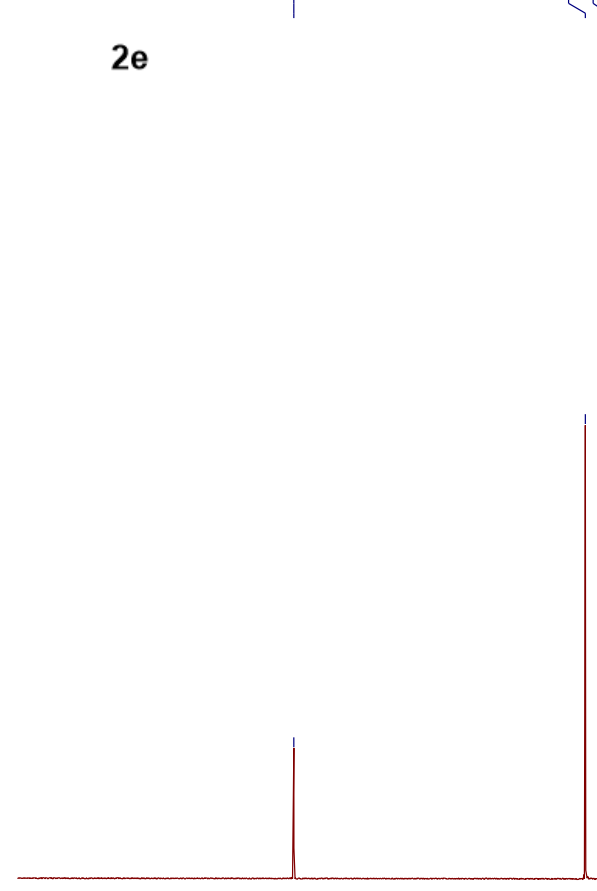

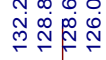

舟,

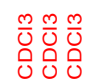

等

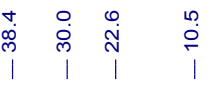

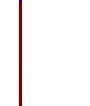




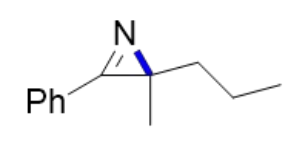

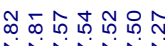

nNiñ

$2 f$

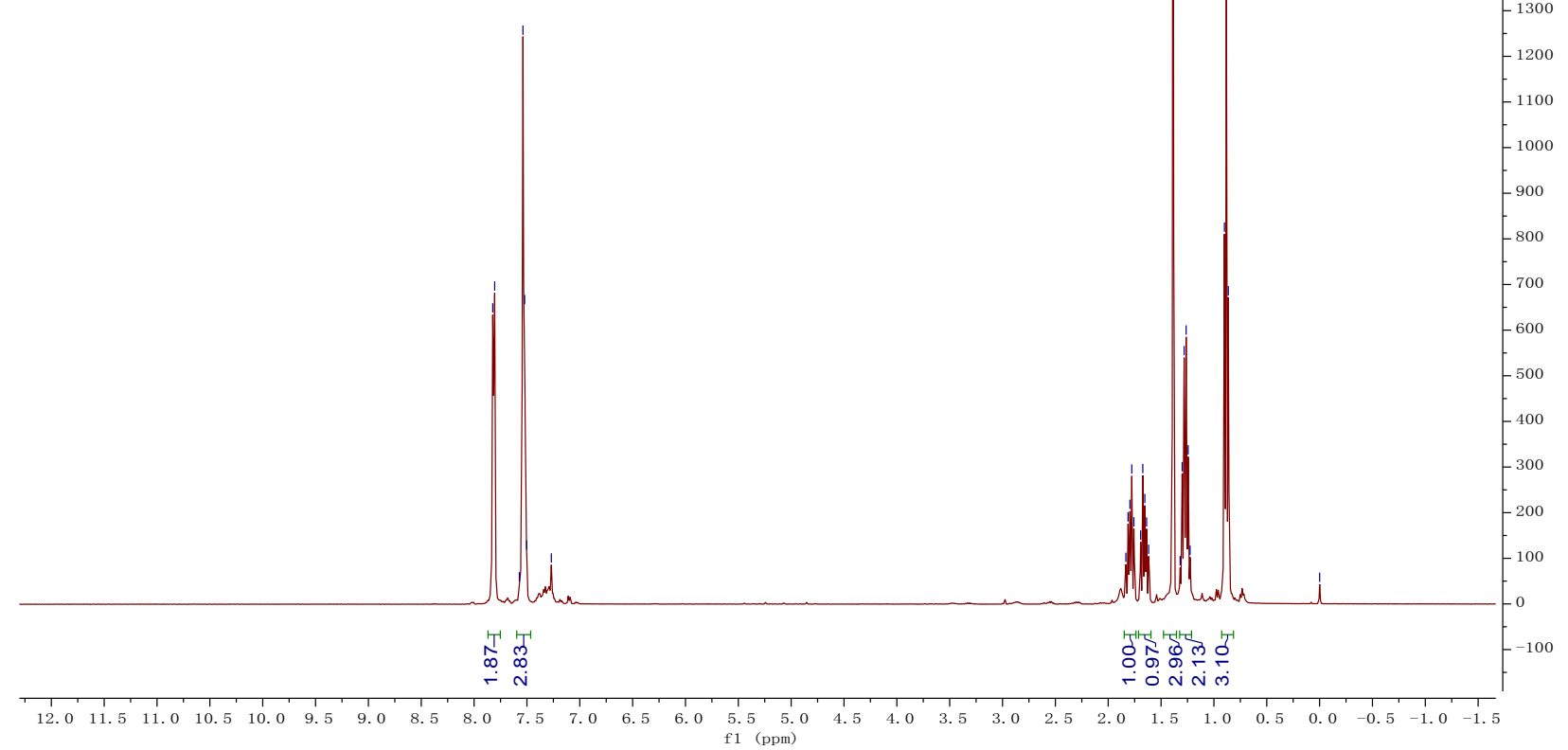<smiles>CCCC1(C)N=C1c1ccccc1</smiles>

$2 f$

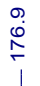

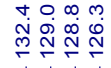

पY

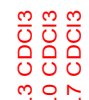

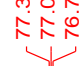

舟

1111

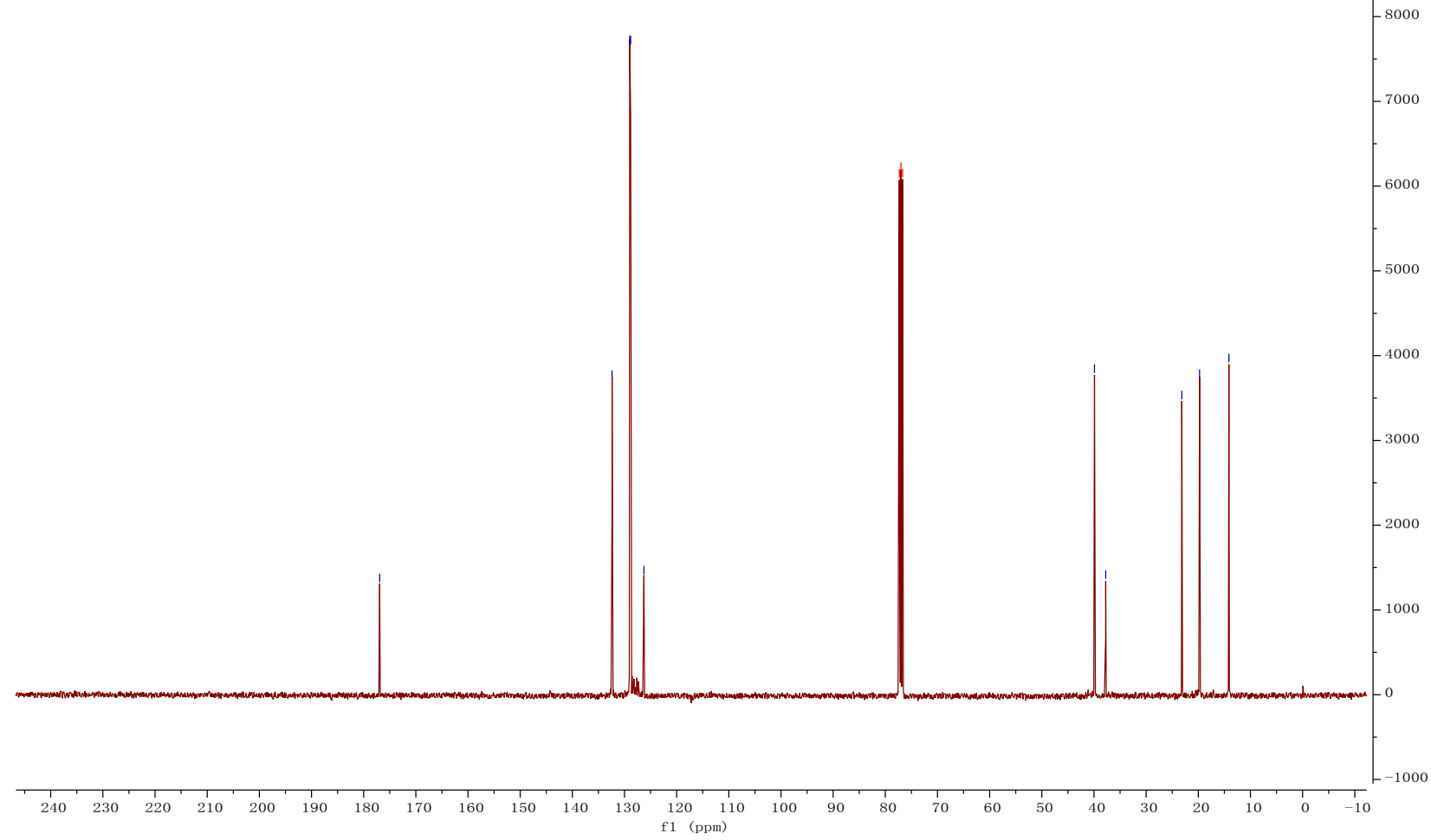




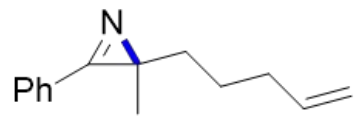

$2 \mathrm{~g}$

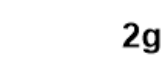

\section{(1)}

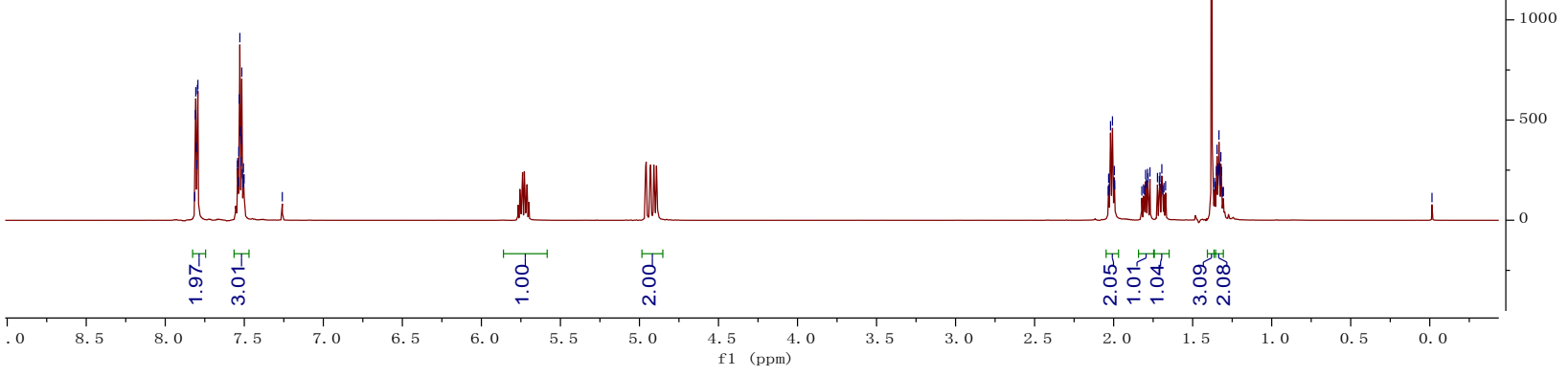

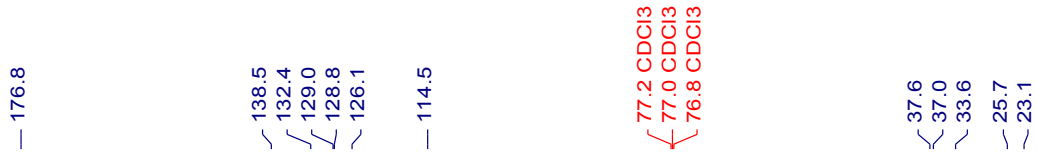

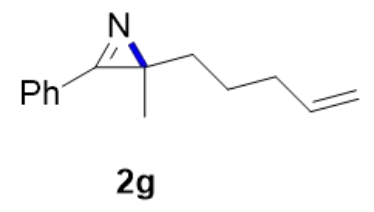

लै।

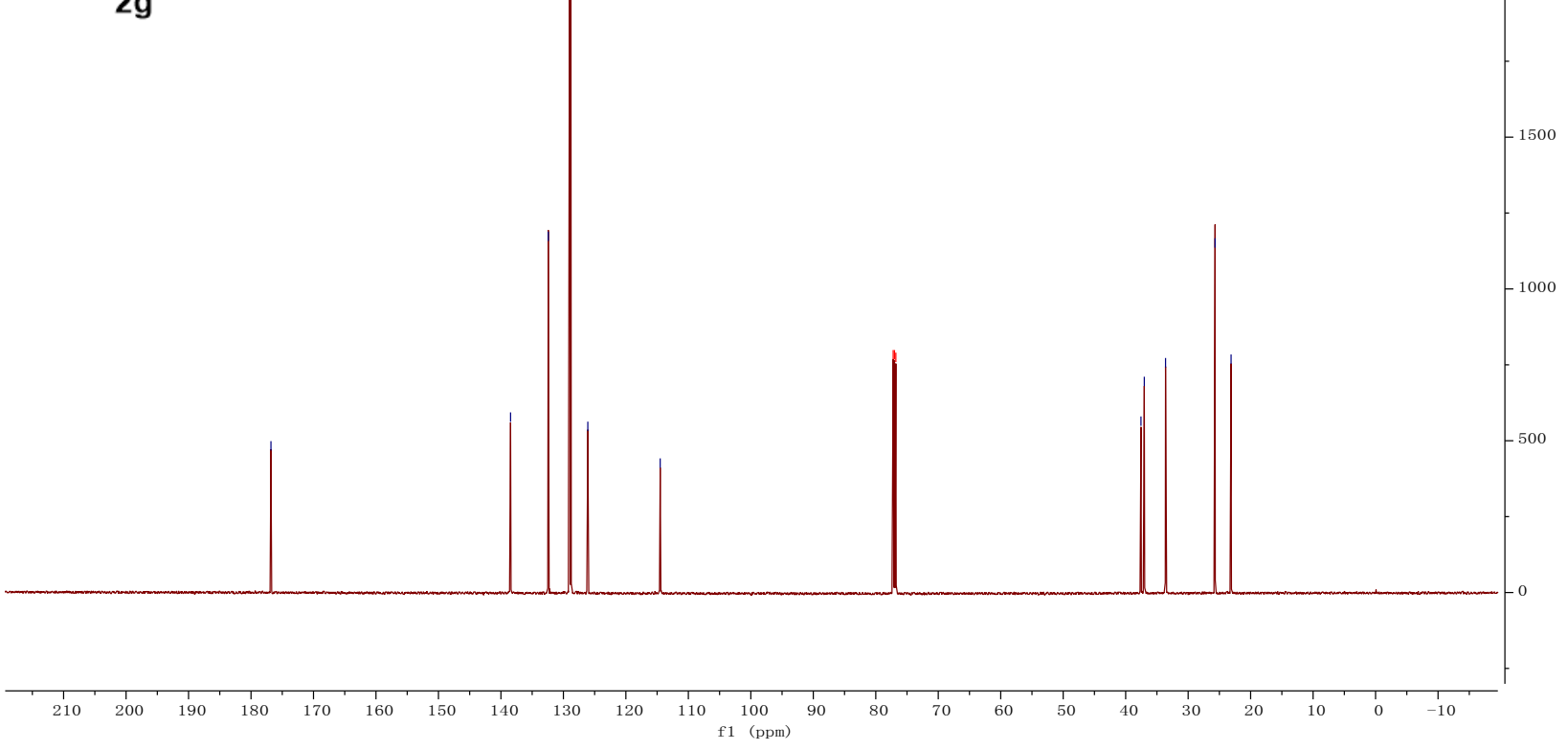


<smiles>CC(C)=CCCC(C)CCC1(C)N=C1c1ccccc1</smiles>

2h

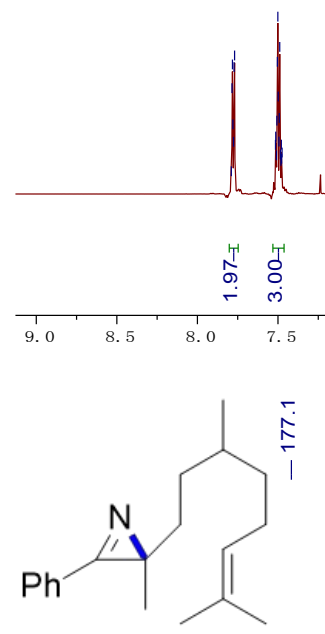

2h

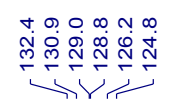

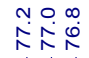

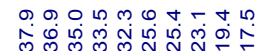

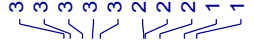

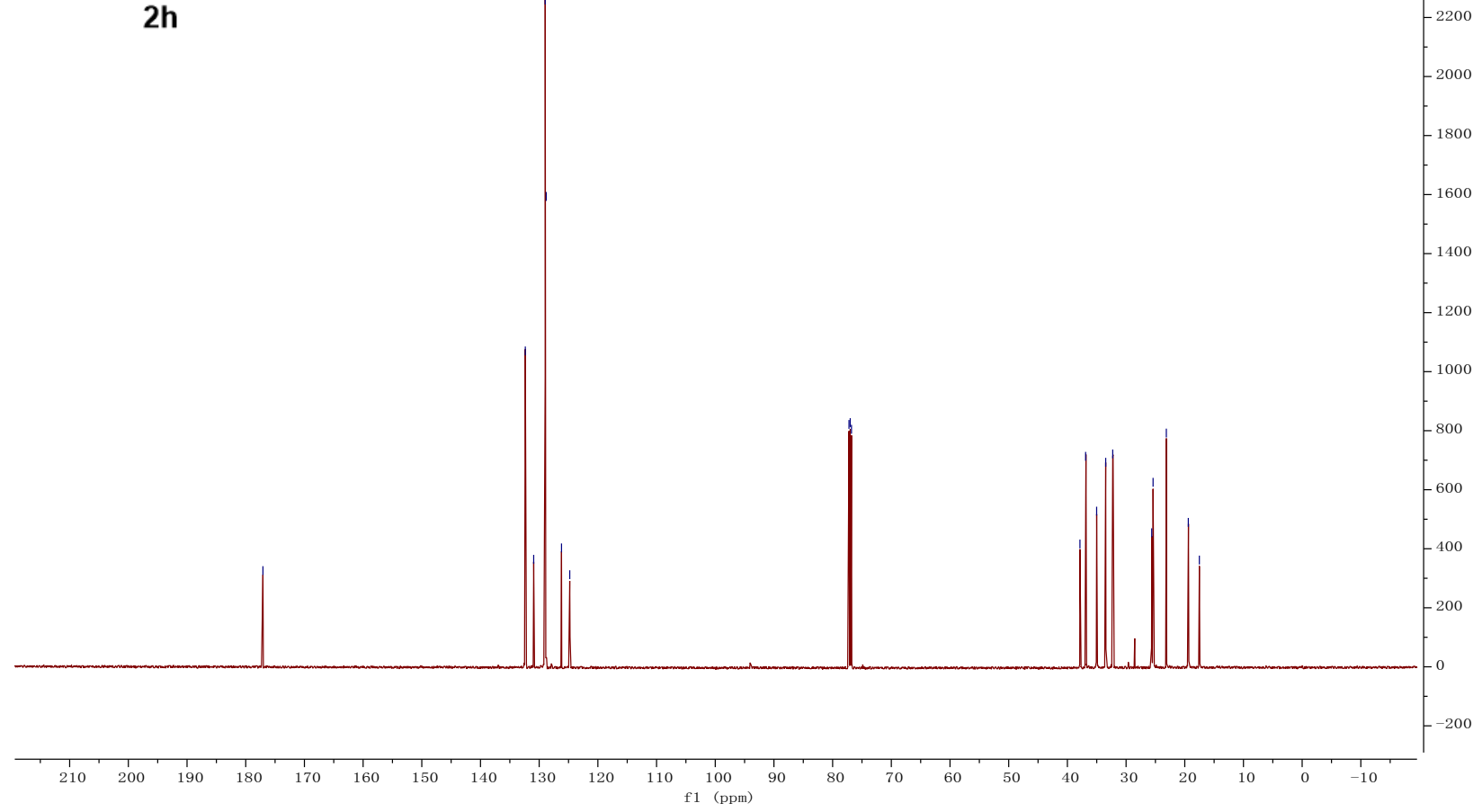




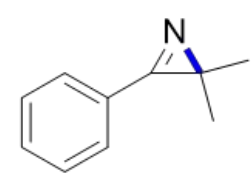

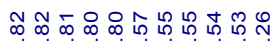

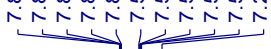

$2 \mathbf{i}$

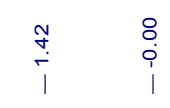

$-2500$
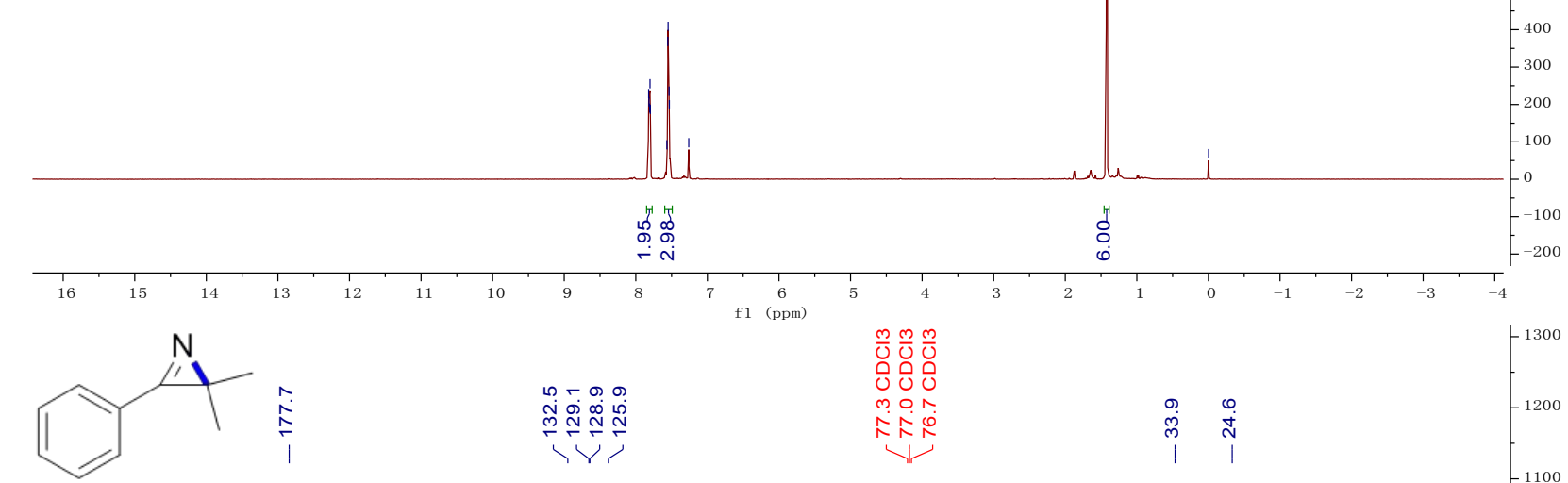

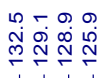

$\frac{m}{0} \frac{m}{0}$
000
000

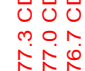

पर?

许

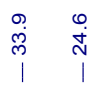

2i

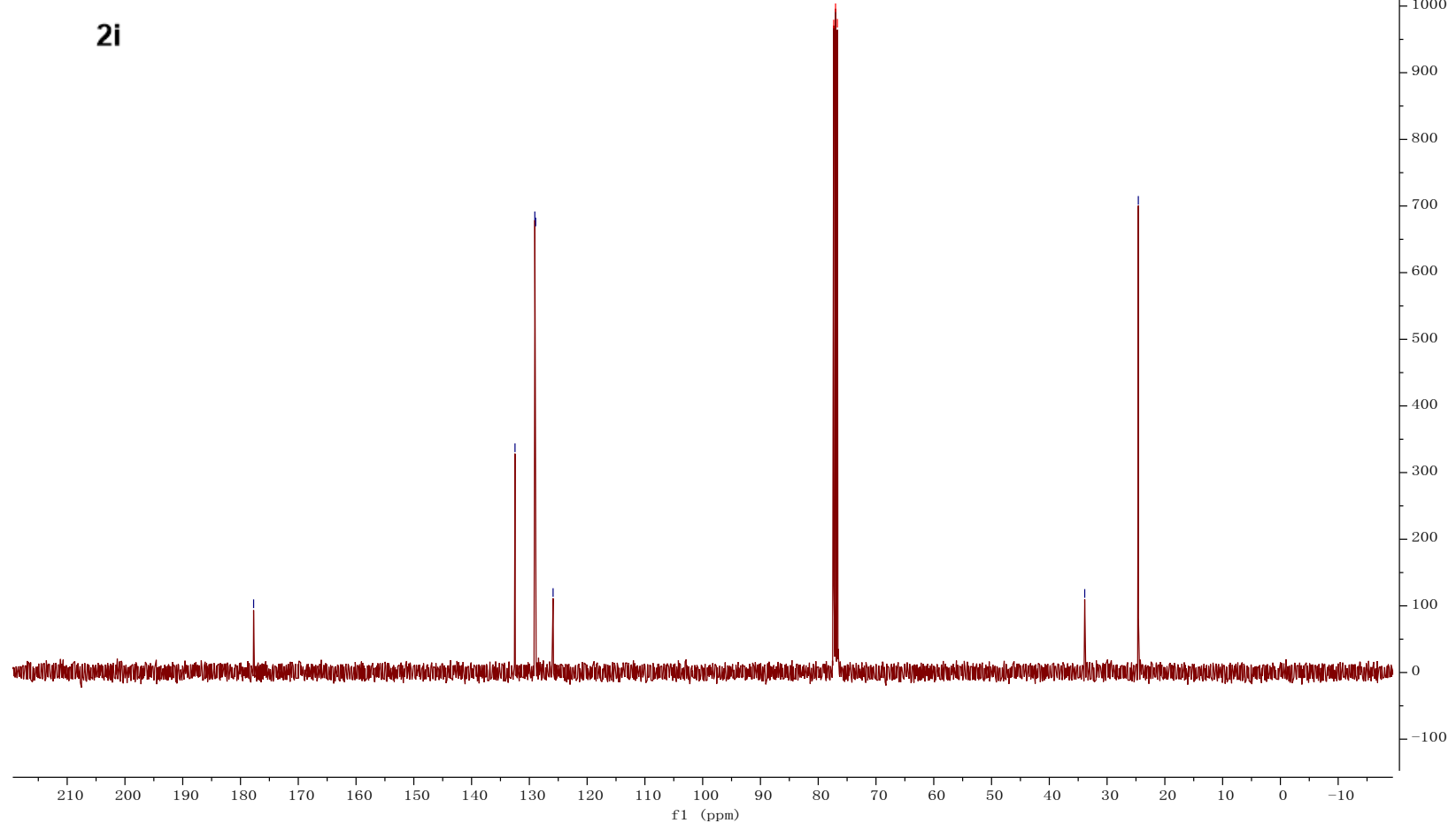


(N)

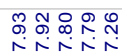

iñtin

2]

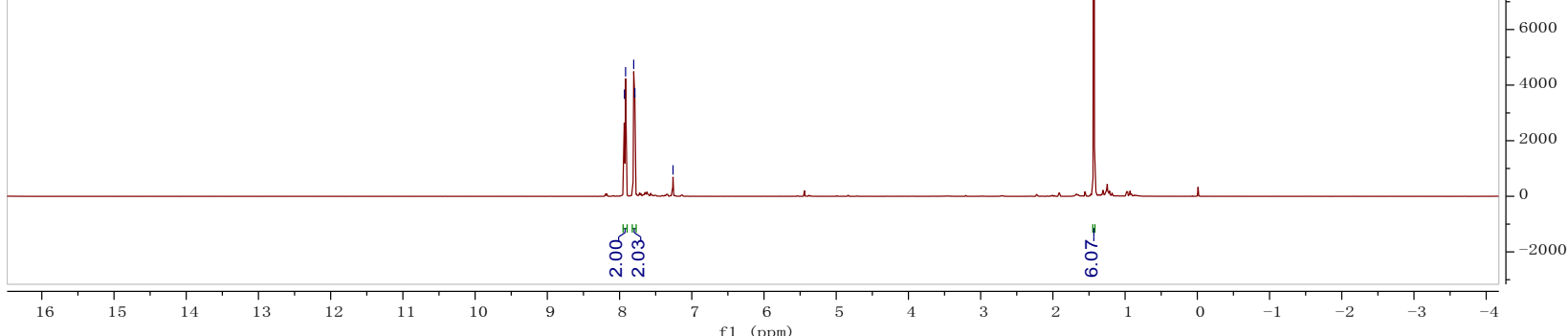

$\mathrm{F}_{3} \mathrm{C}$<smiles>Ic1ccc(C2CC2(I)C2CC2)cc1</smiles>

2j

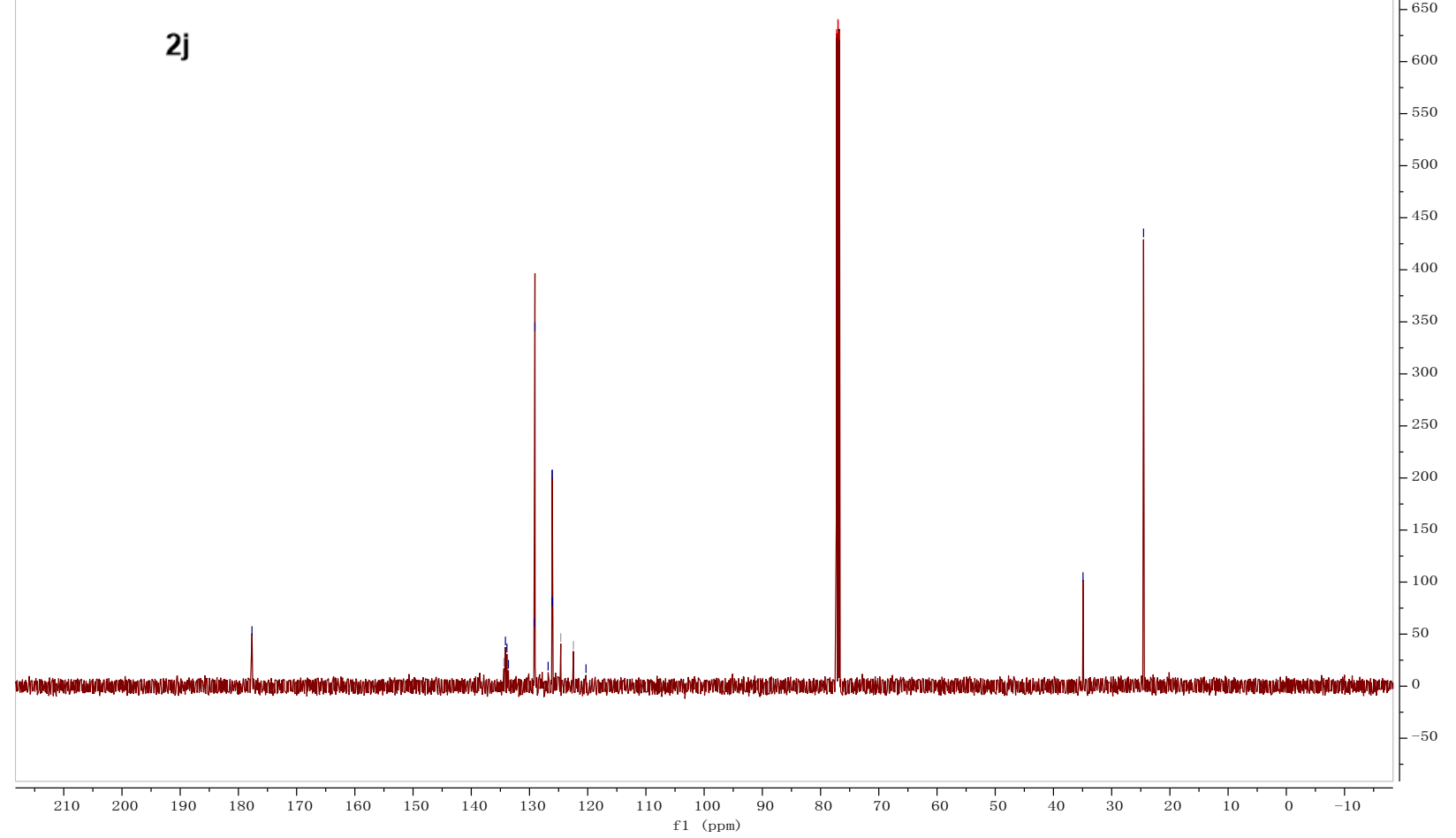




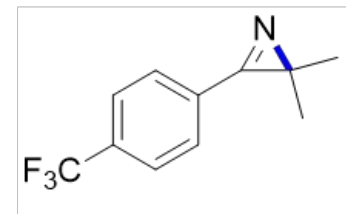

2j

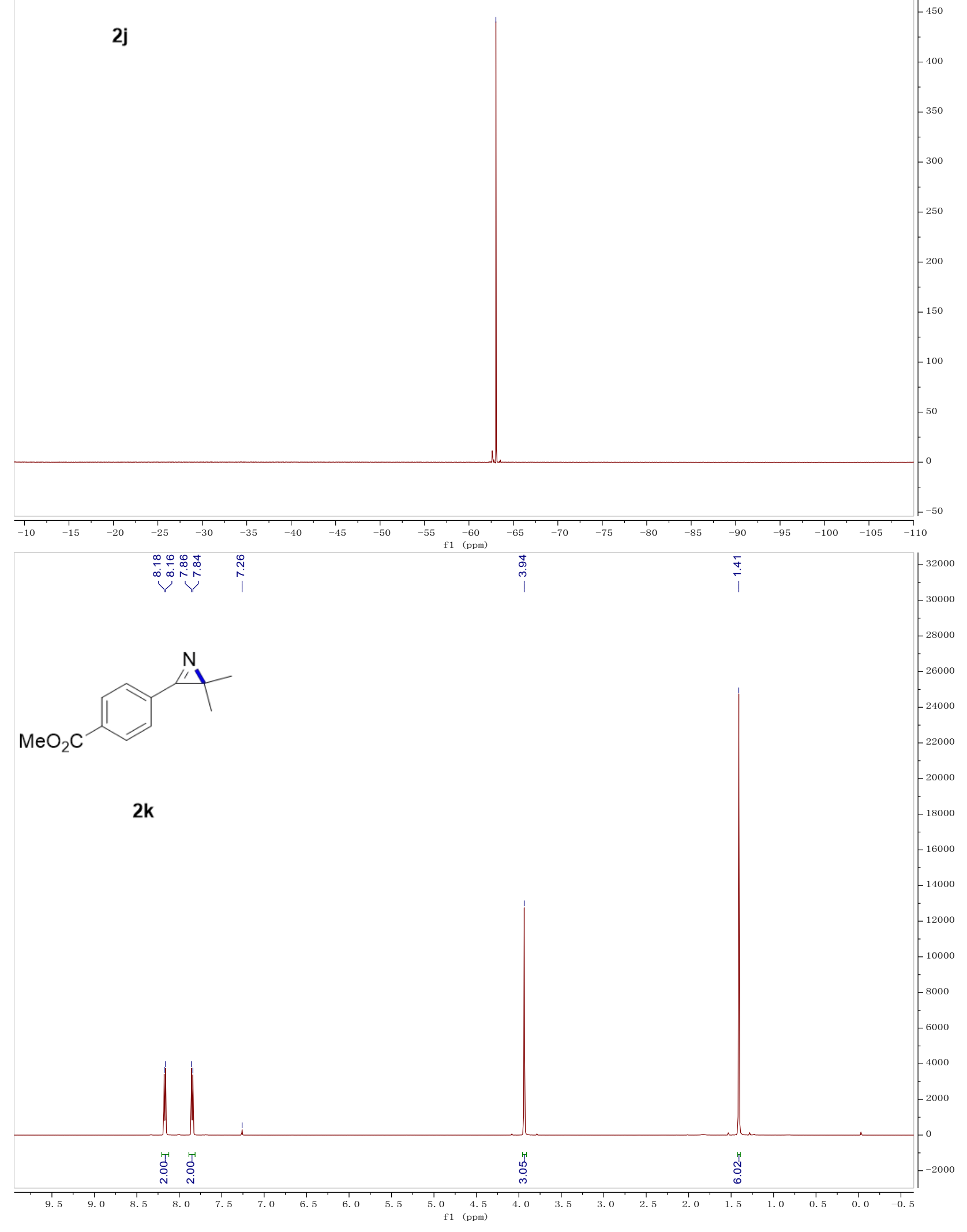




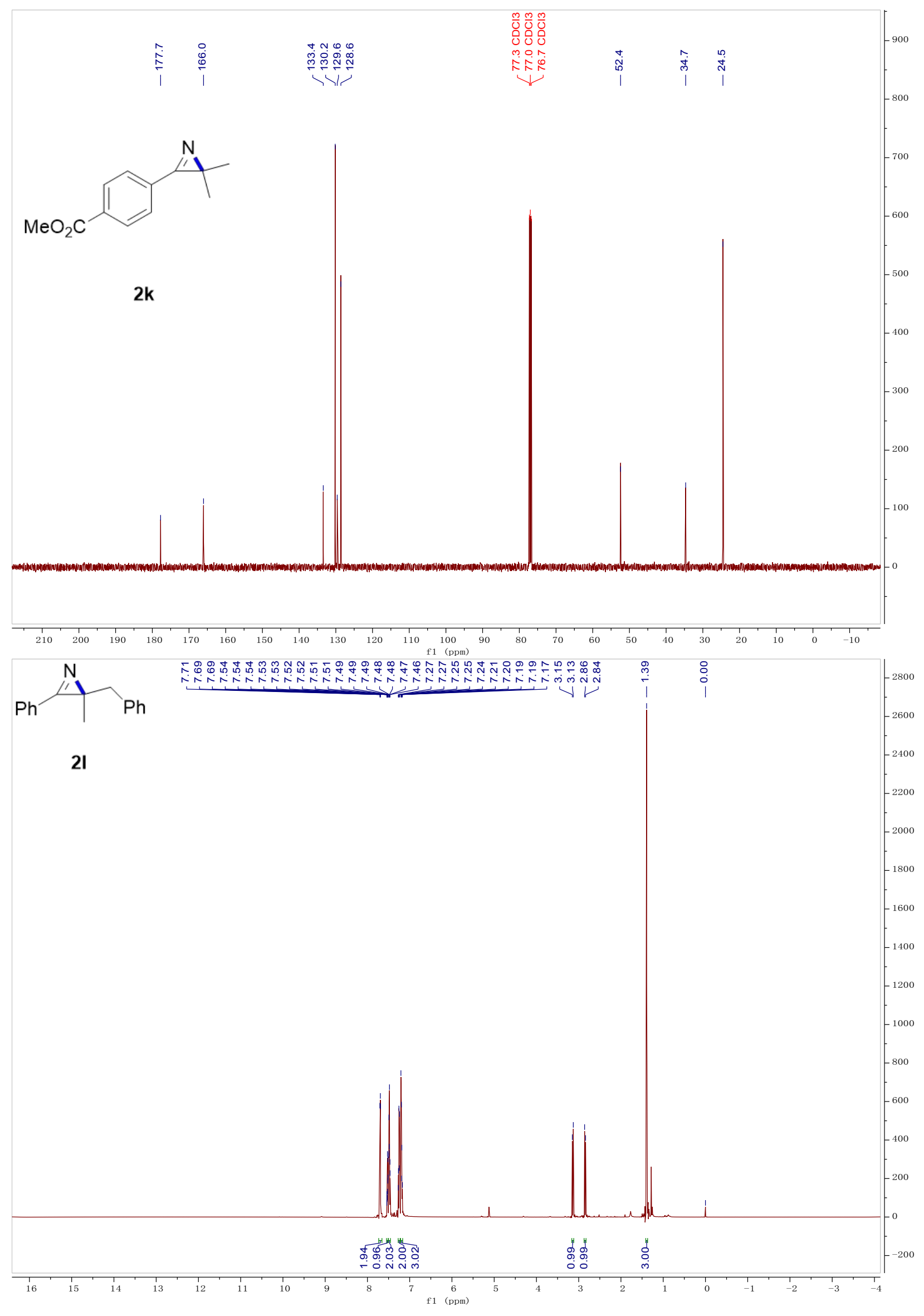




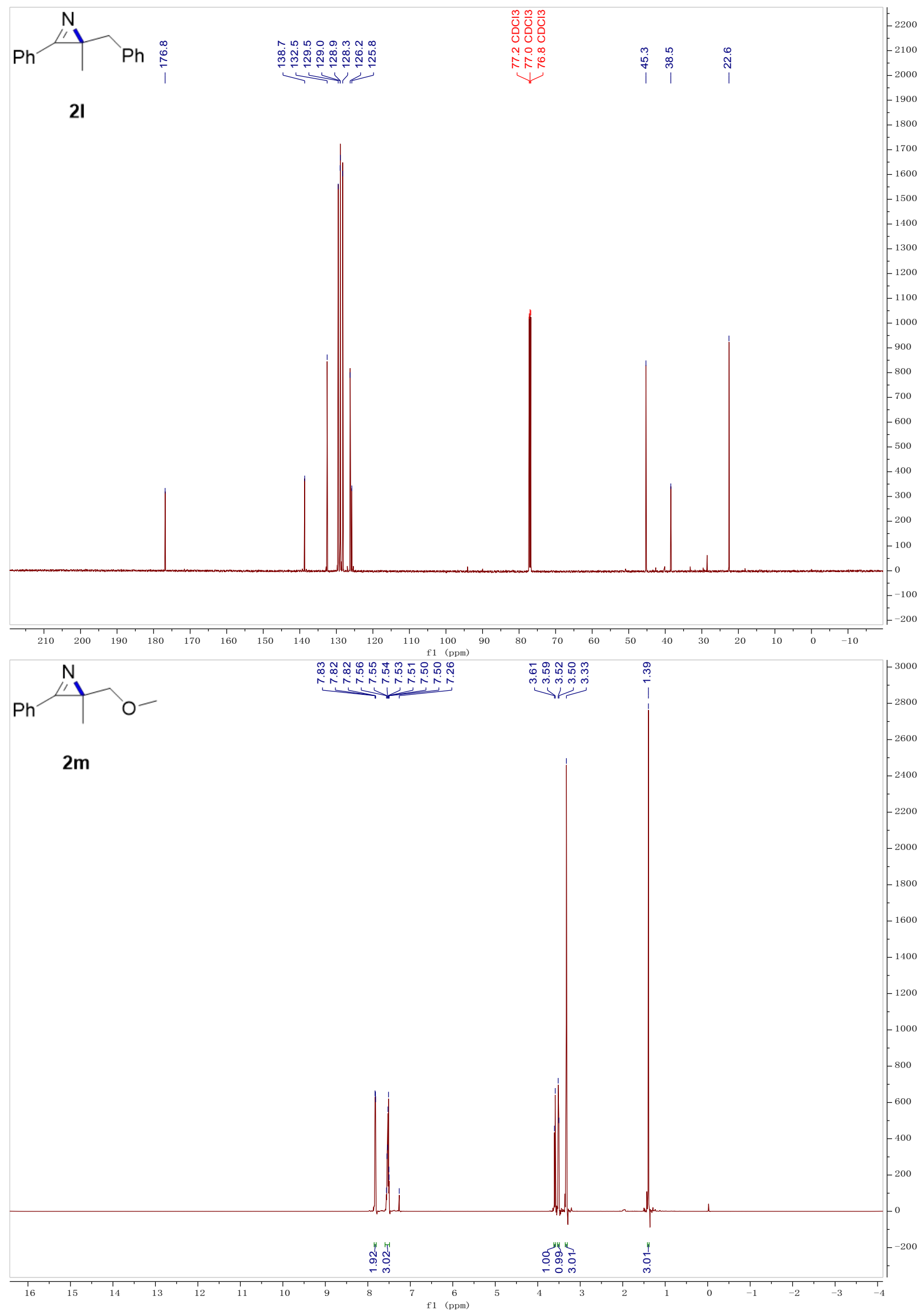




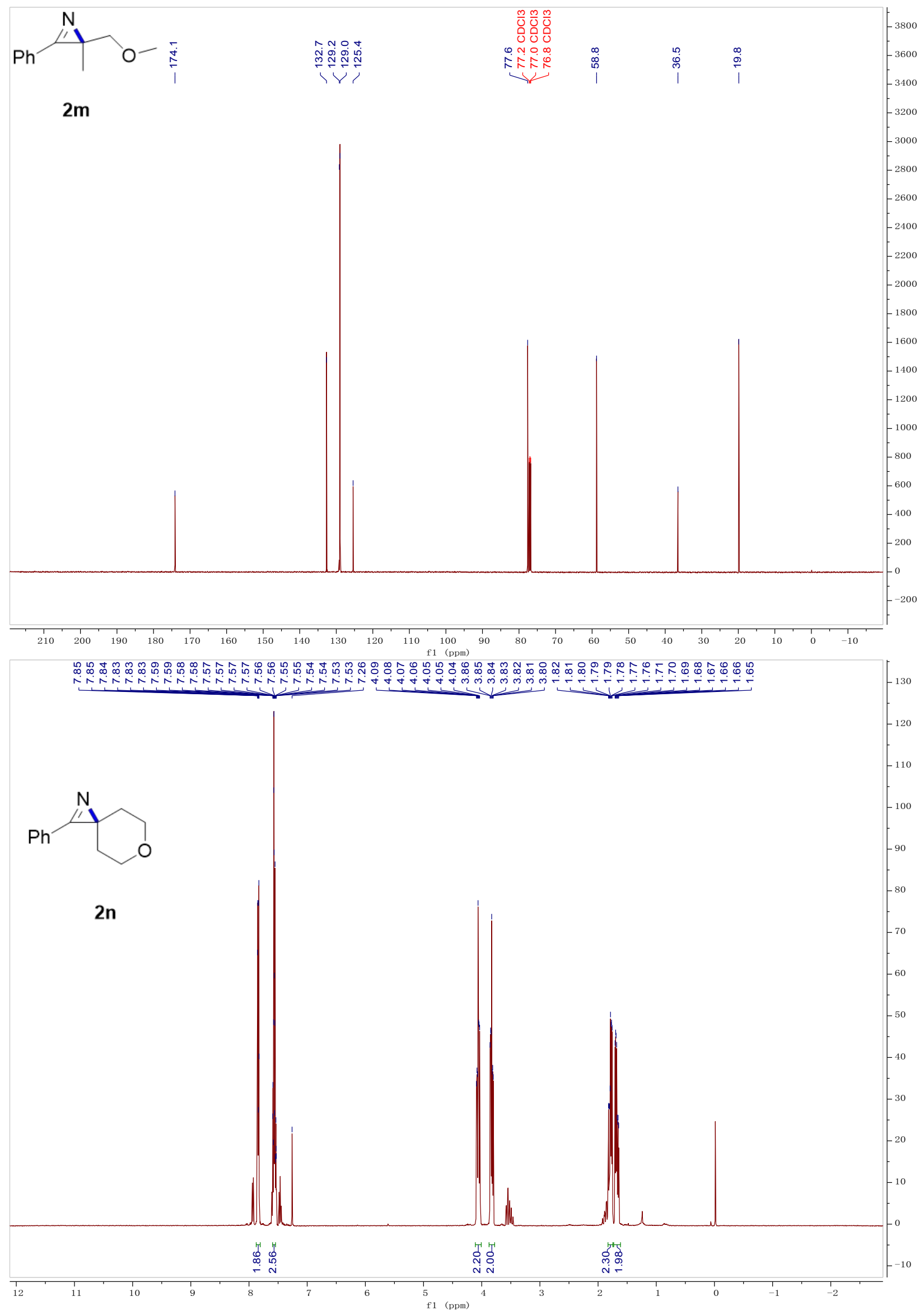


$\mathrm{Ph}_{0}^{\mathrm{N}}$

2n

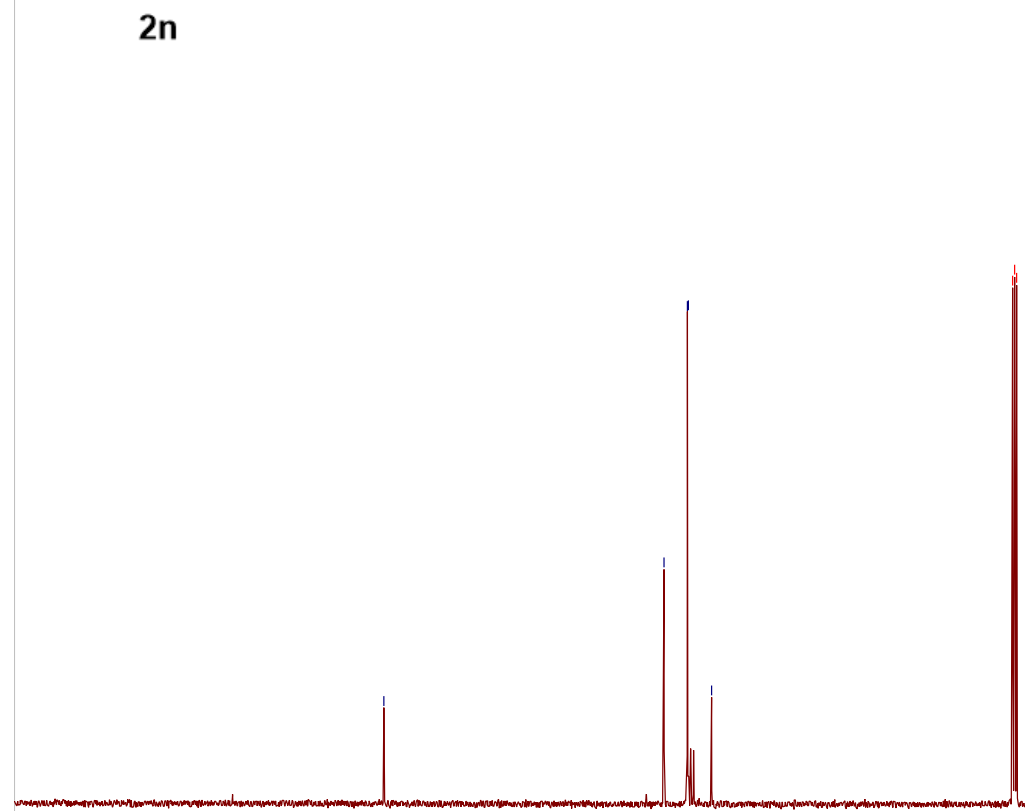<smiles>c1ccc(C2=NC23CCSCC3)cc1</smiles>

20

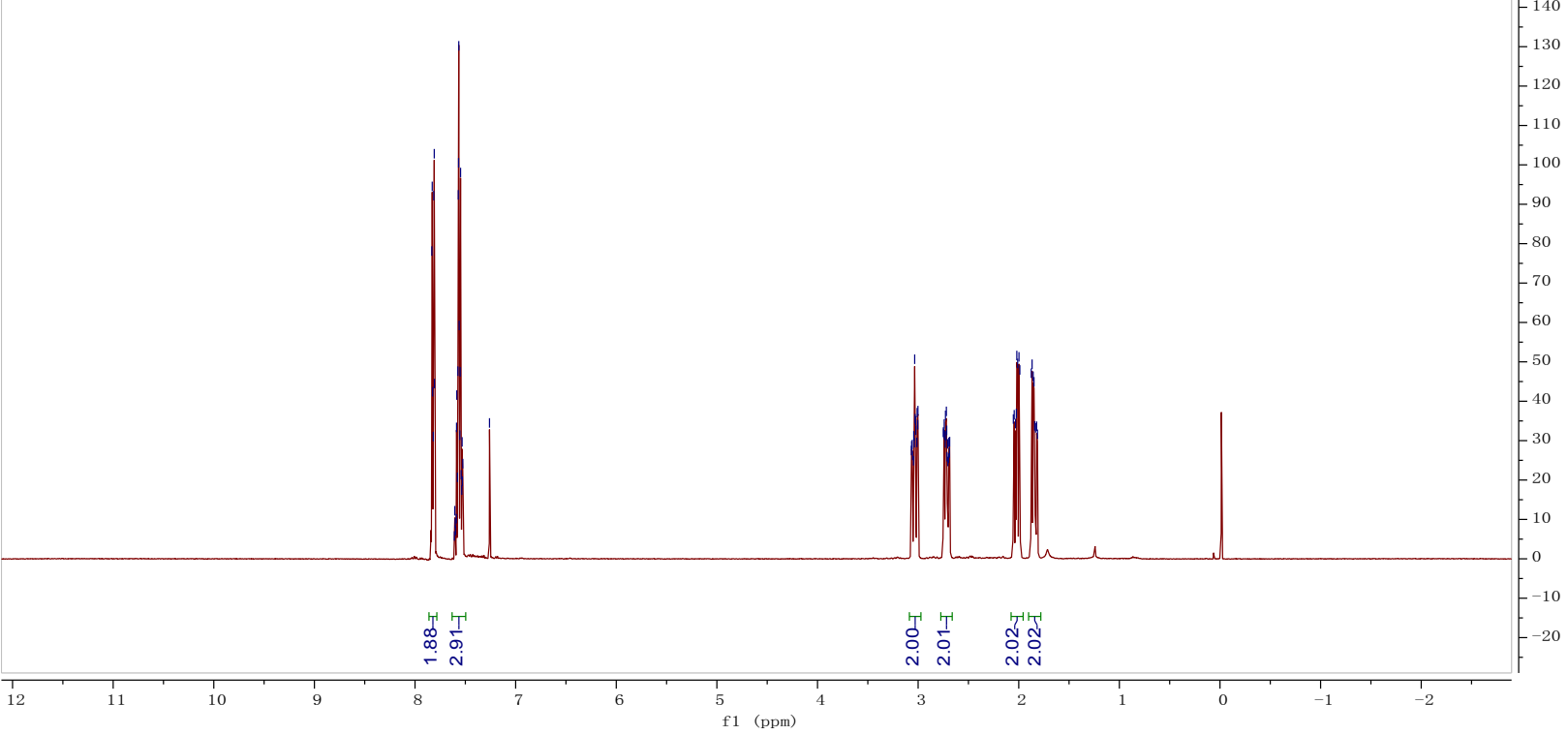


$\mathrm{Ph}_{\mathrm{S}}^{\mathrm{N}}$

20
일ำ

|Yे

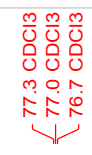

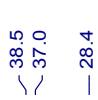

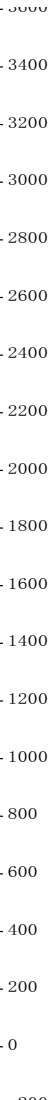

230

$\begin{array}{lllll}230 & 220 & 210 & 200 & 190\end{array}$

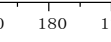

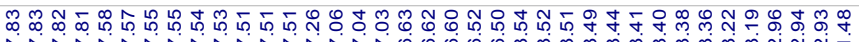

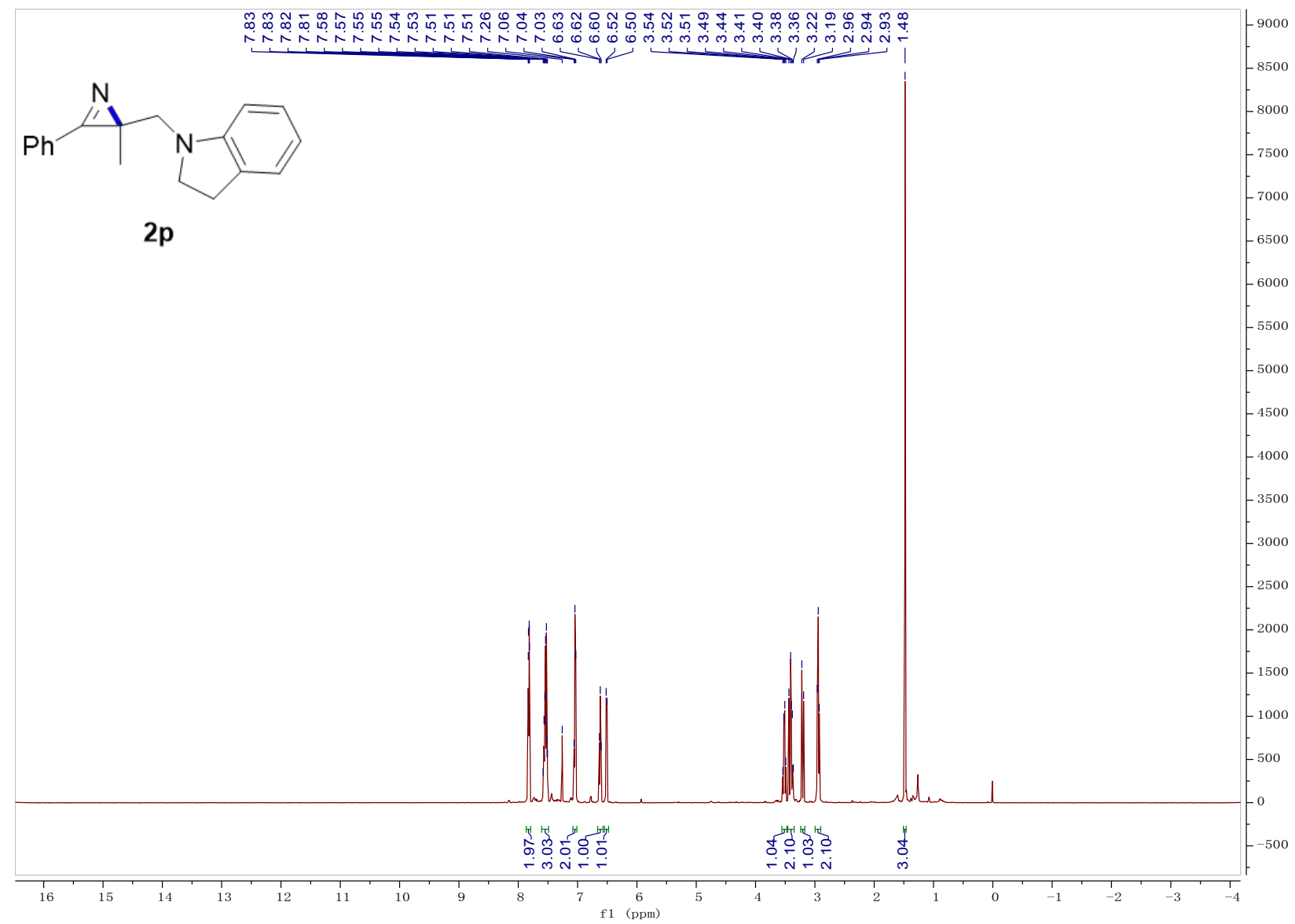




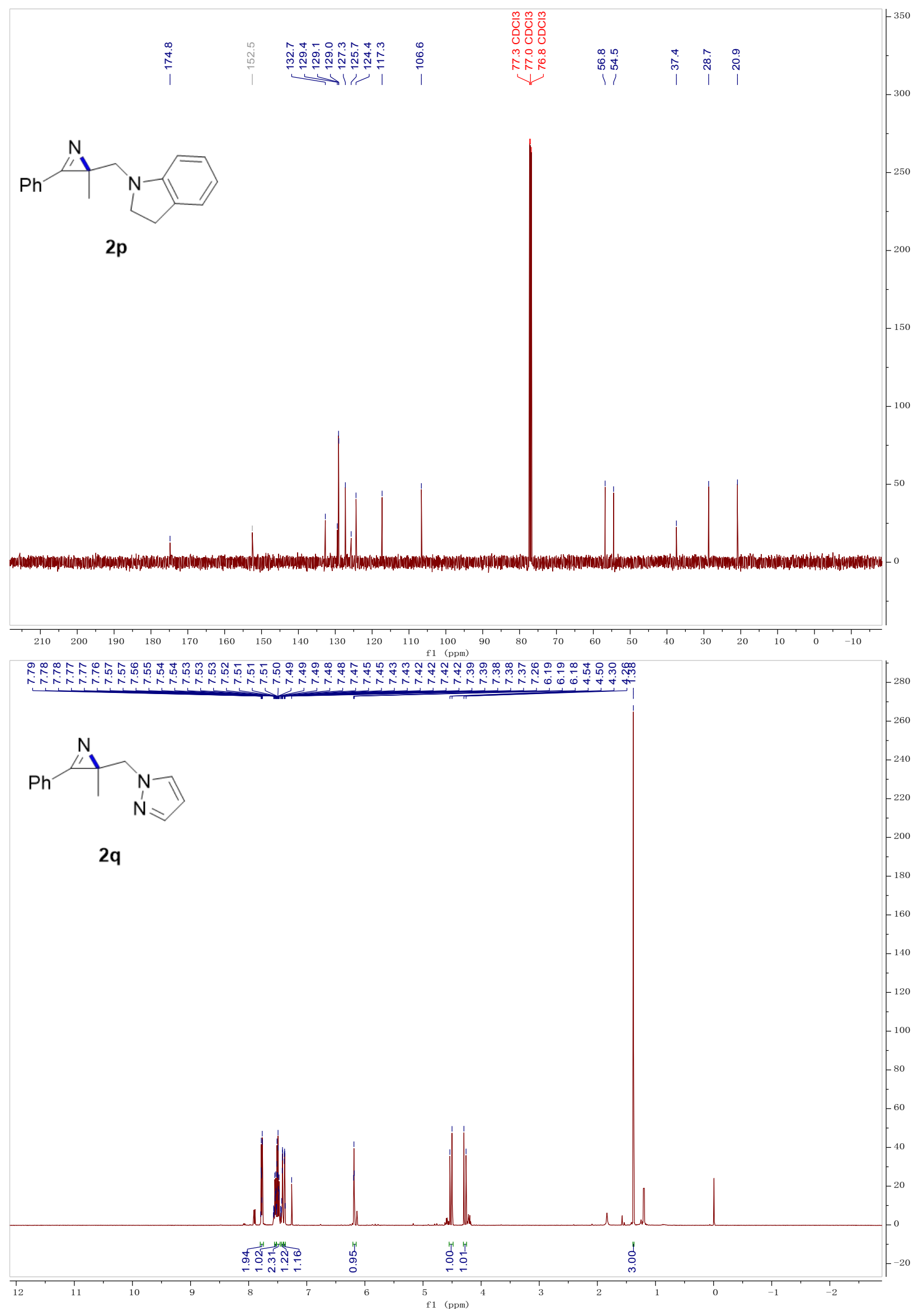



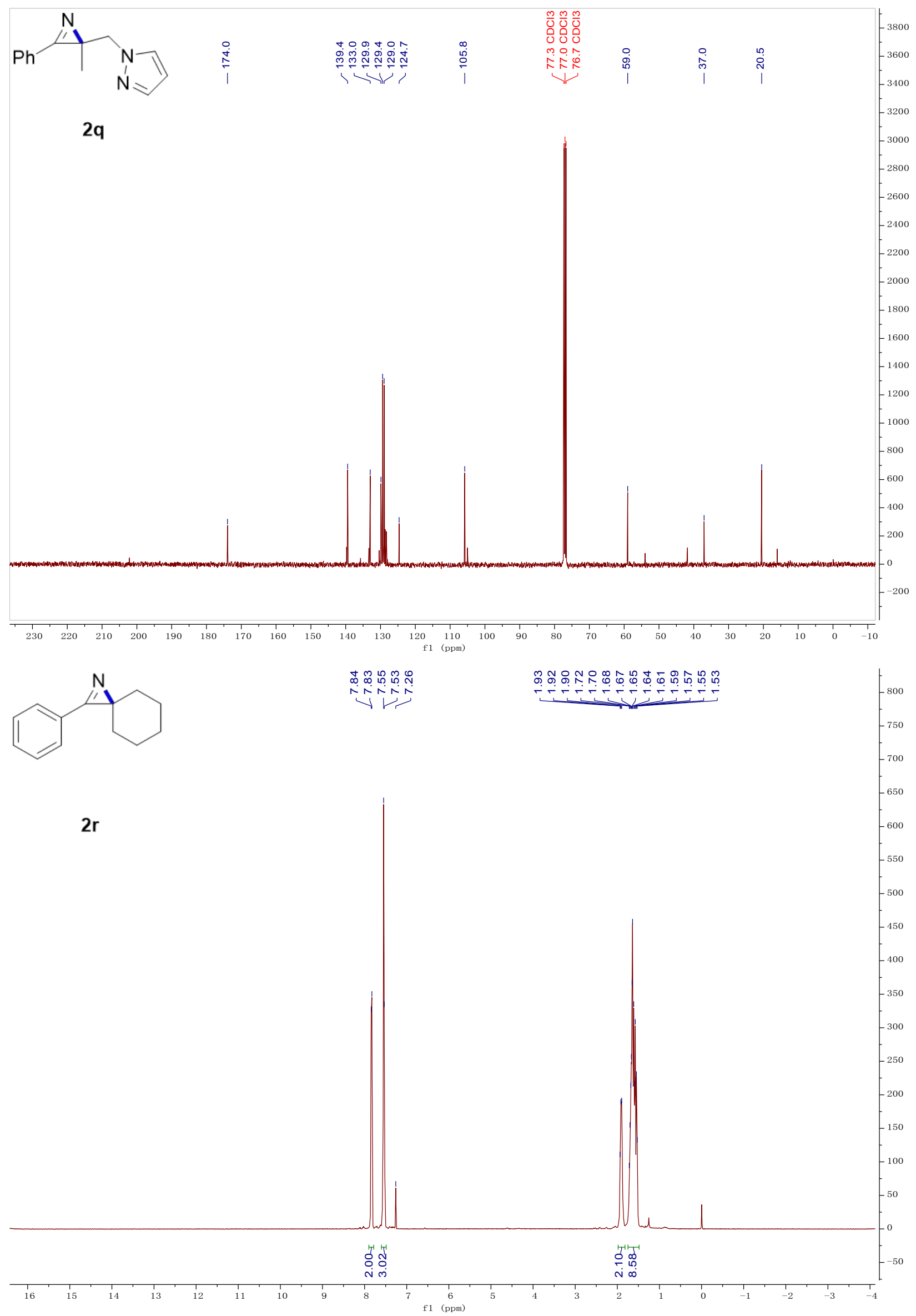


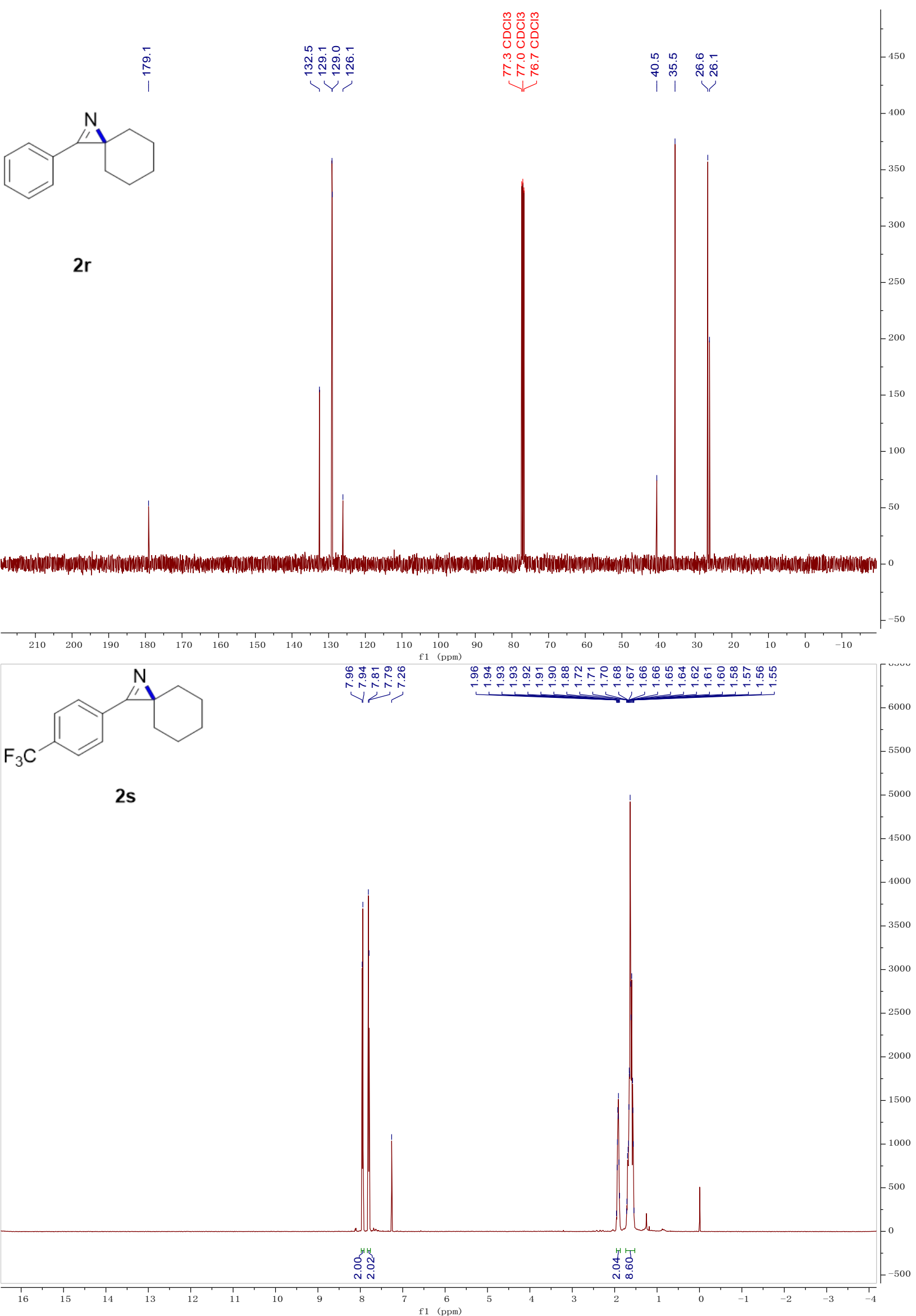

1 (ppm)

S40 

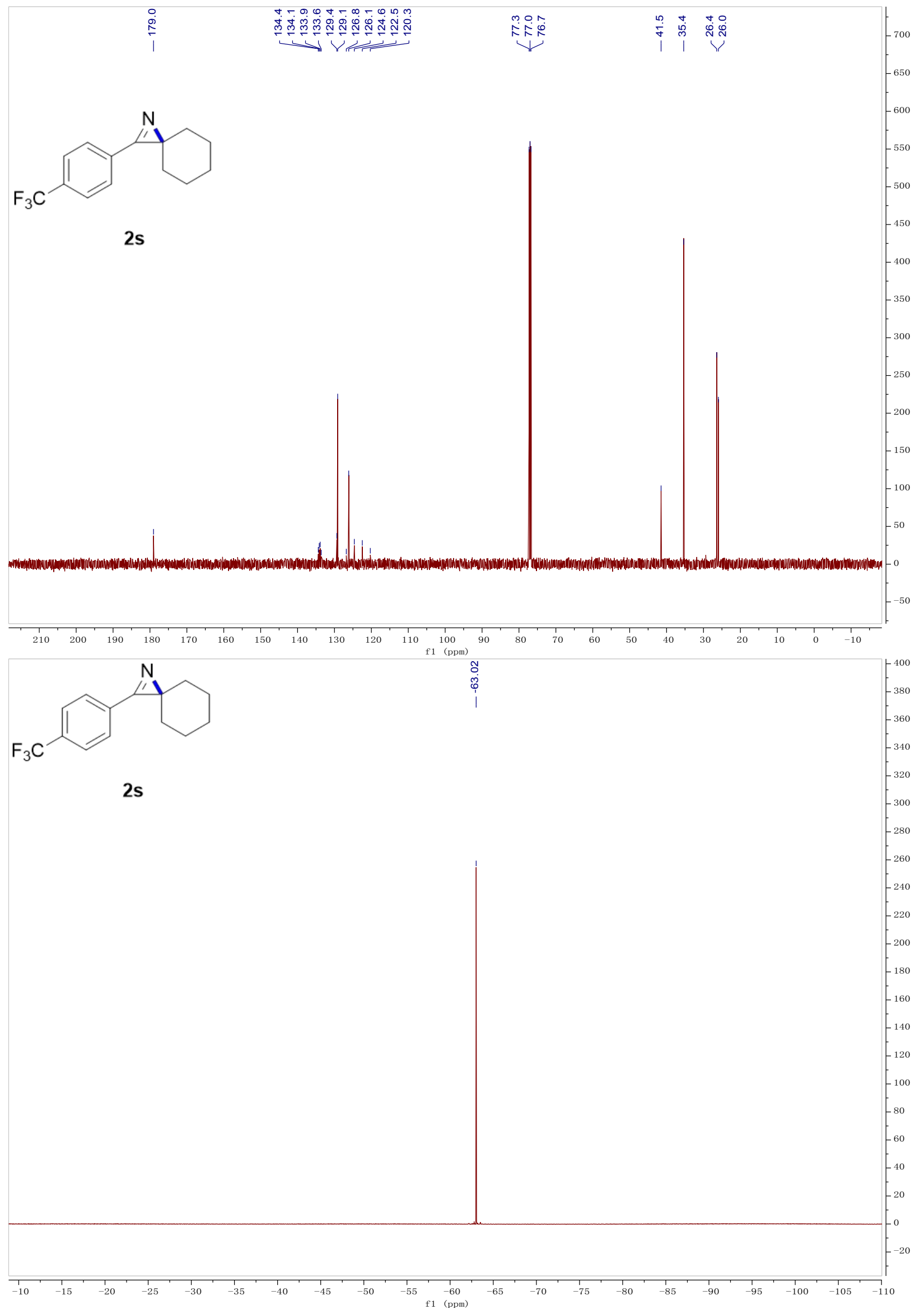

S41 


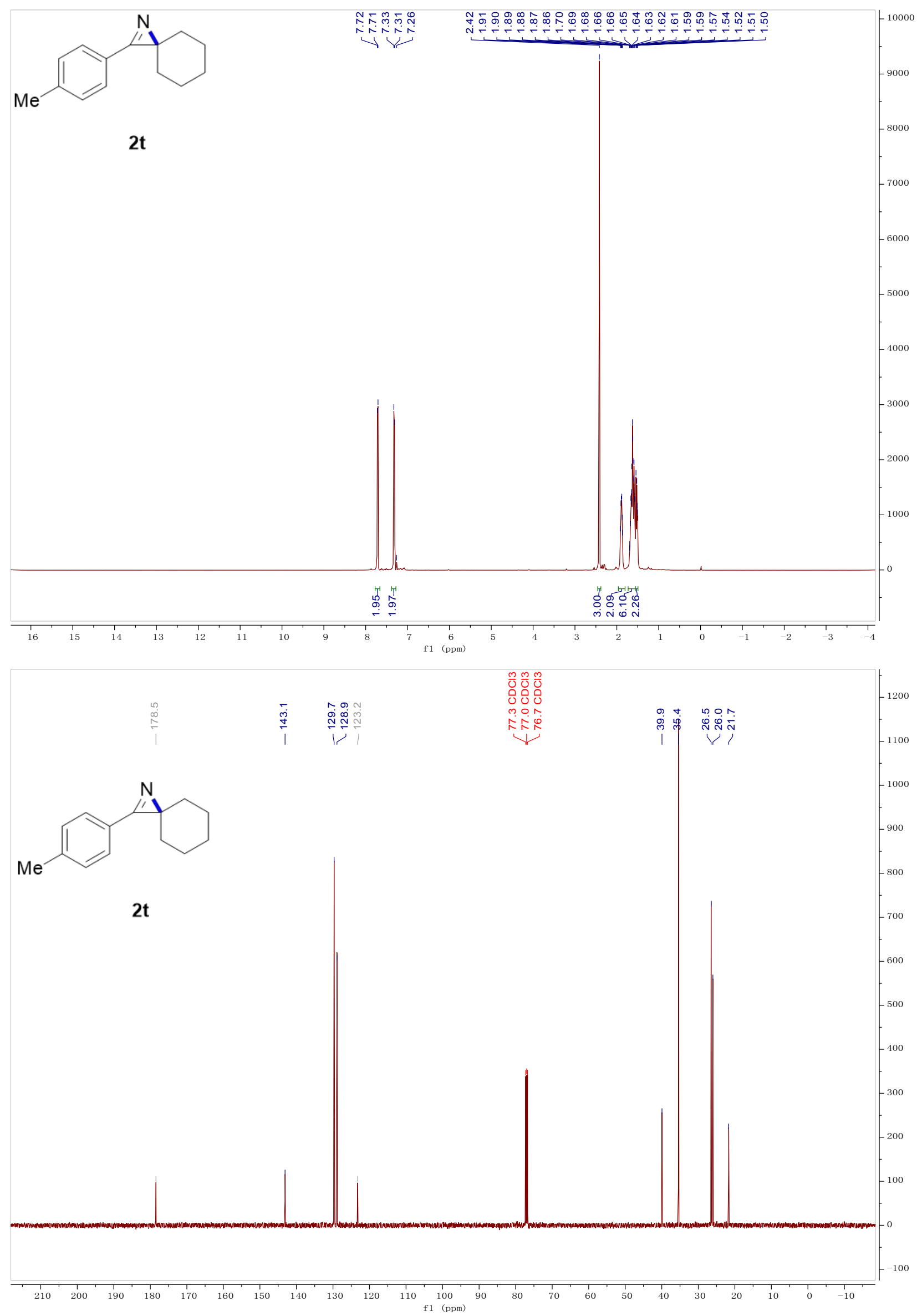




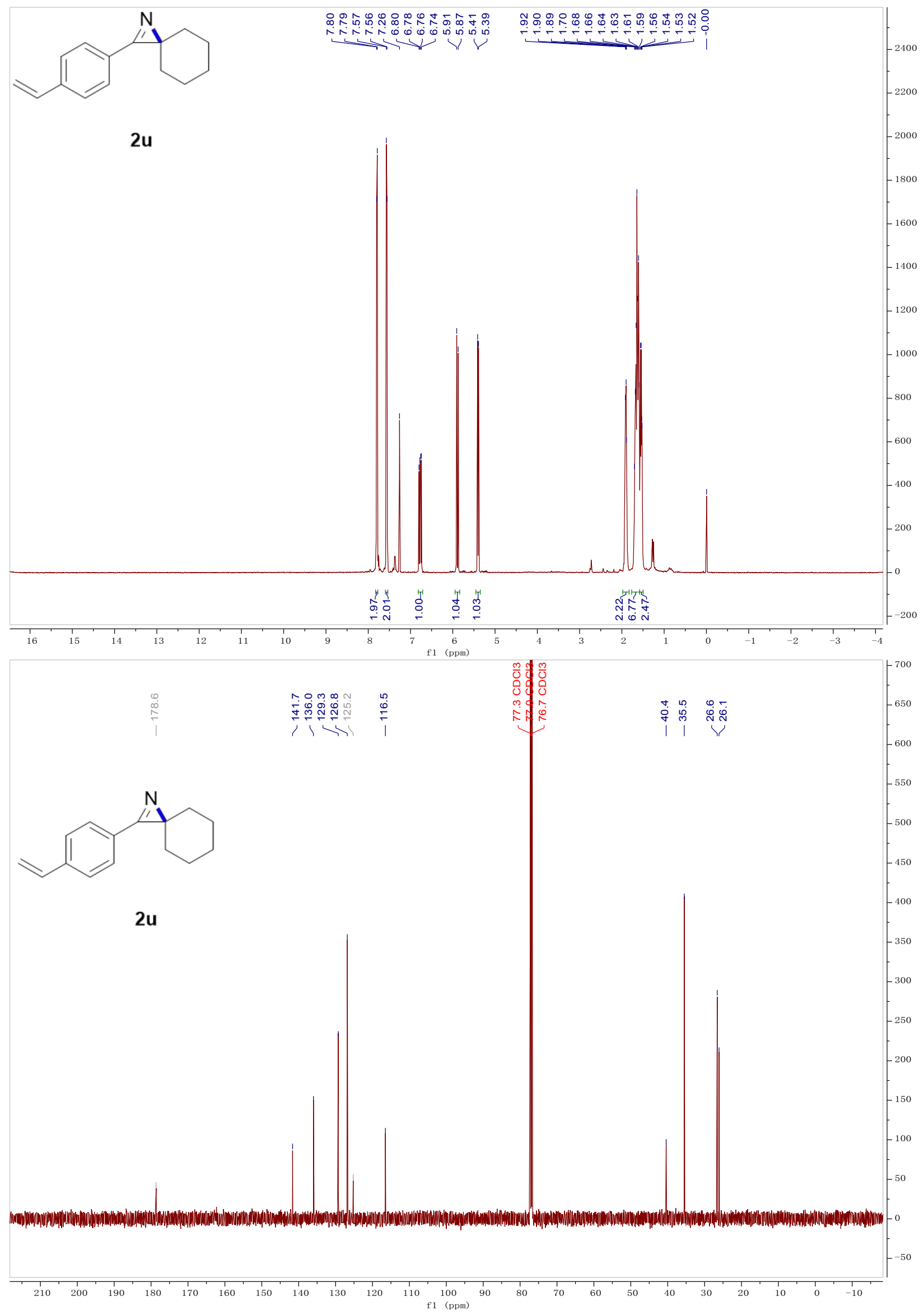




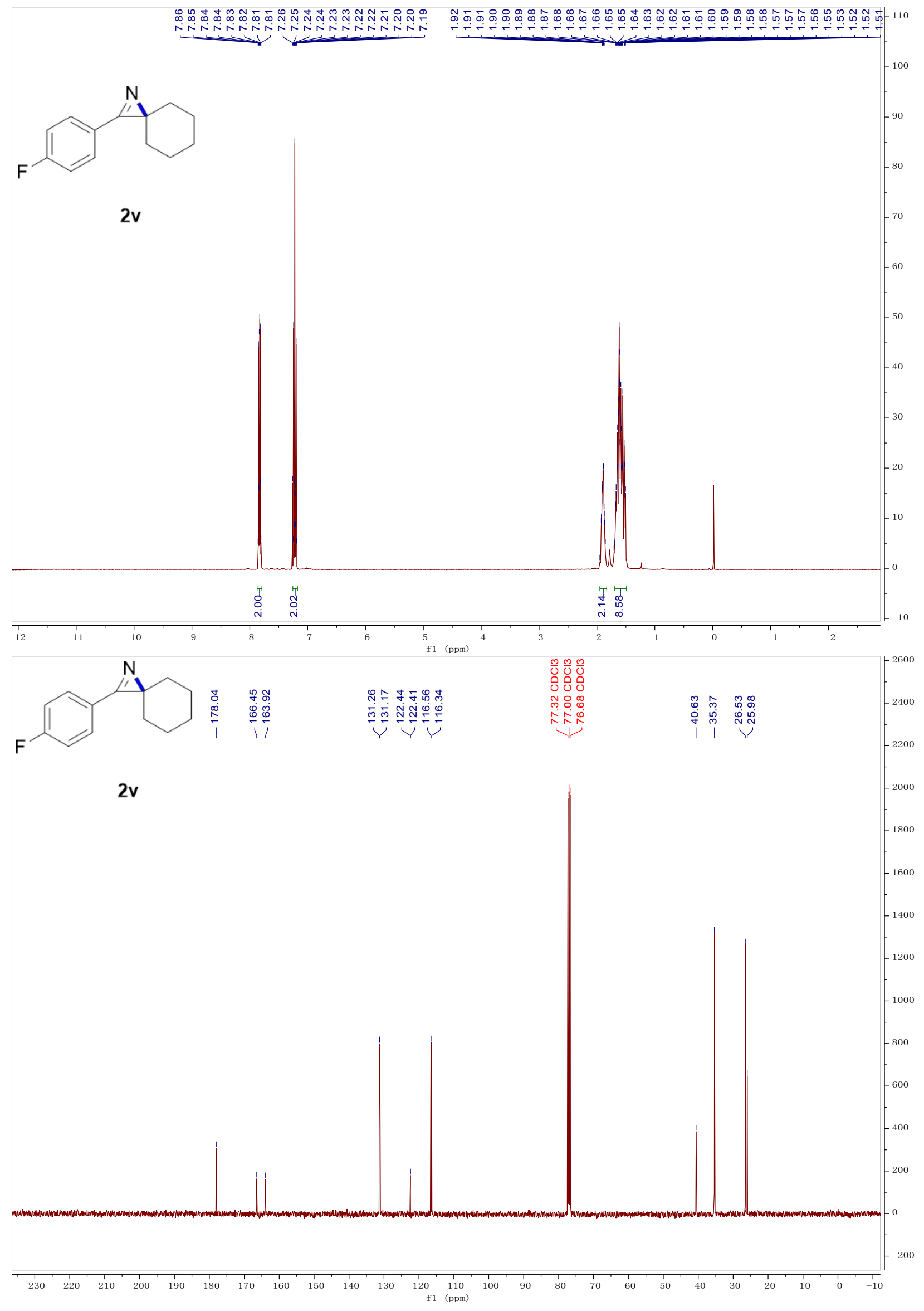



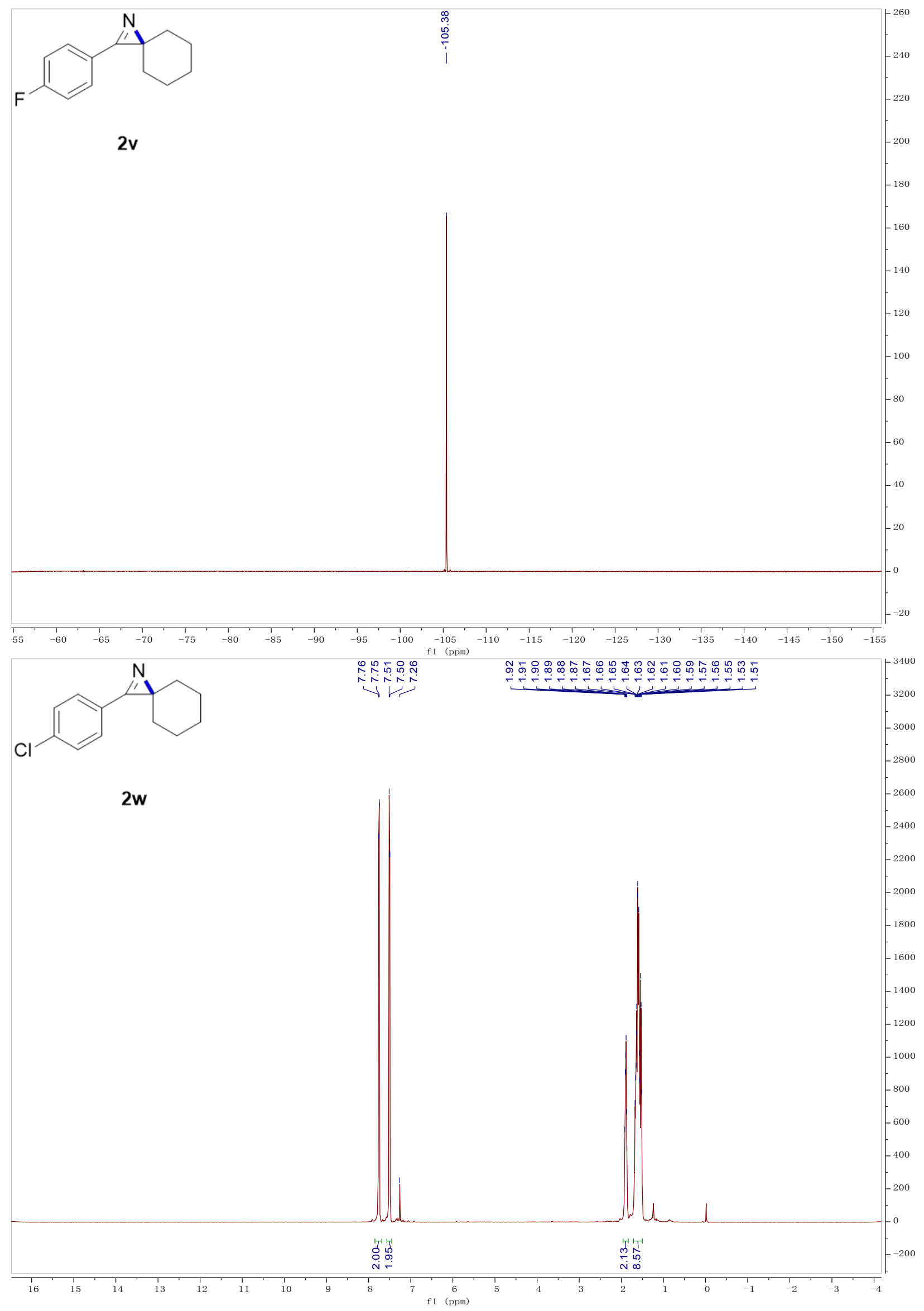


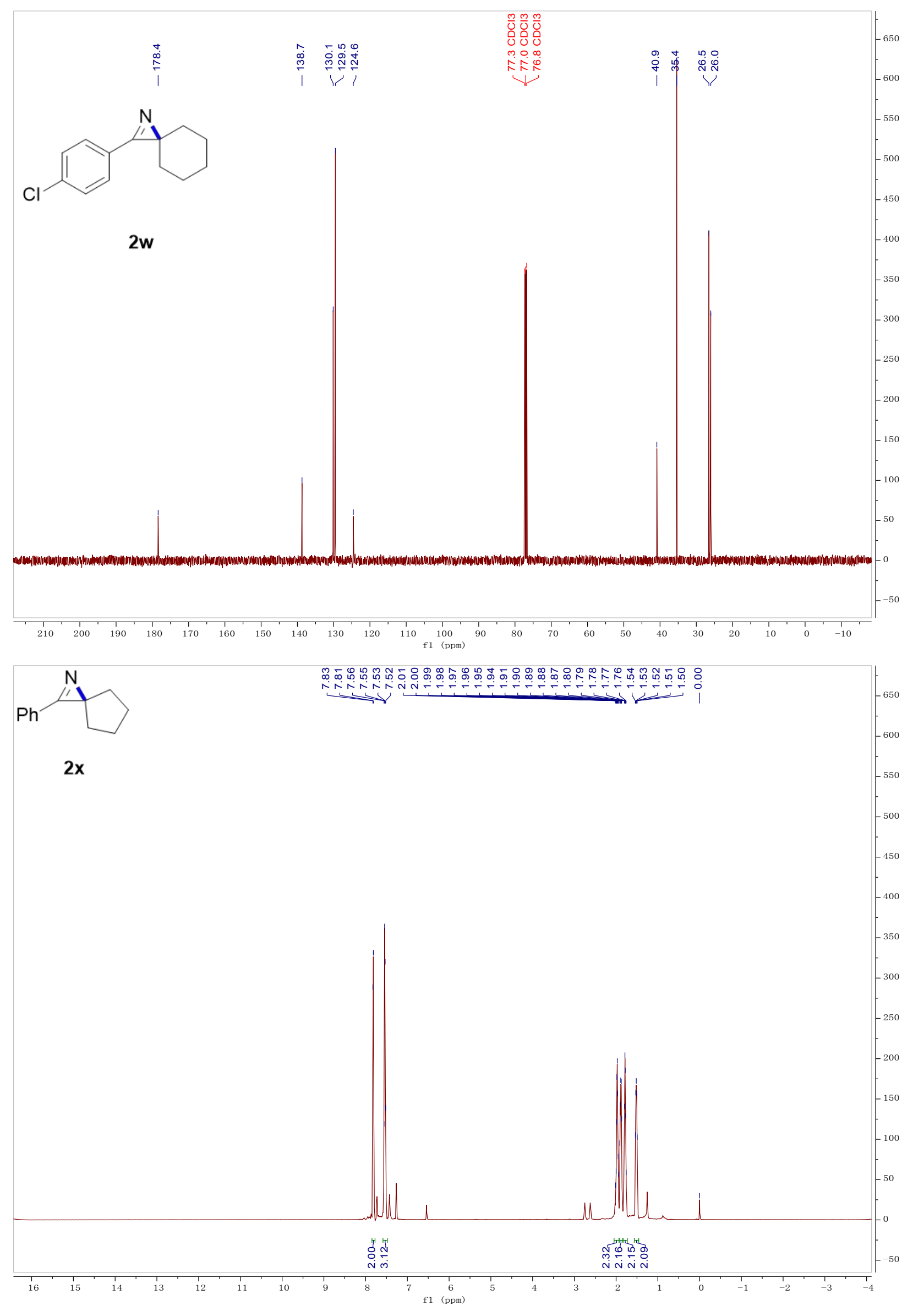



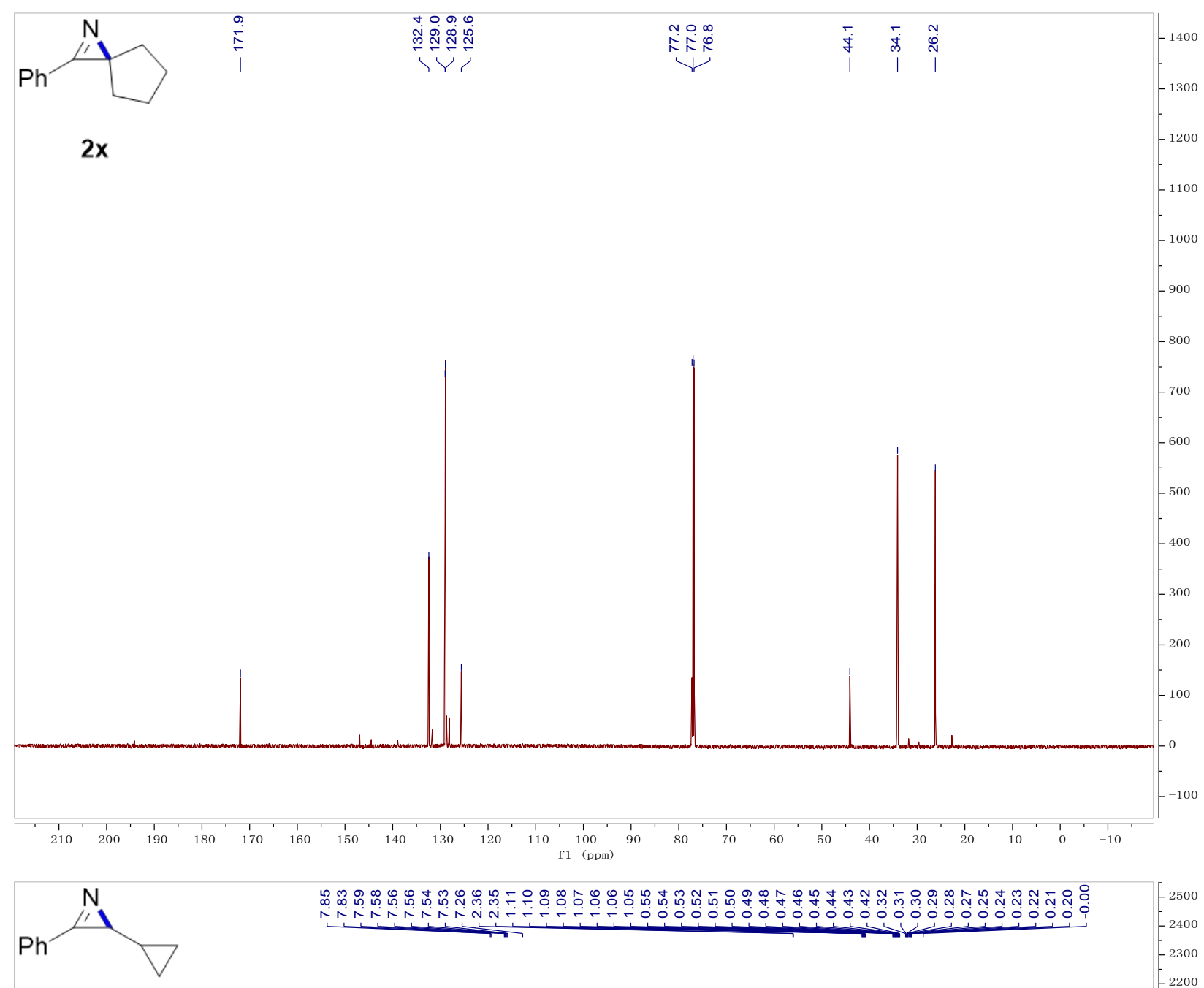

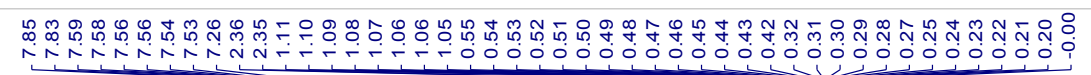

$-2500$

$2 y$

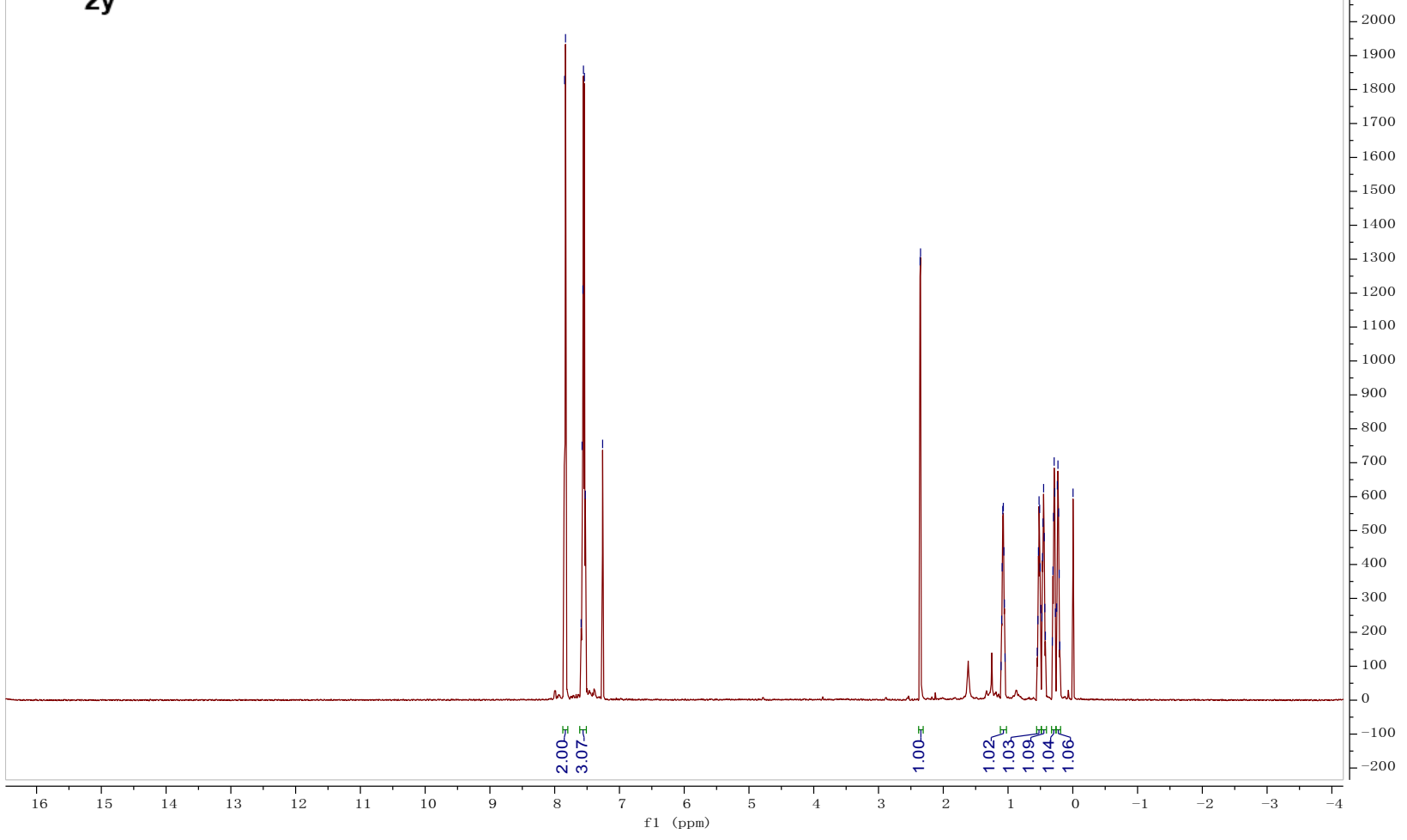




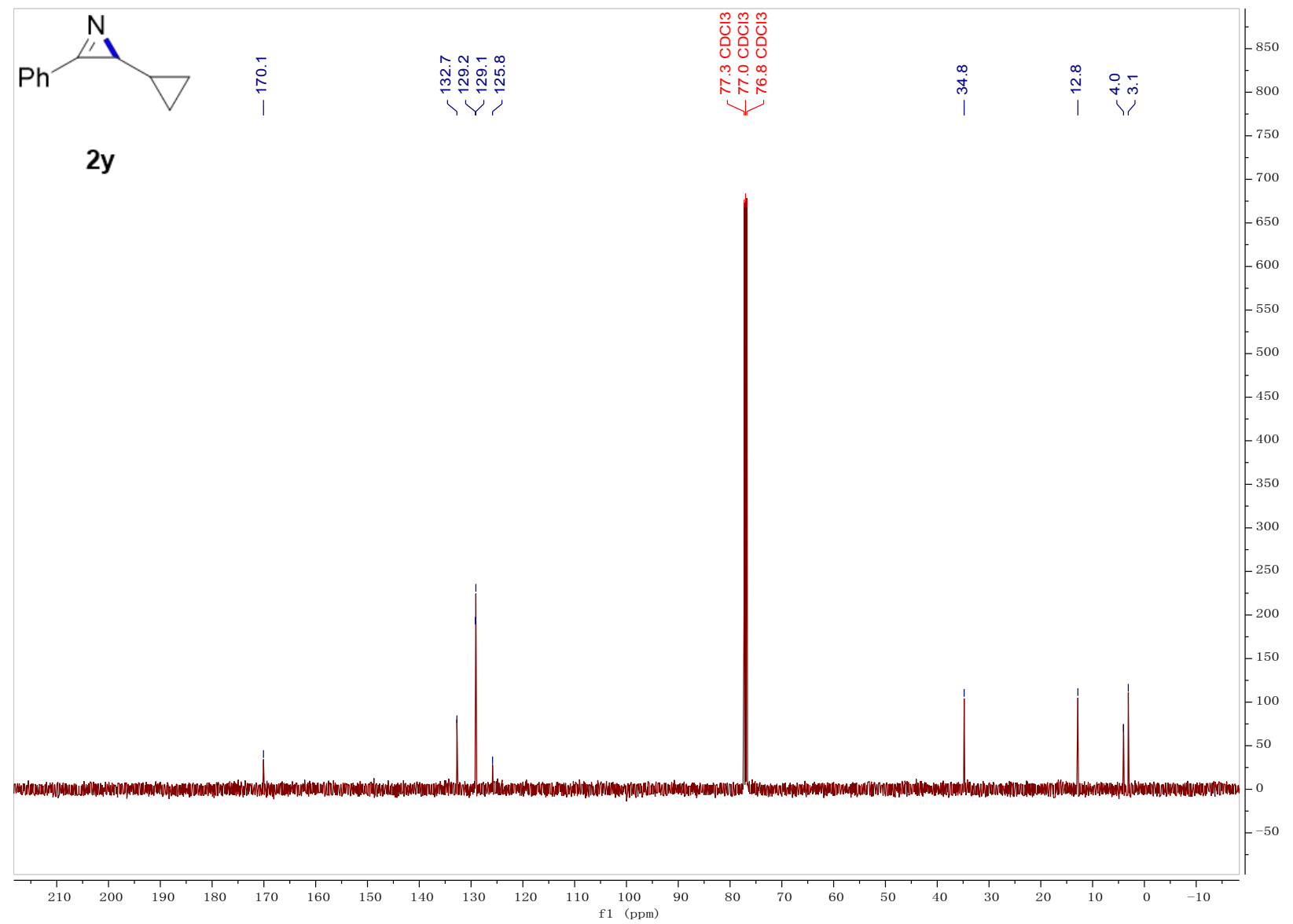<smiles>CC(CCOC(=O)c1ccccc1)C1=N[C@@H]1c1ccccc1</smiles>

$2 z$

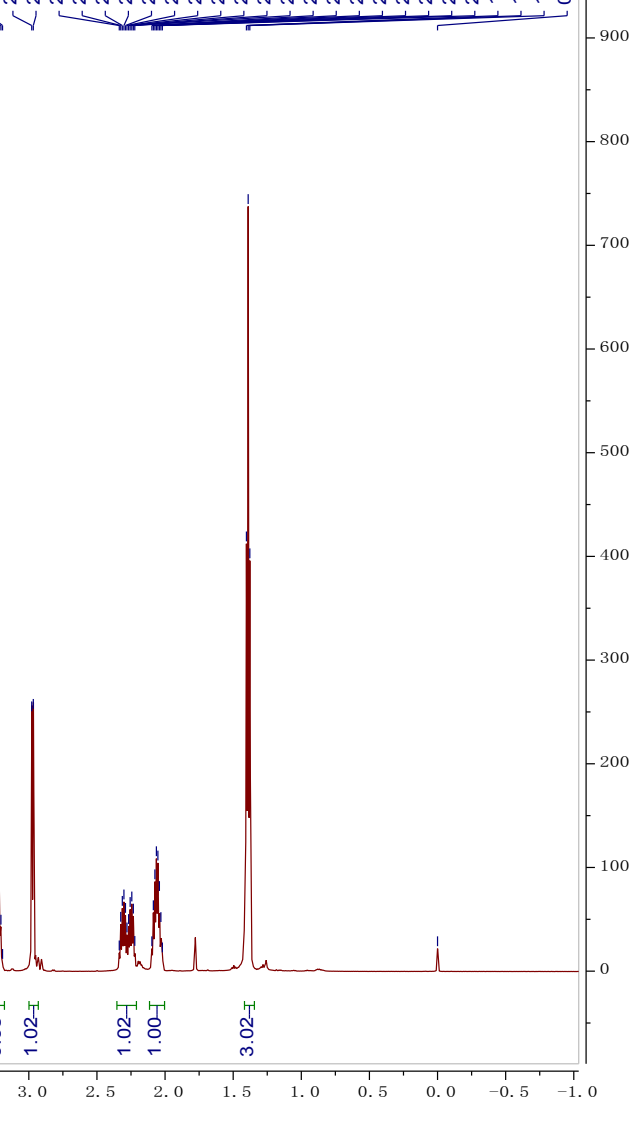




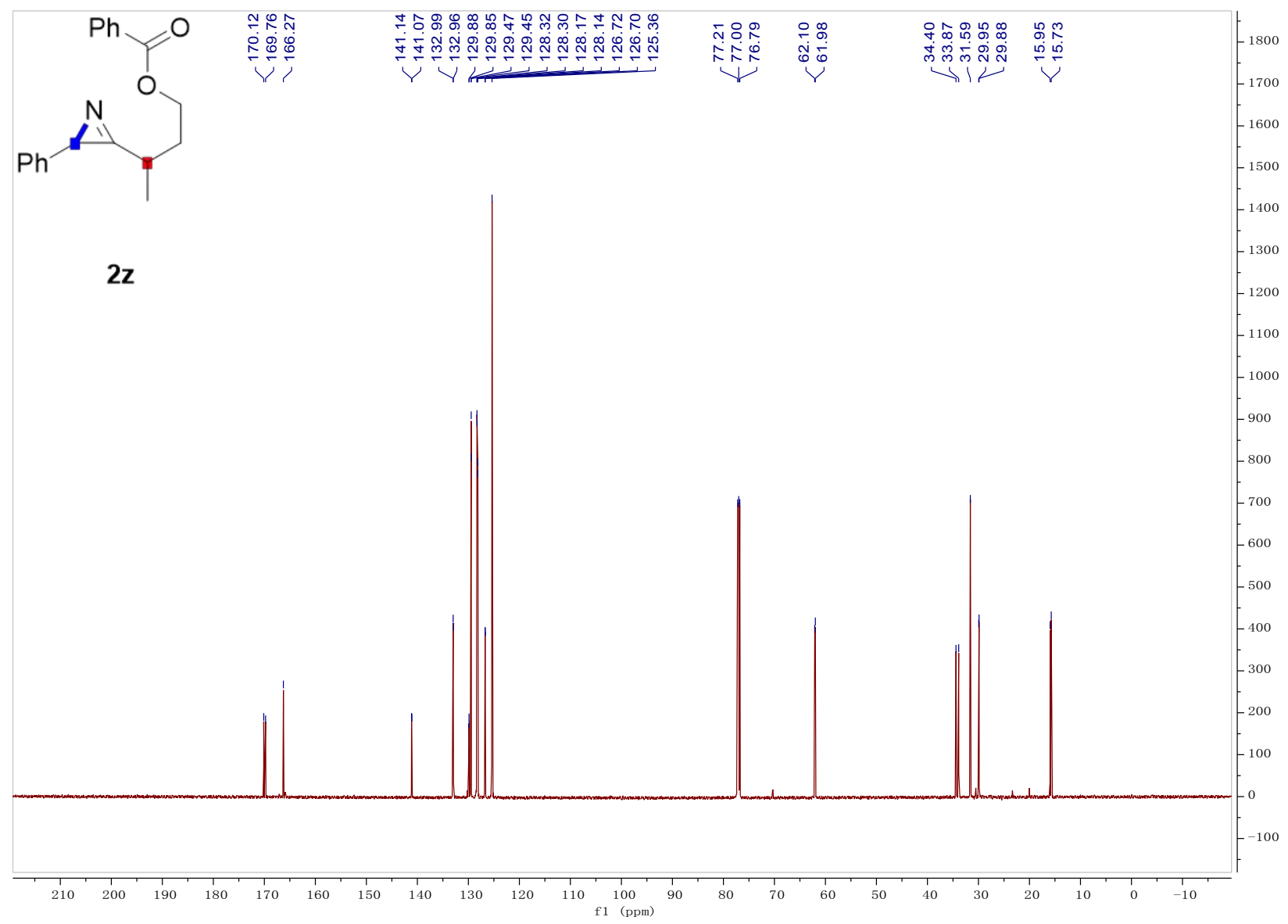

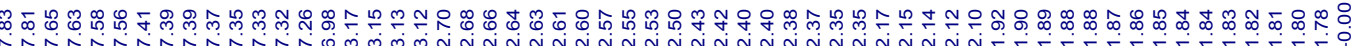

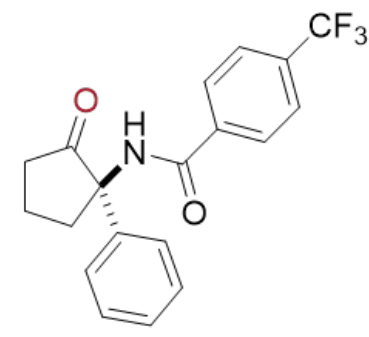

$4 a$

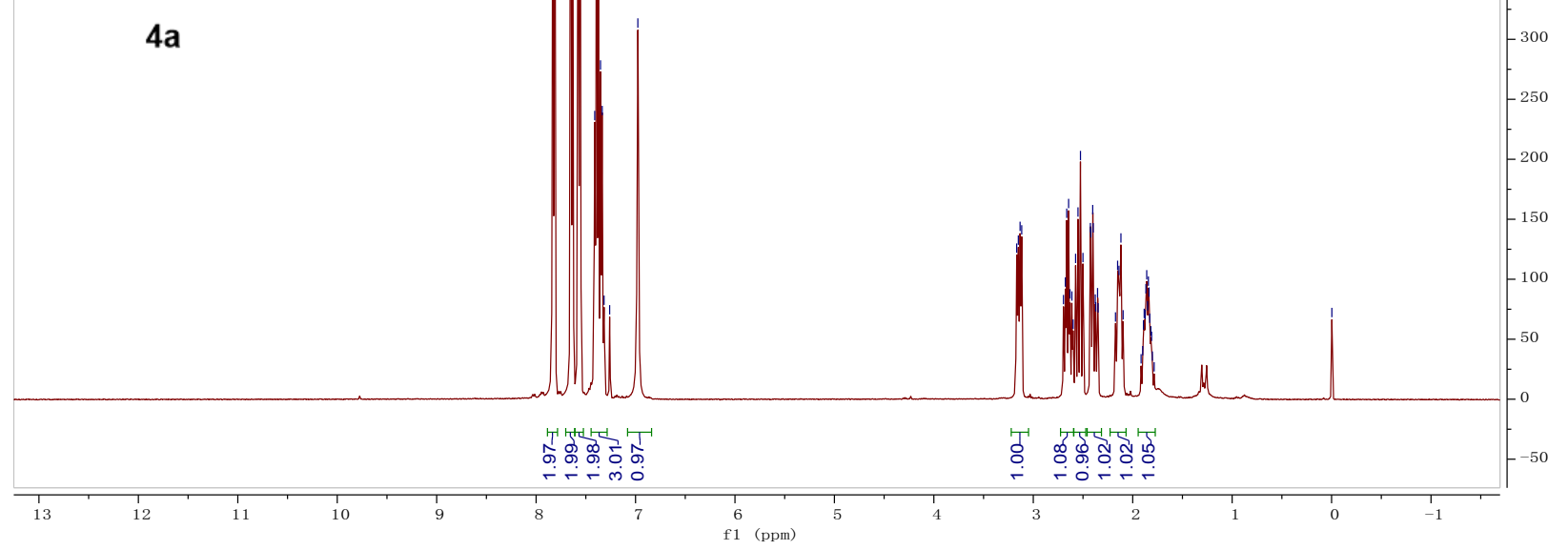




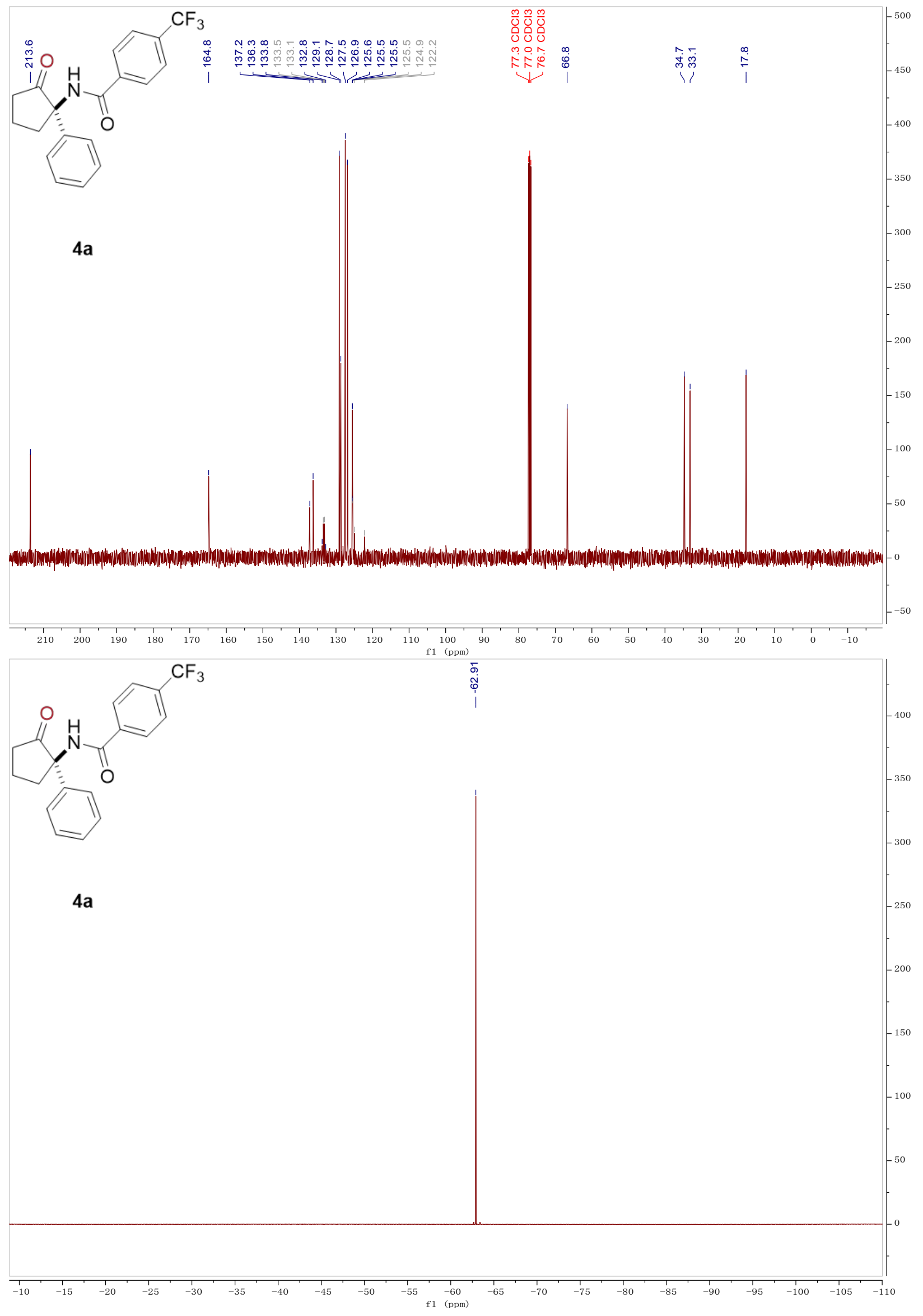




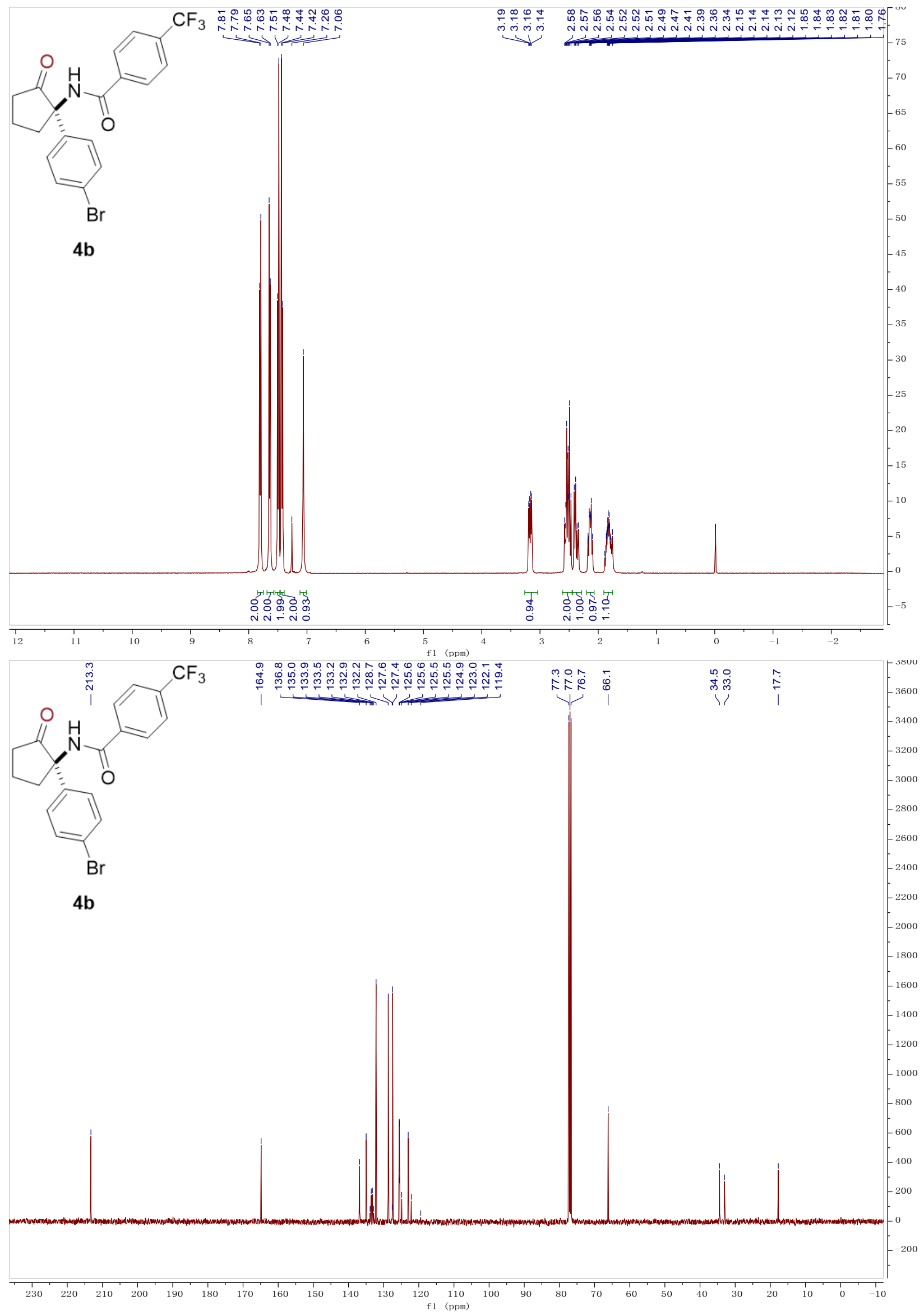




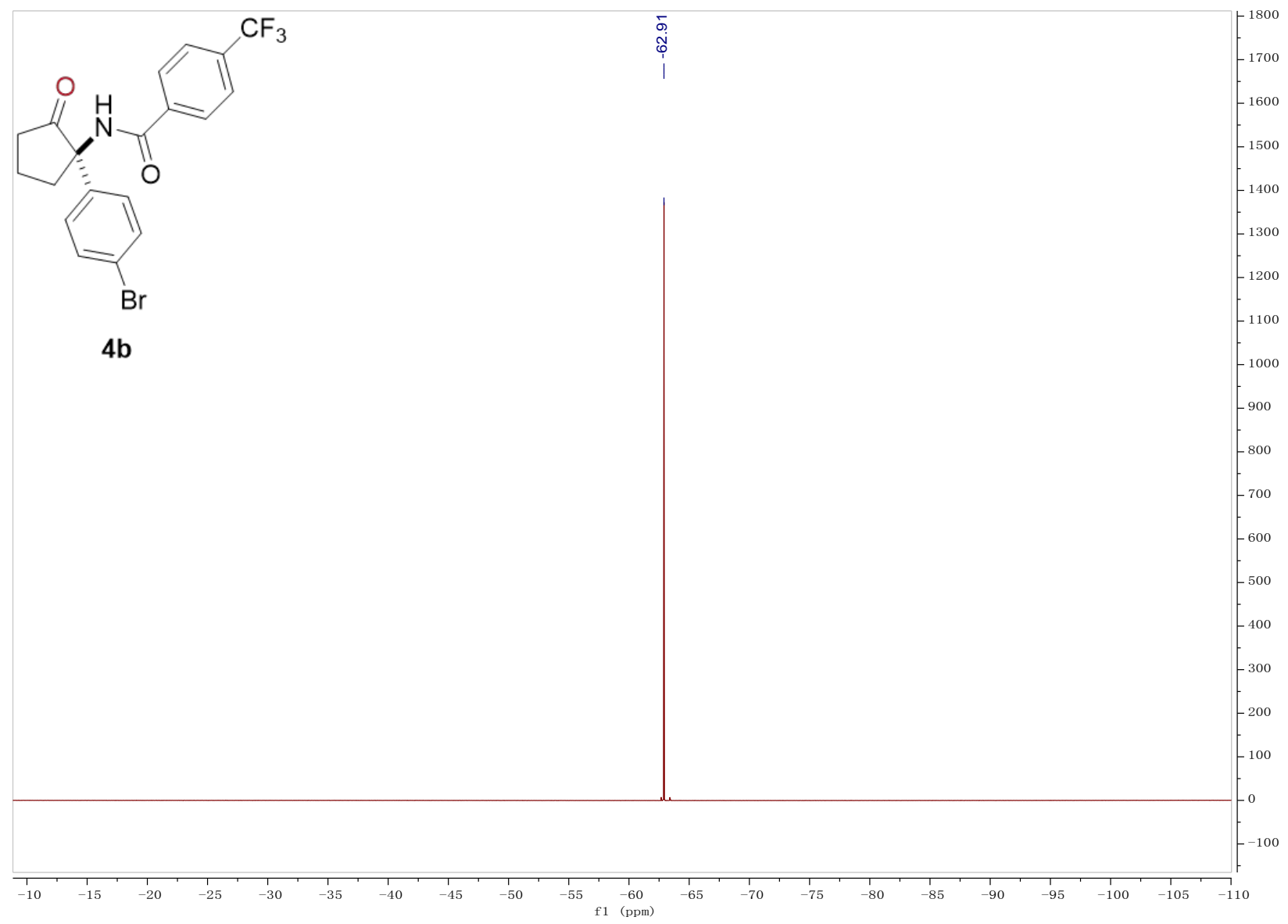

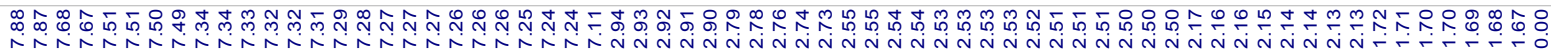

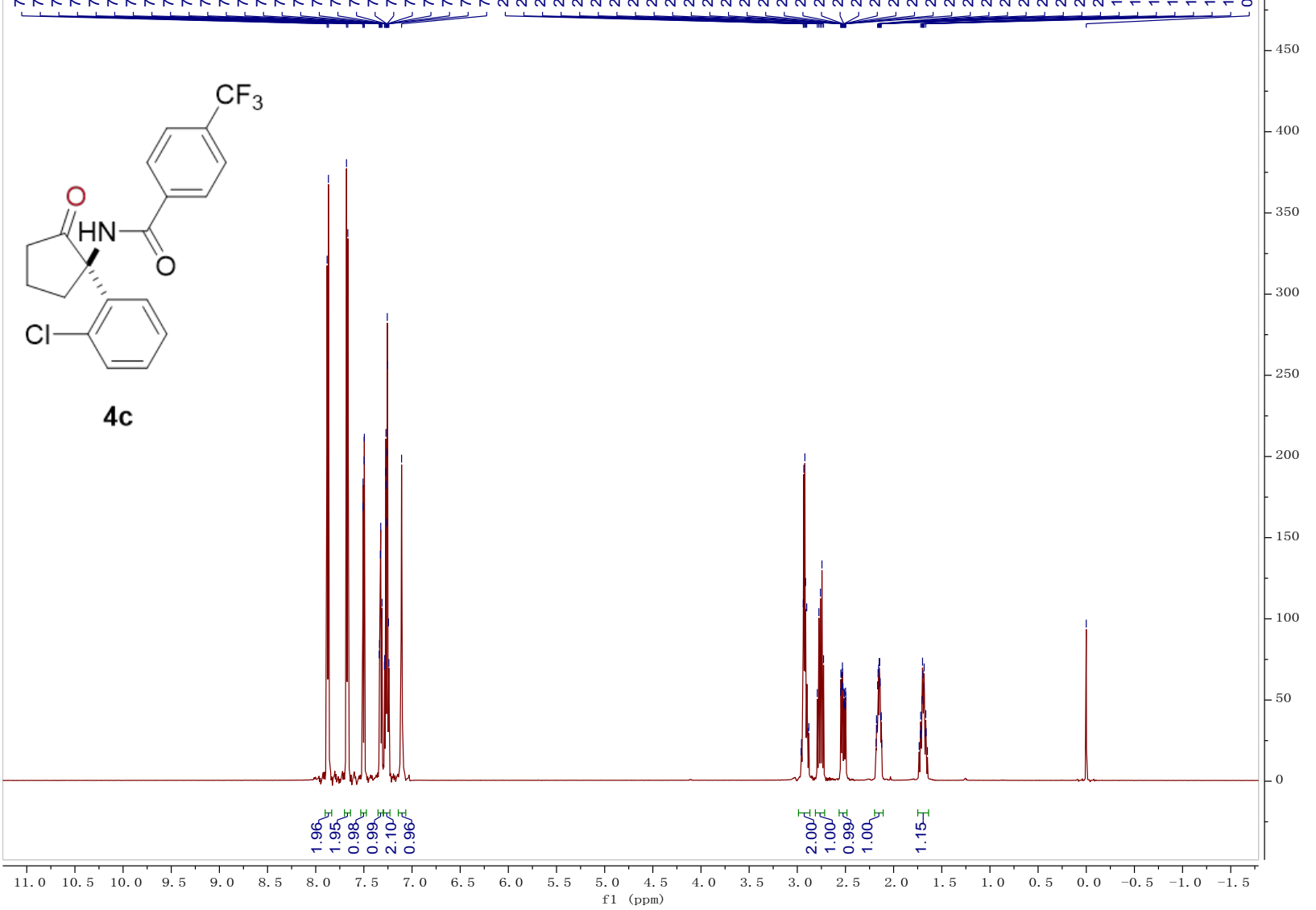




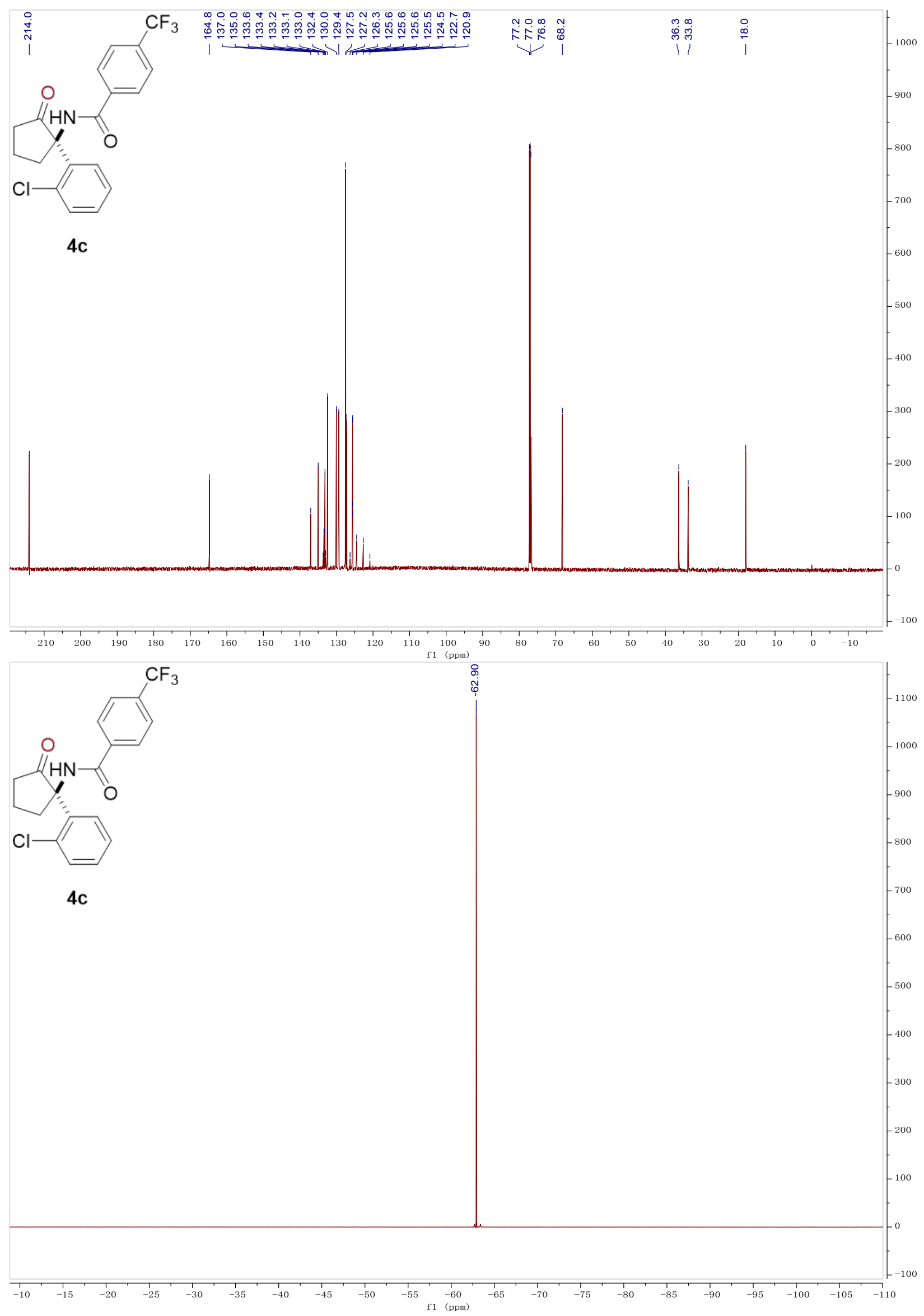




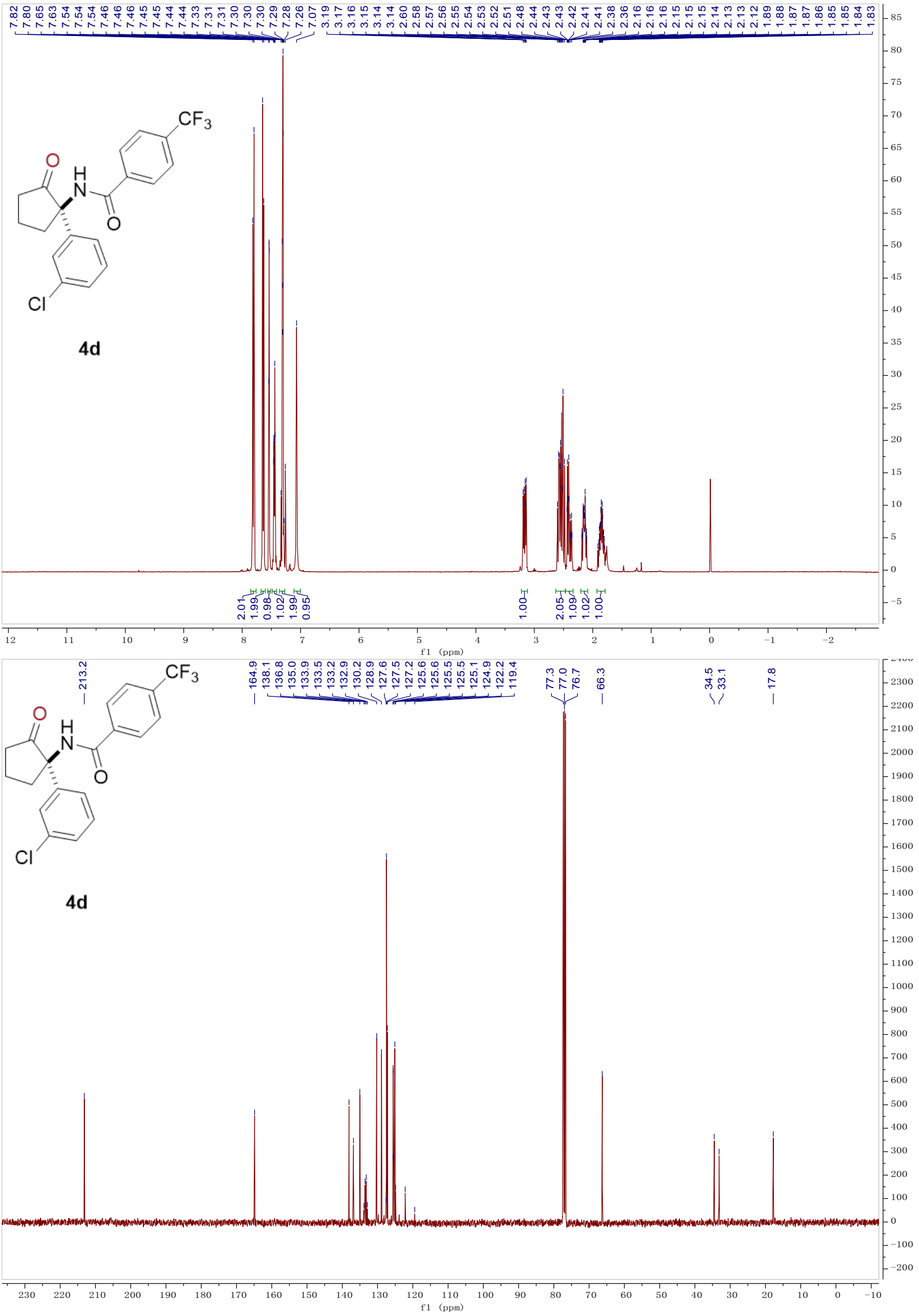




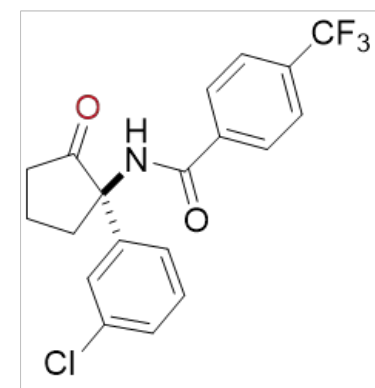

4d
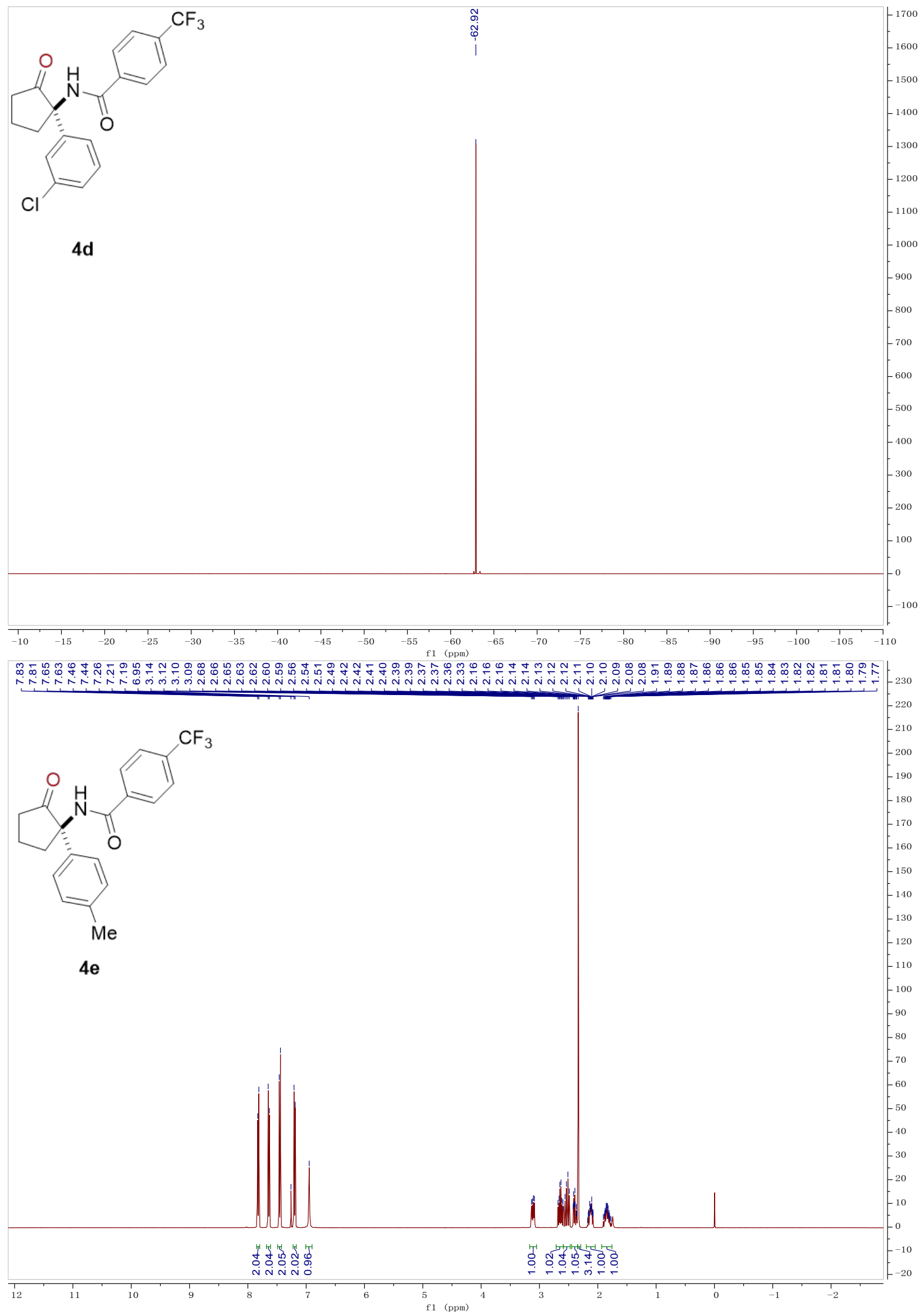


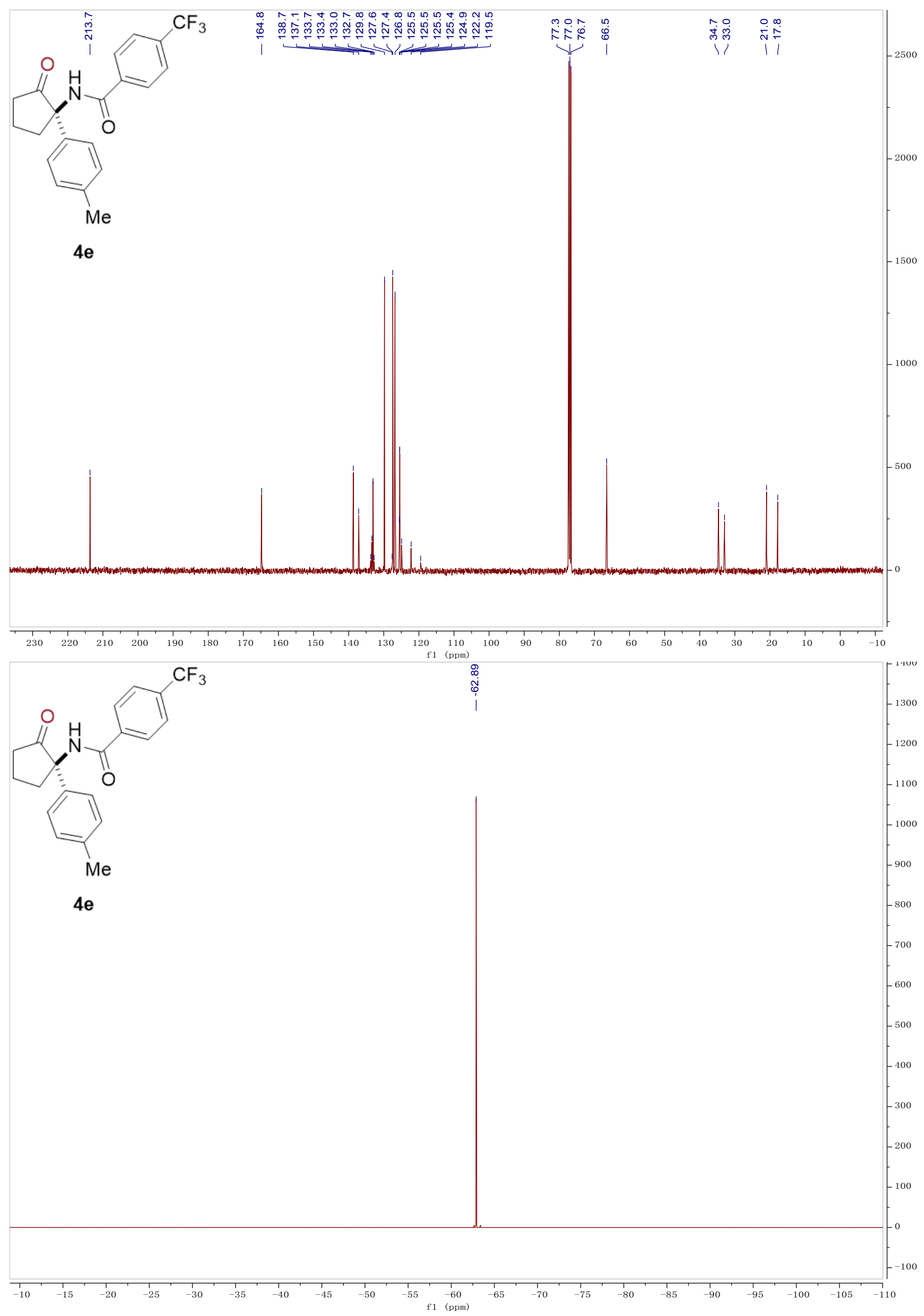




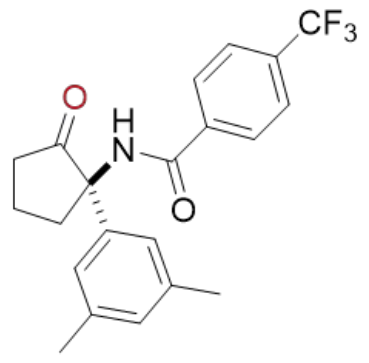

$4 \mathbf{f}$
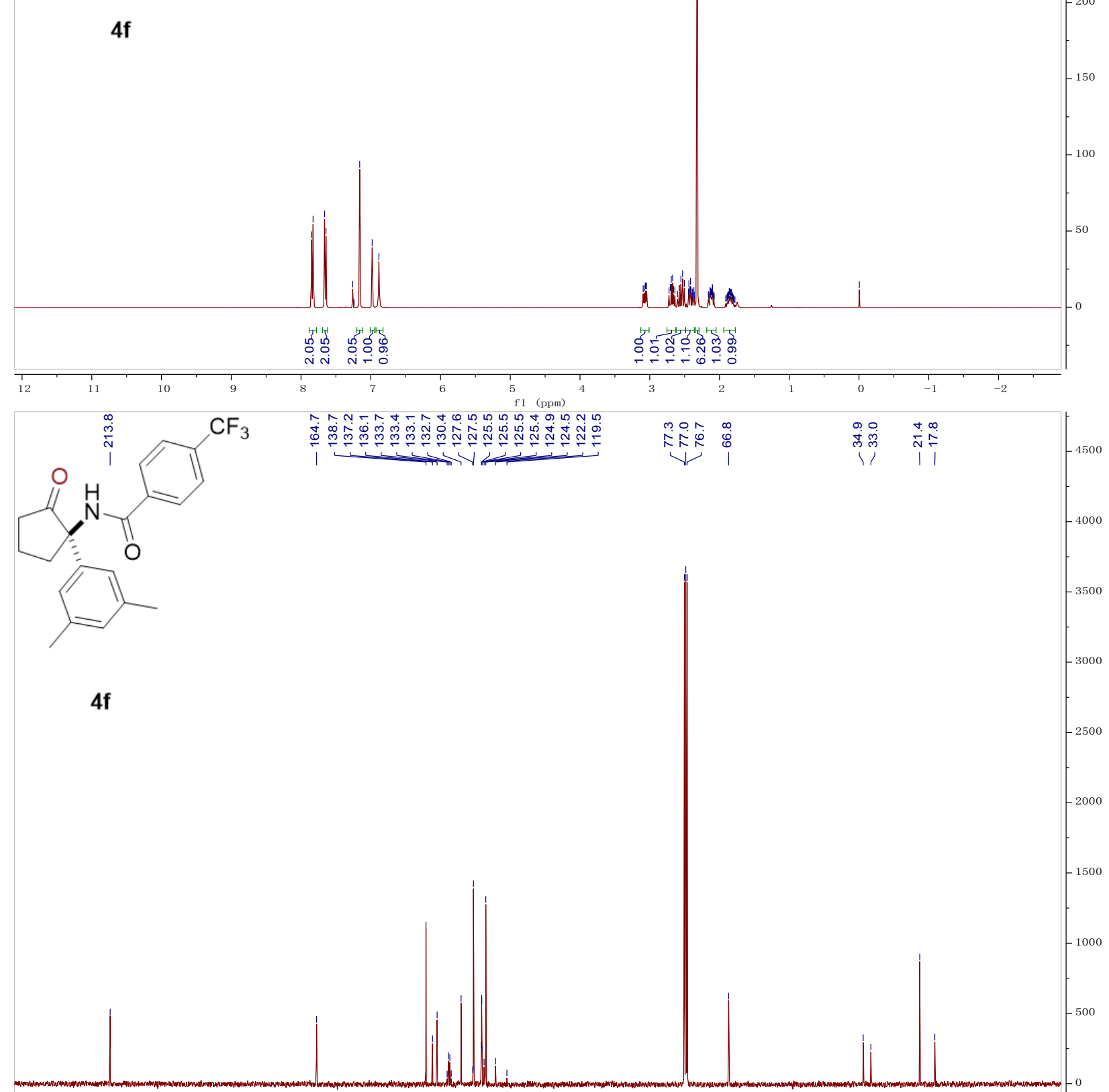

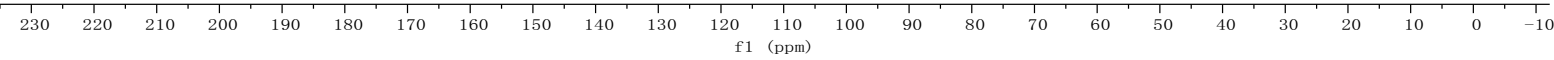




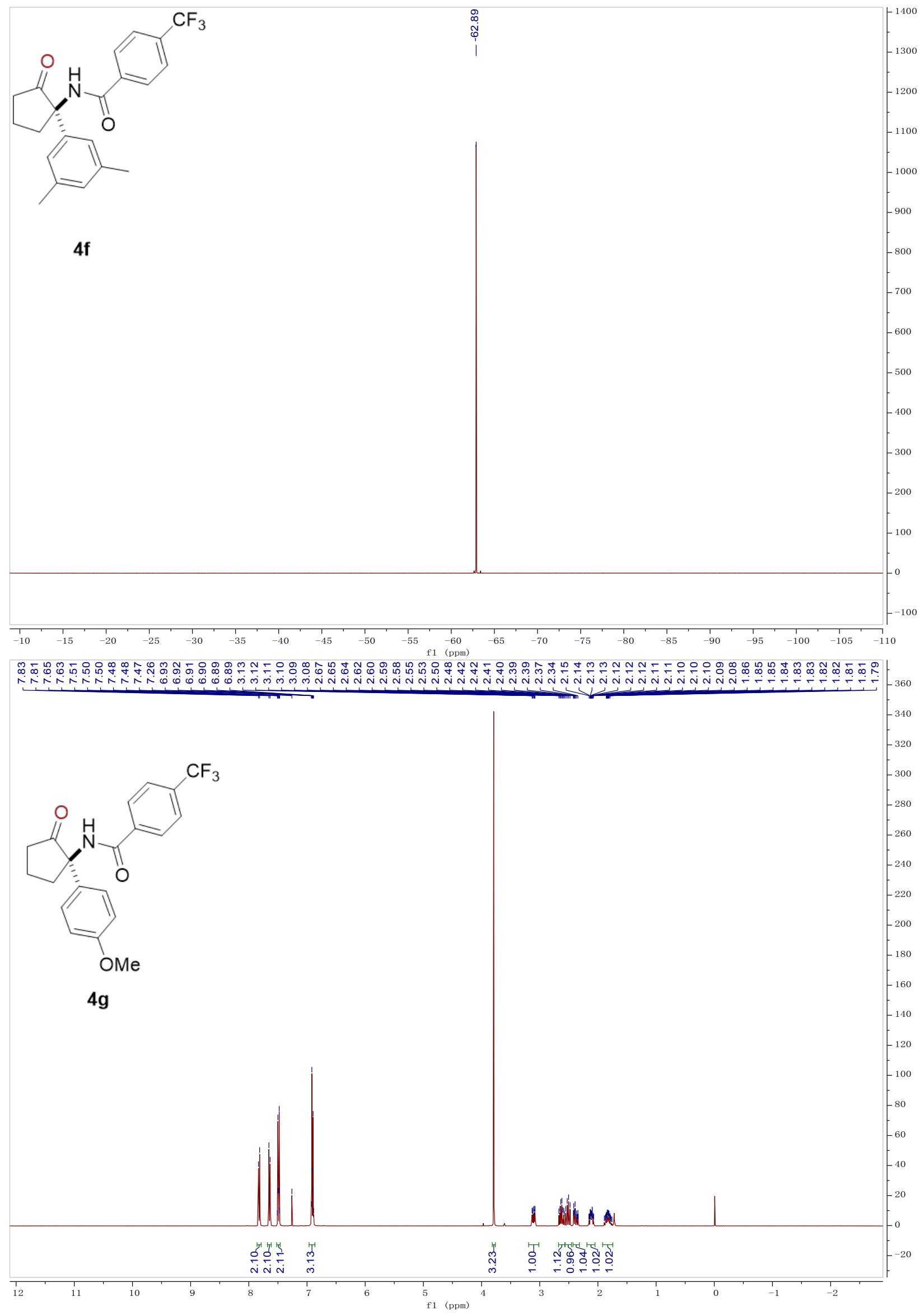




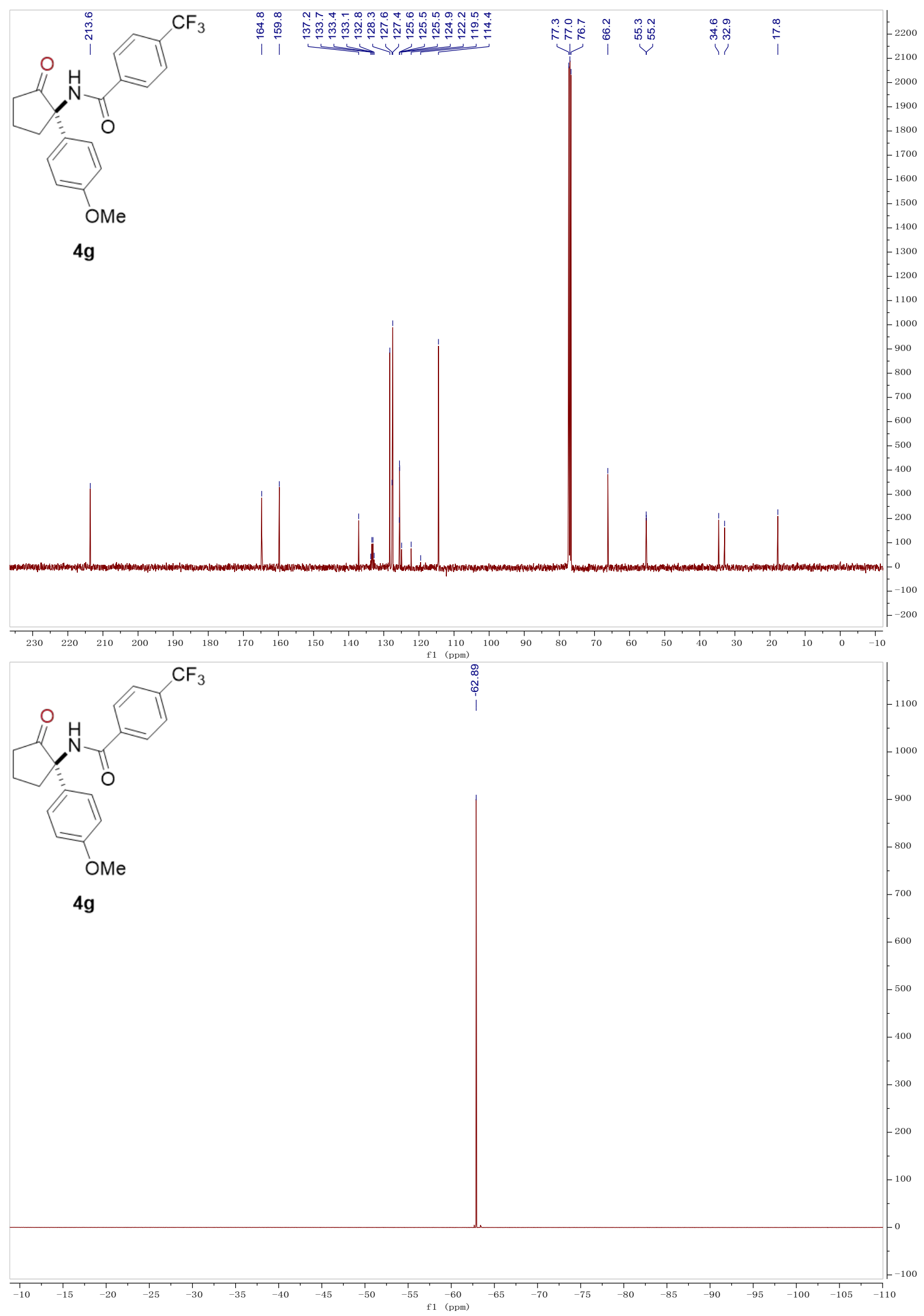




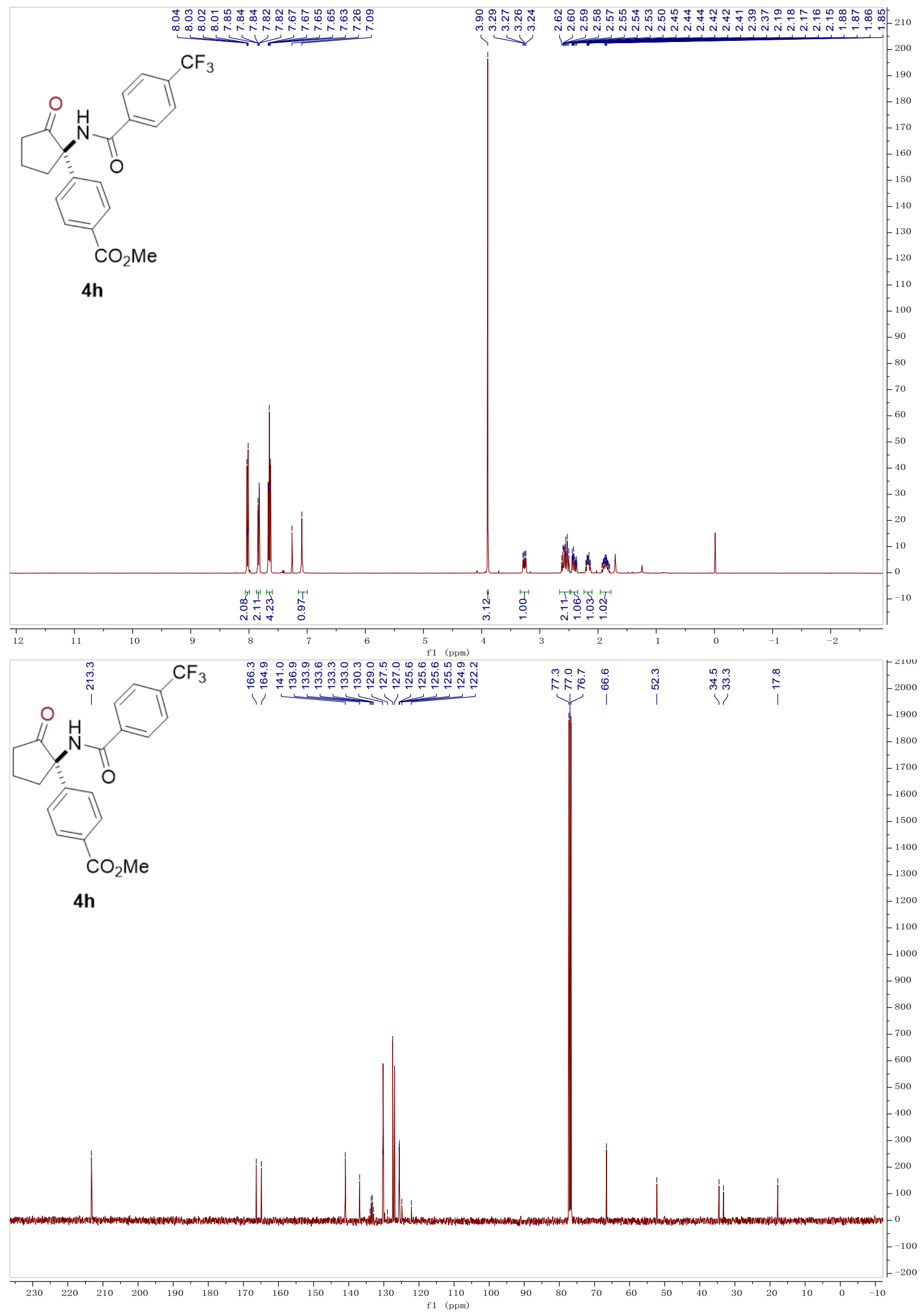




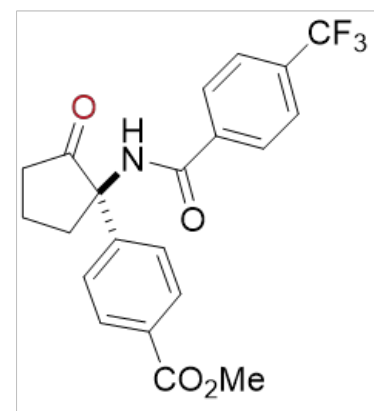

4h

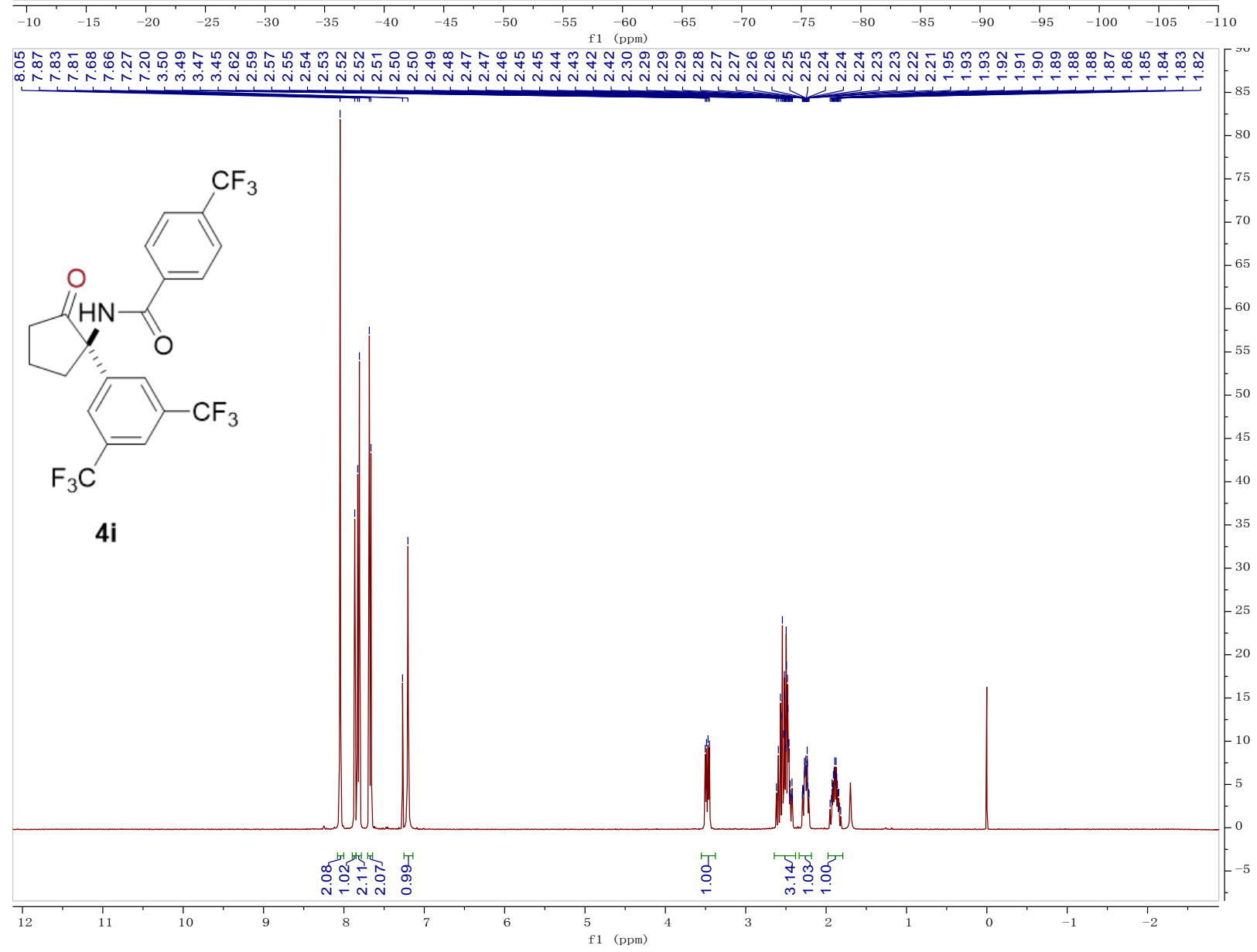




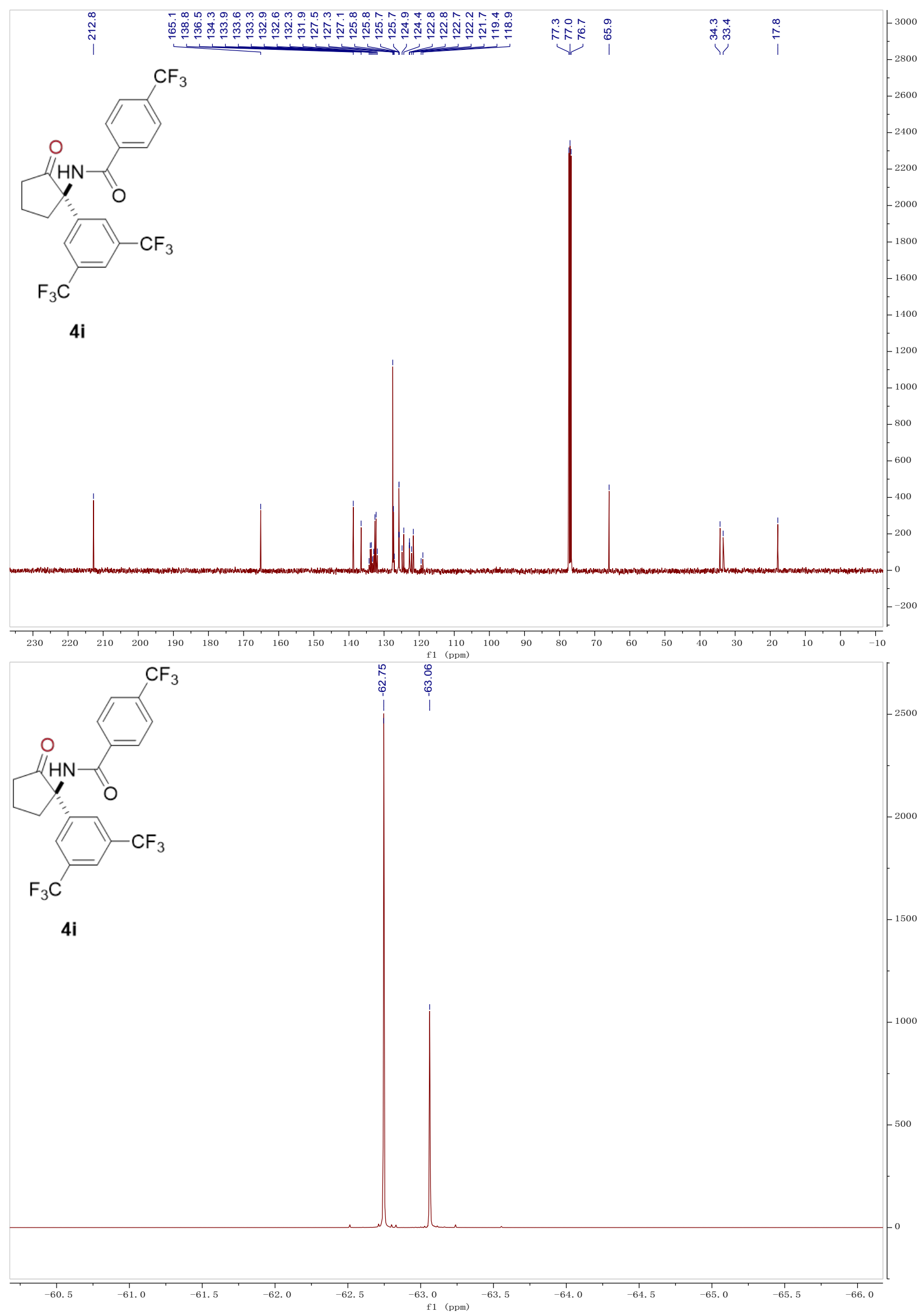




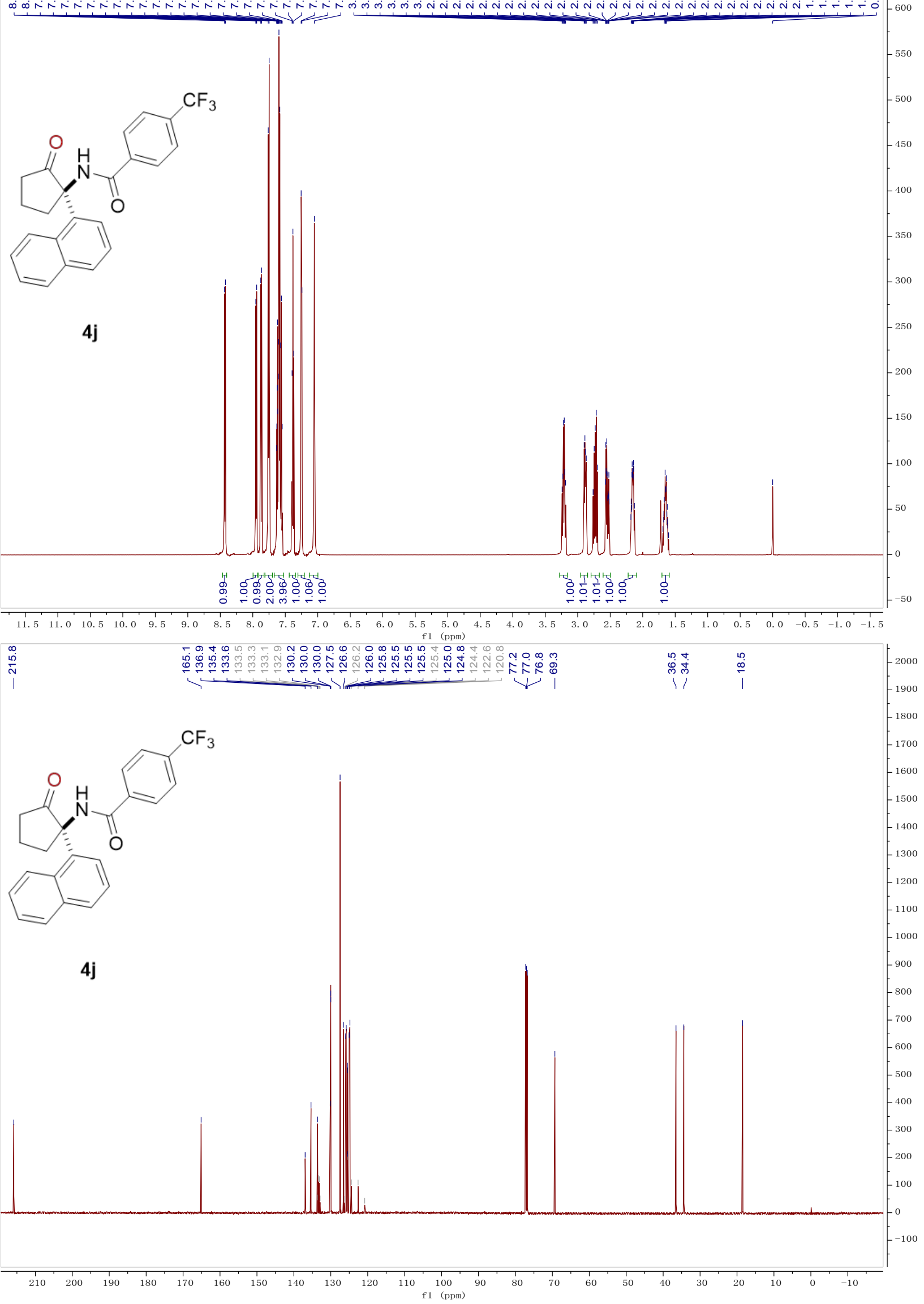




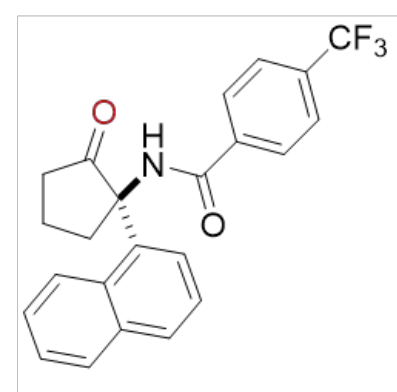

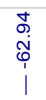

4j

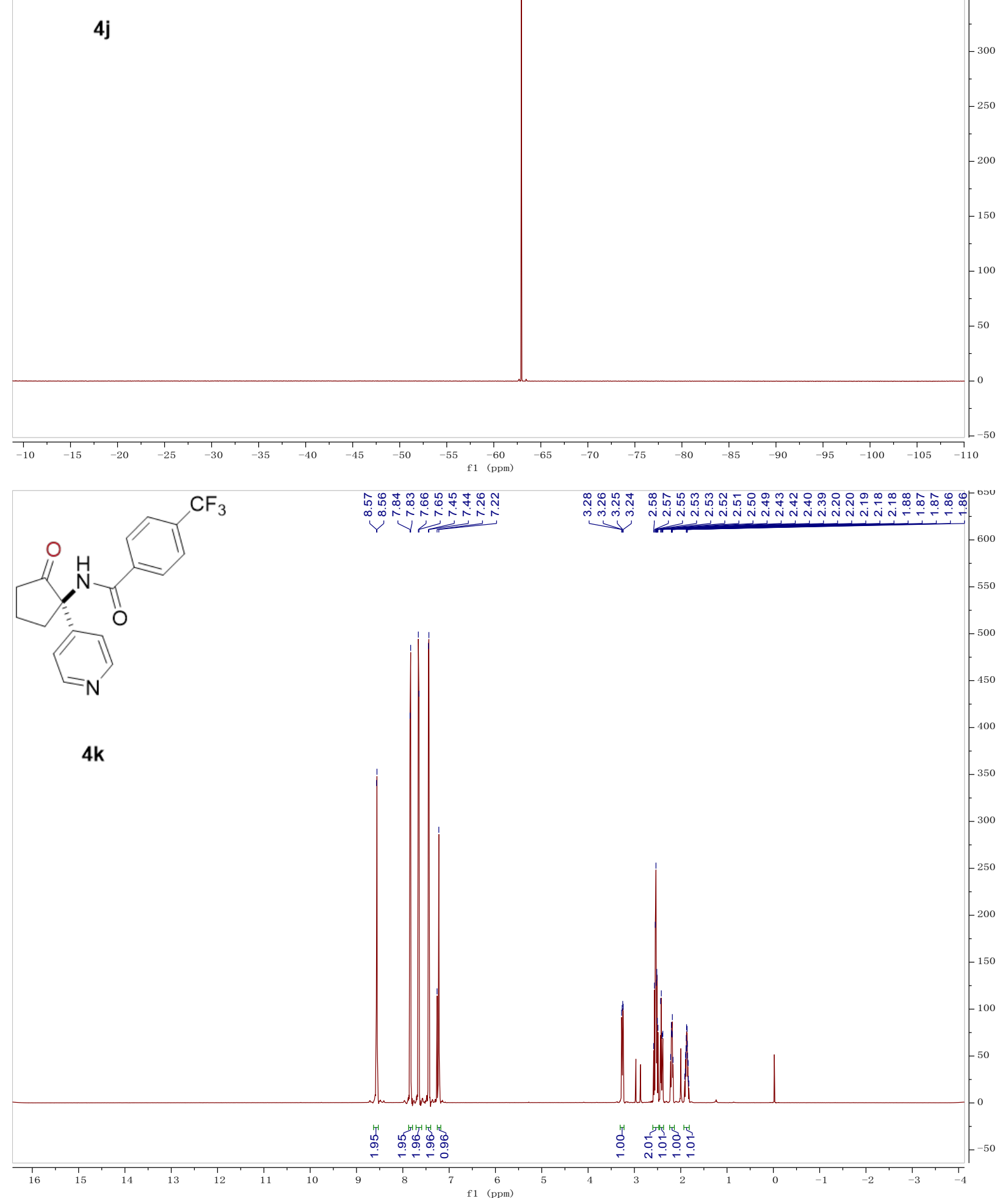



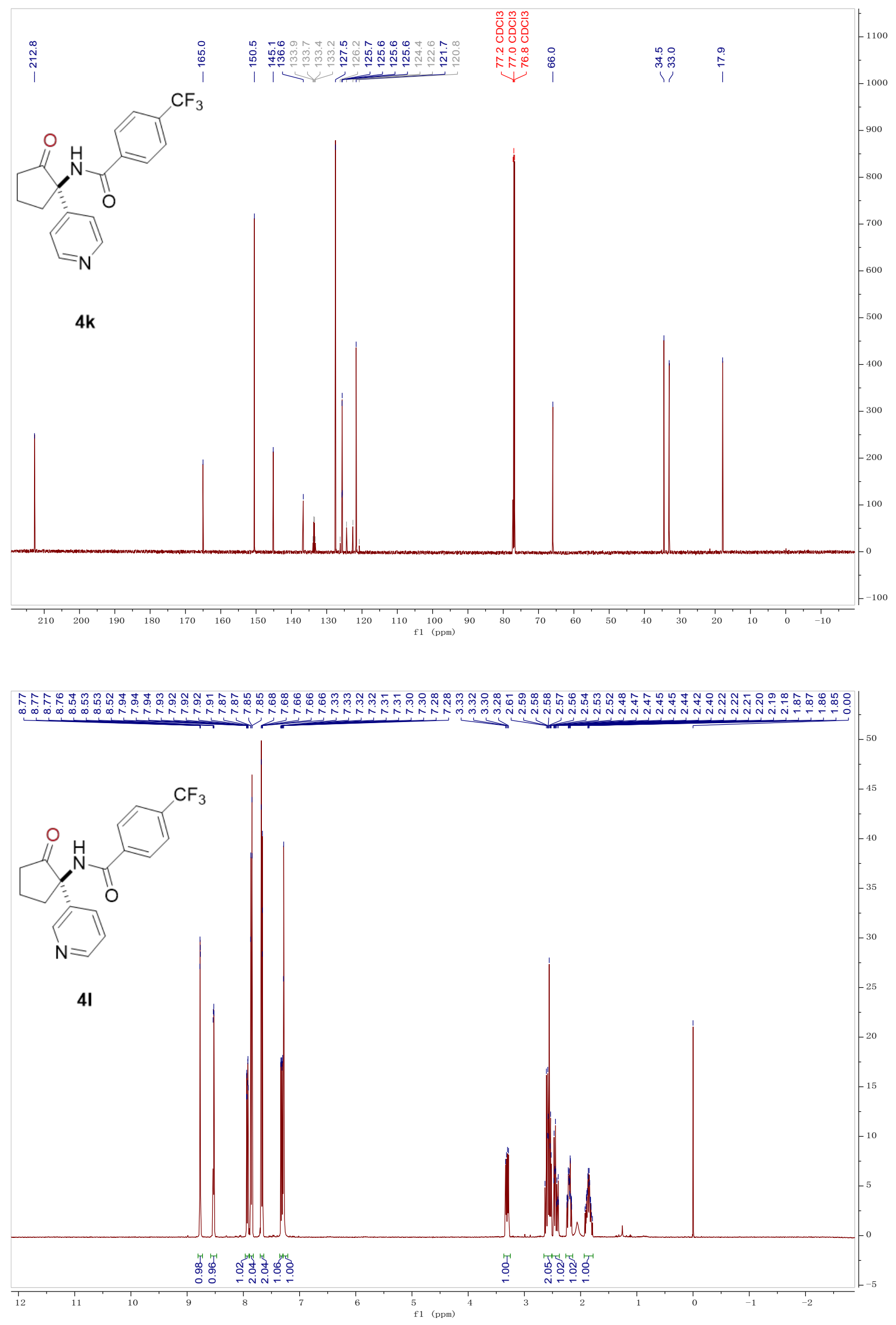

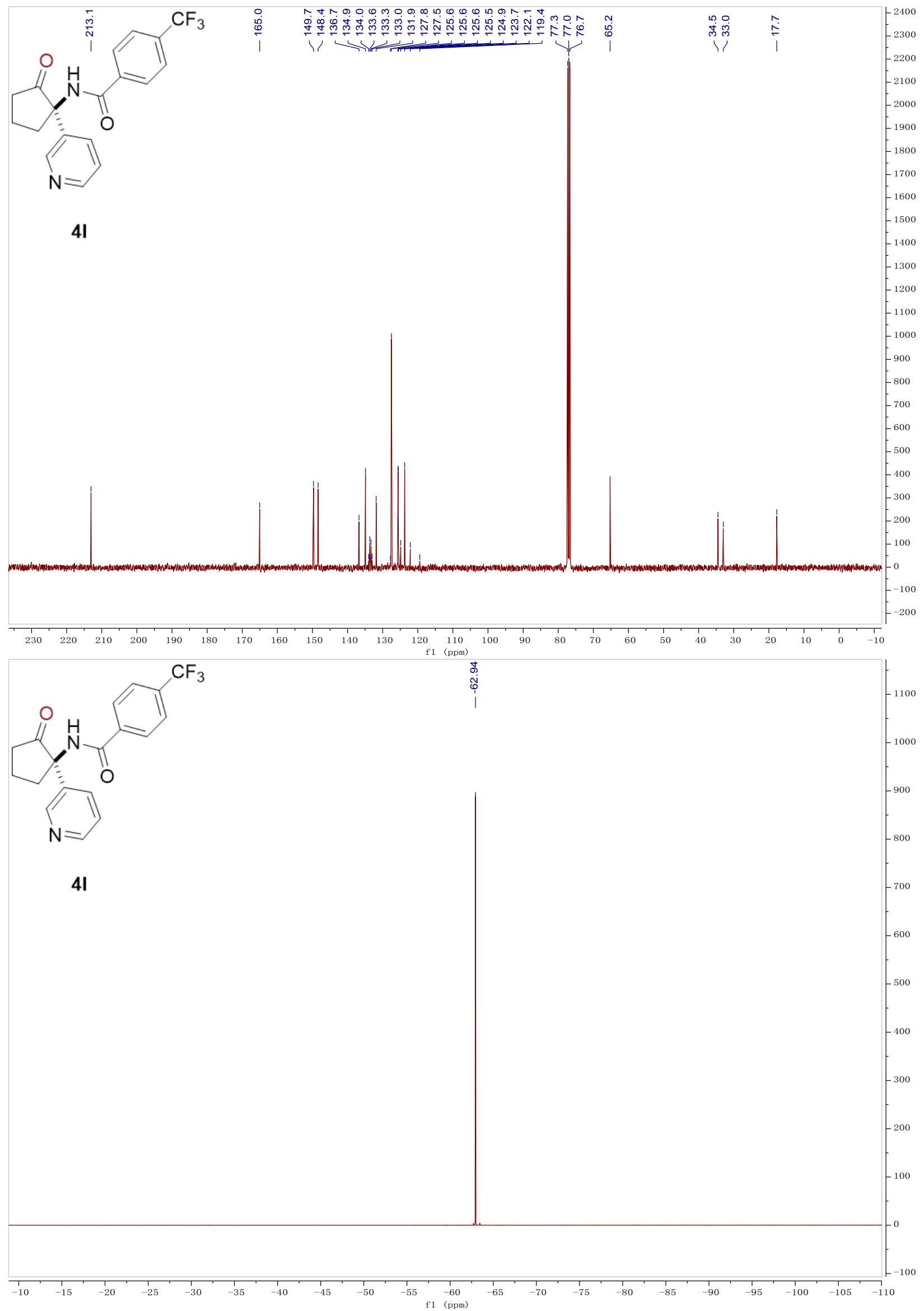

S66 


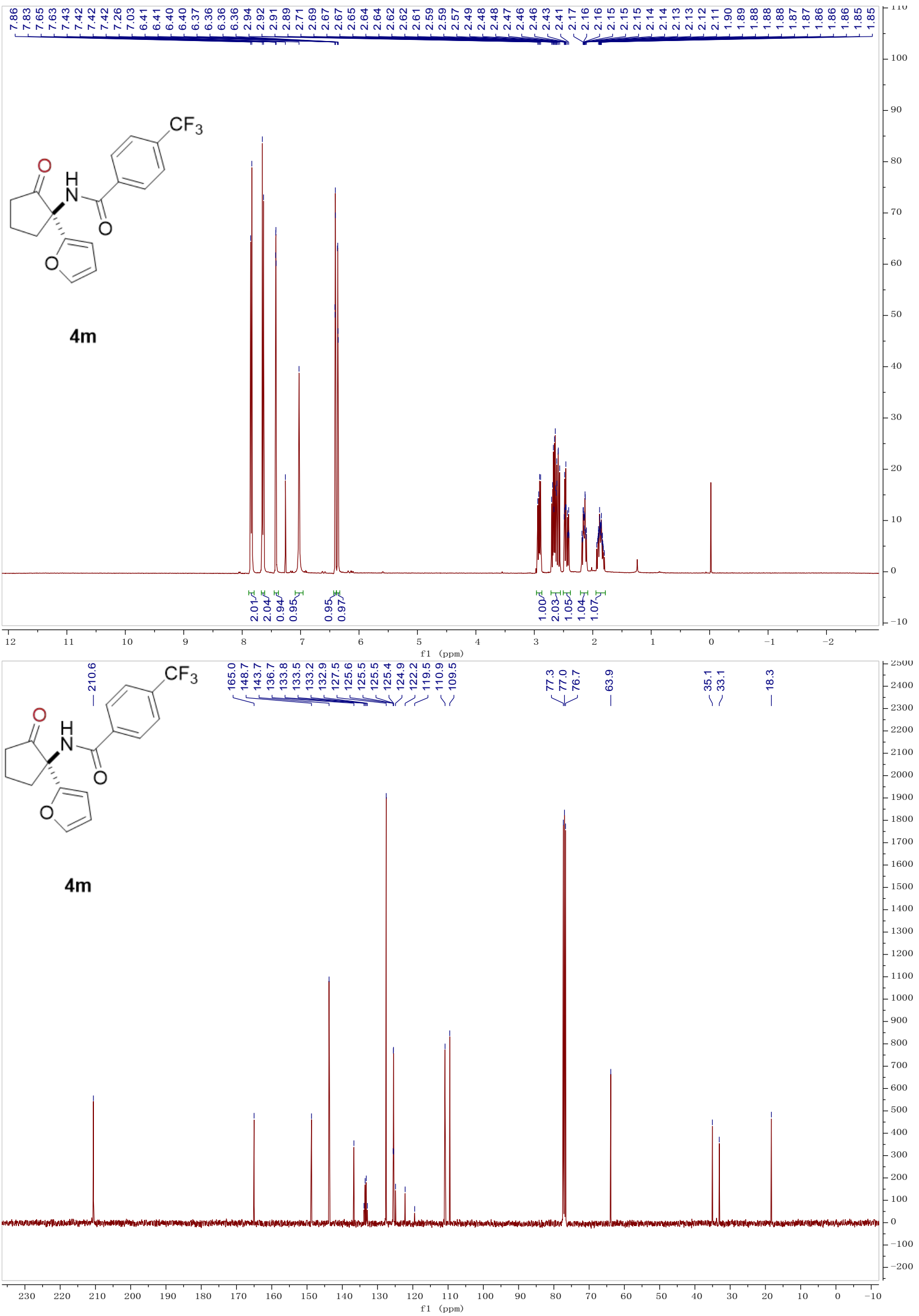




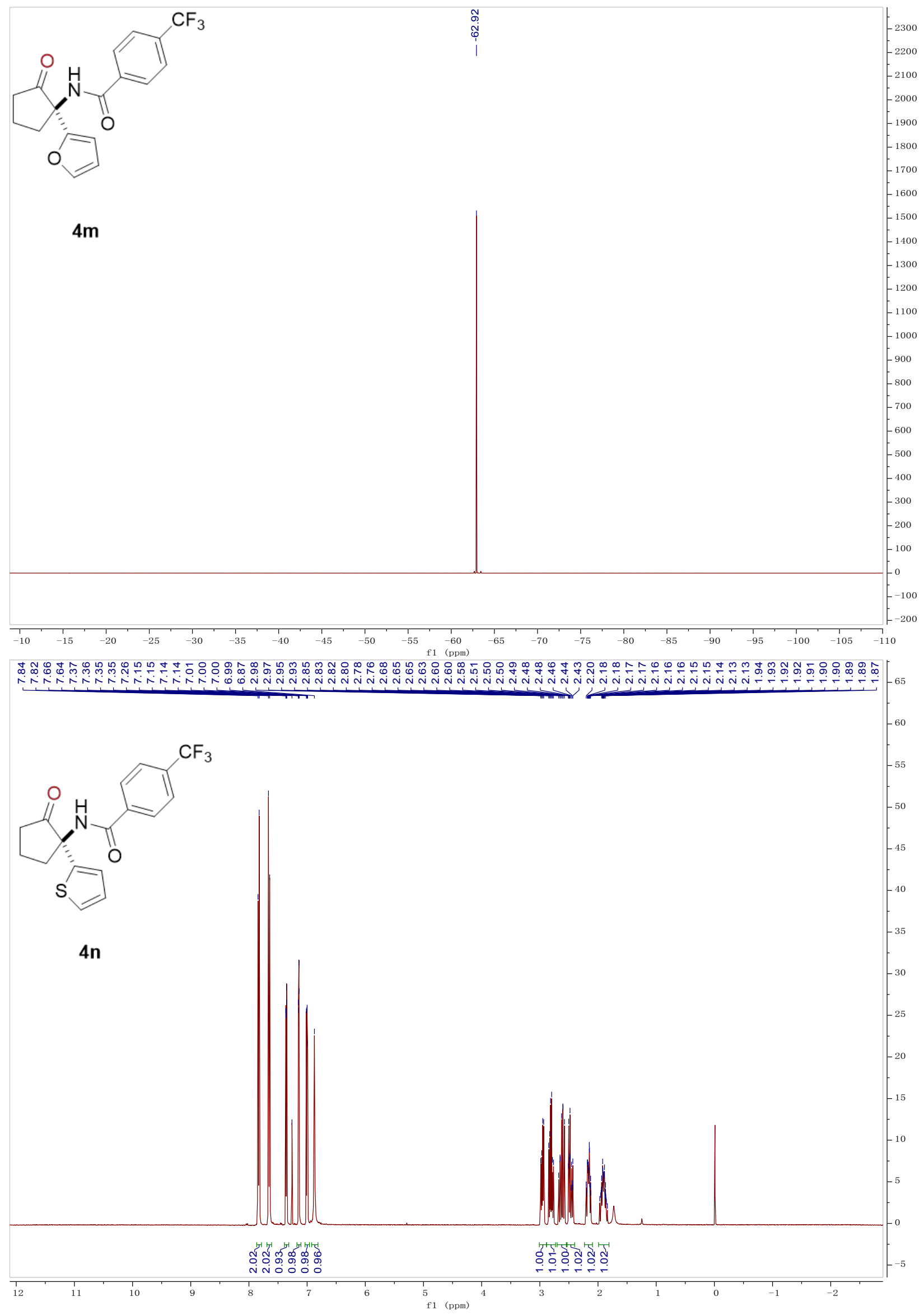




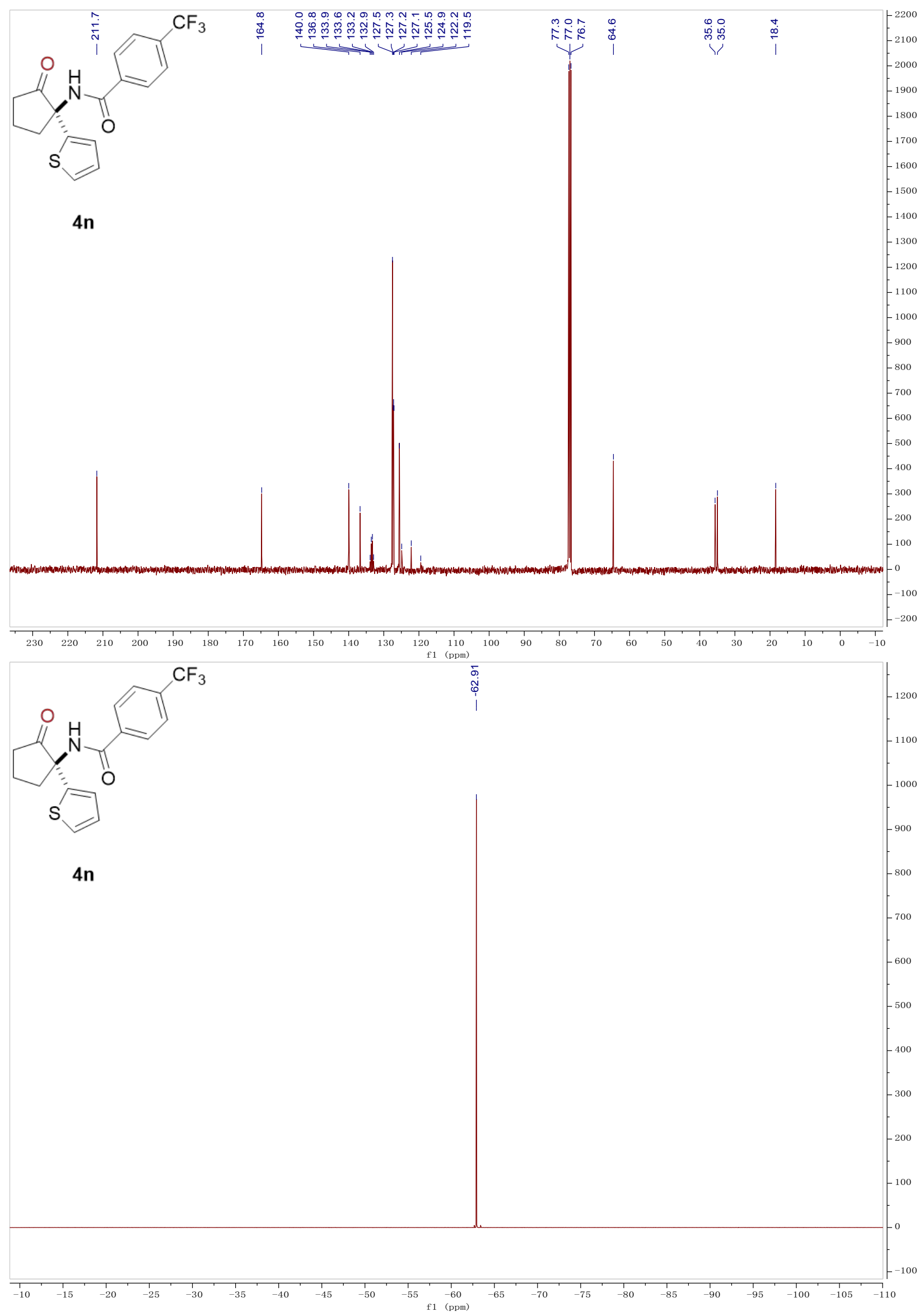



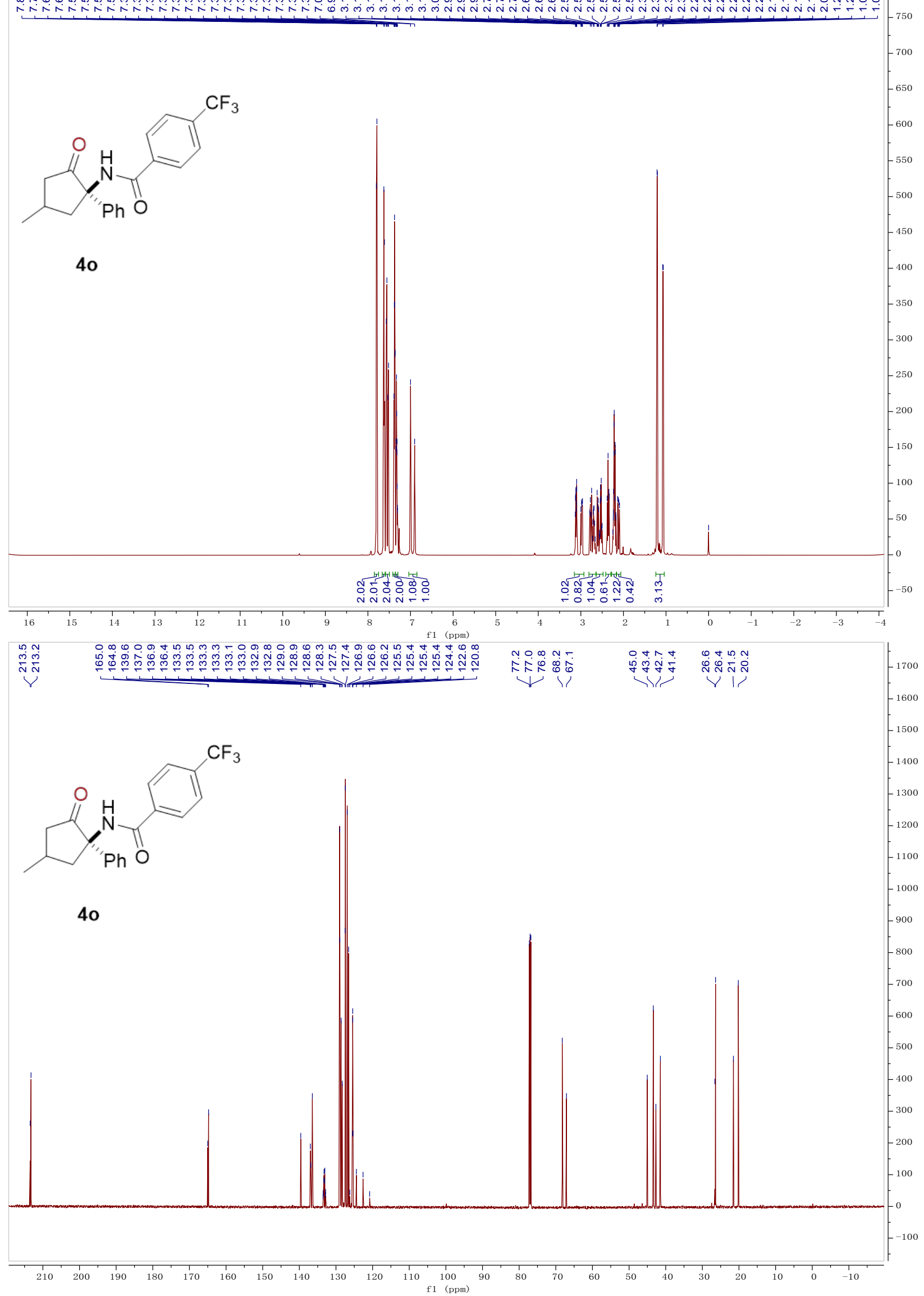

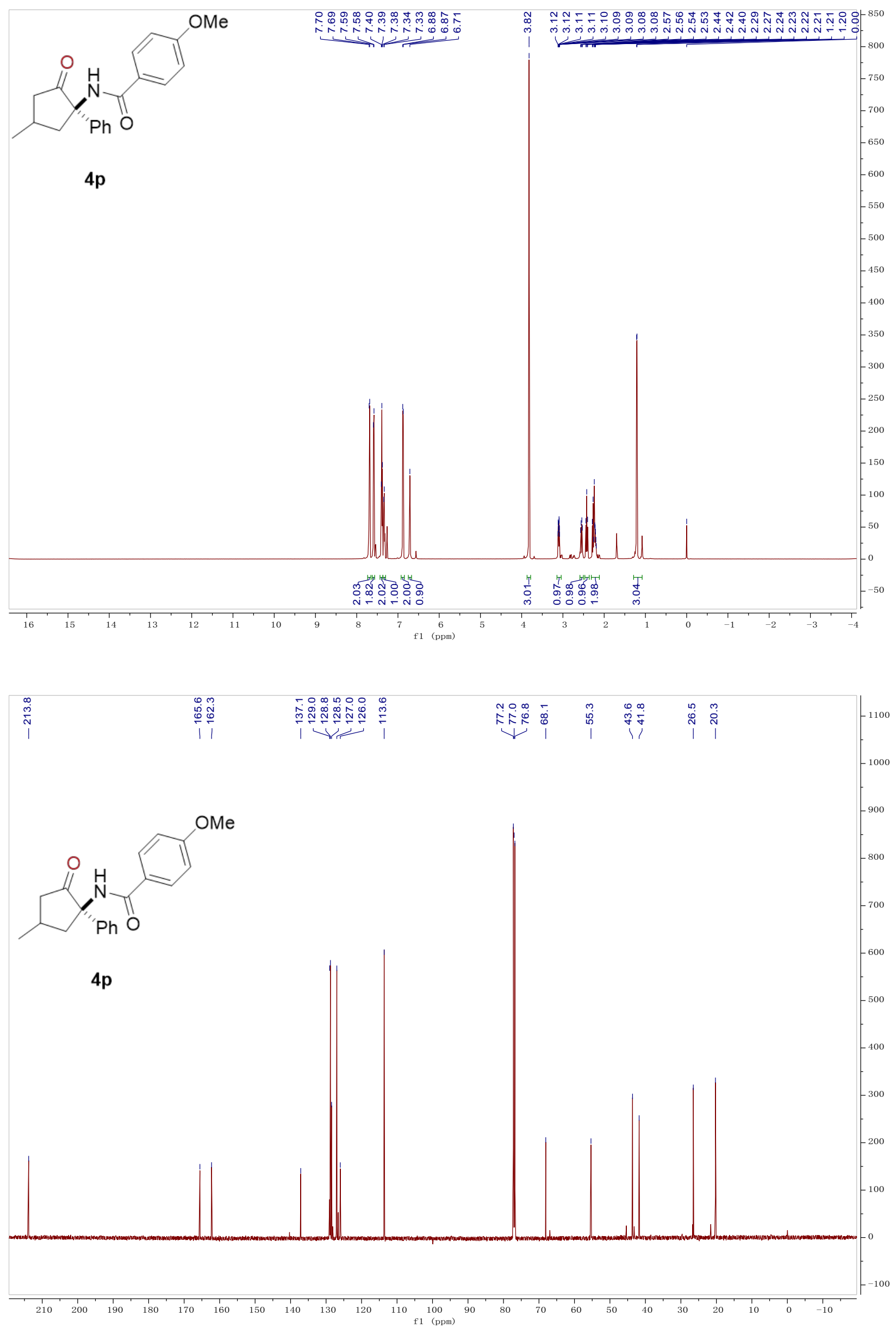


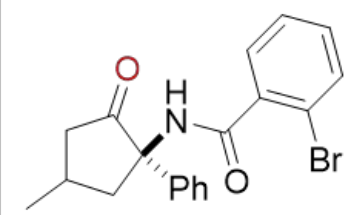

$4 q$
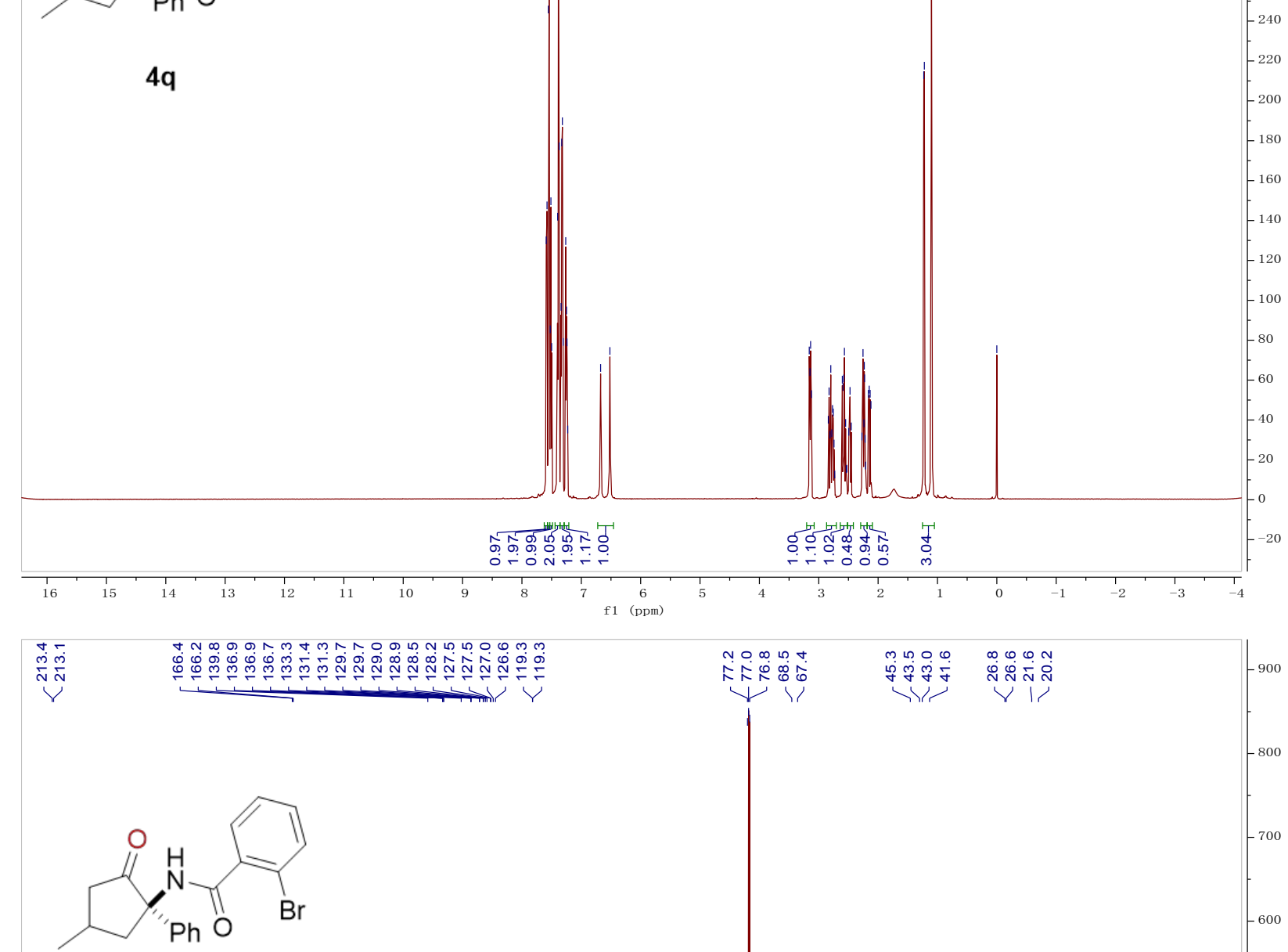

$4 q$

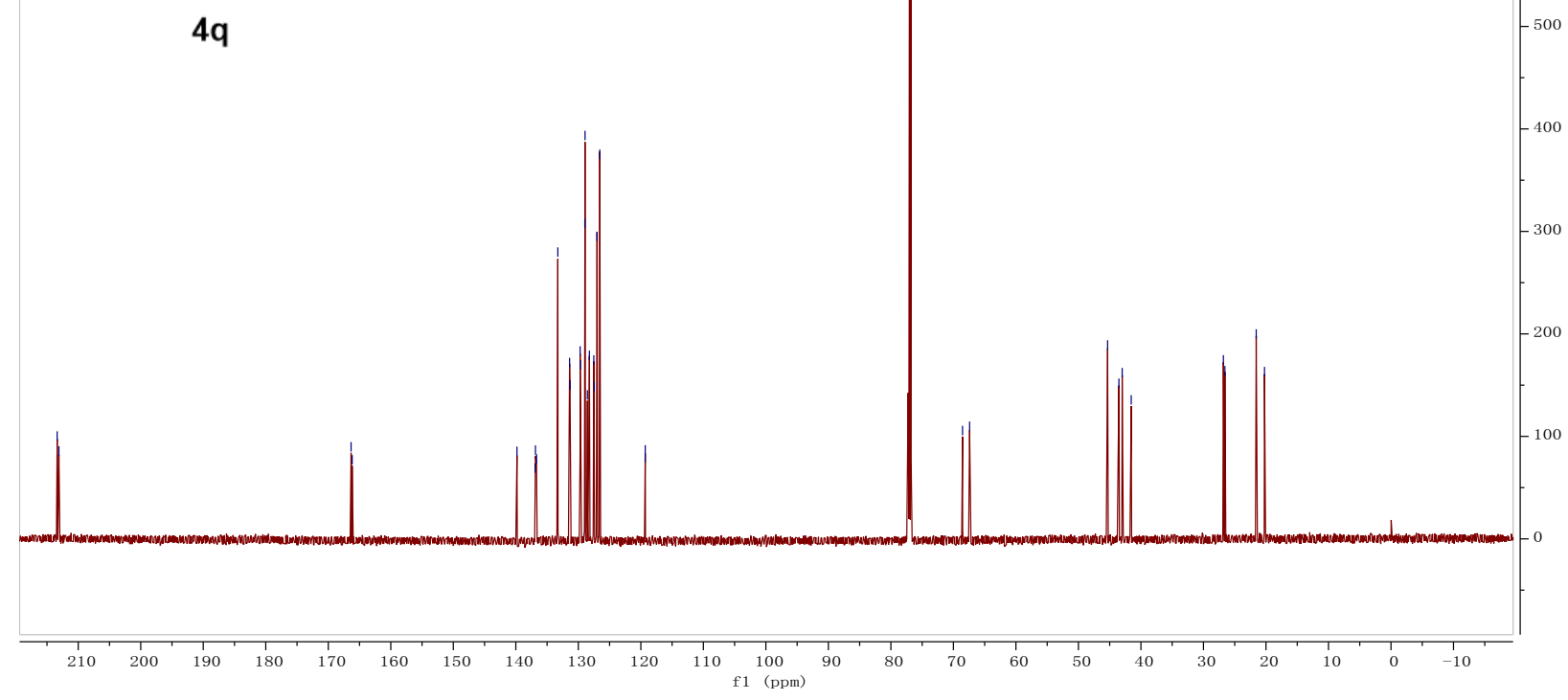




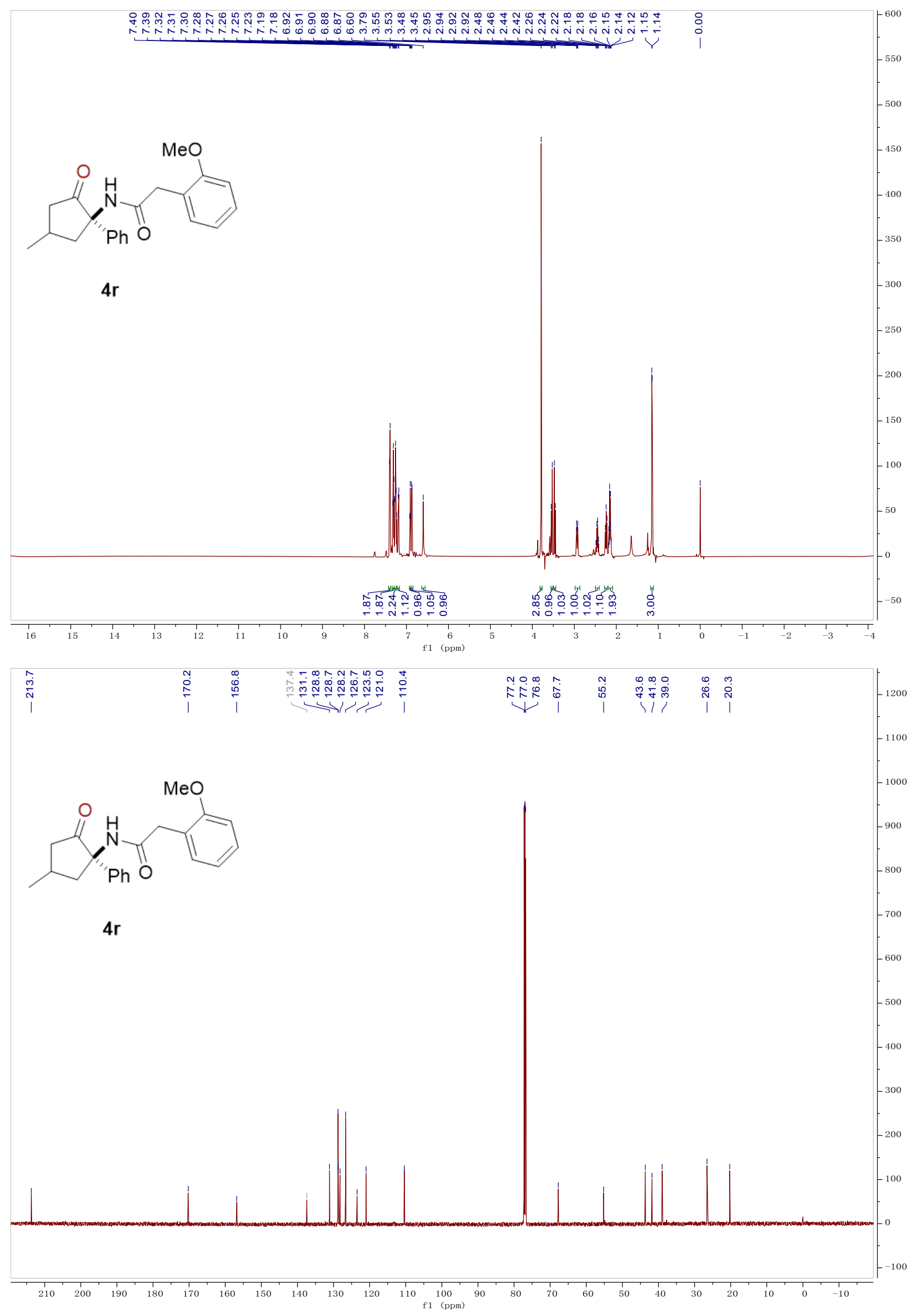



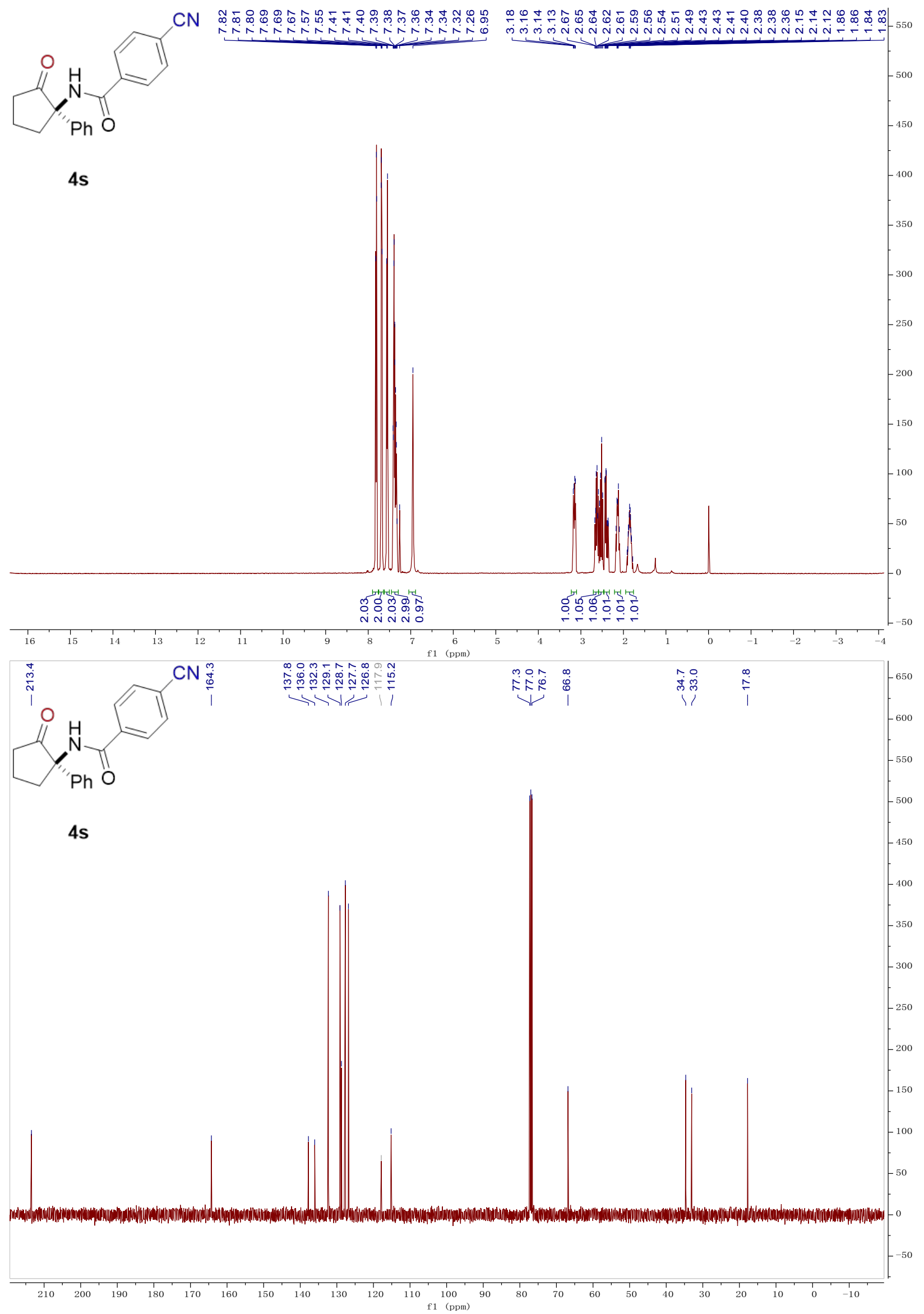

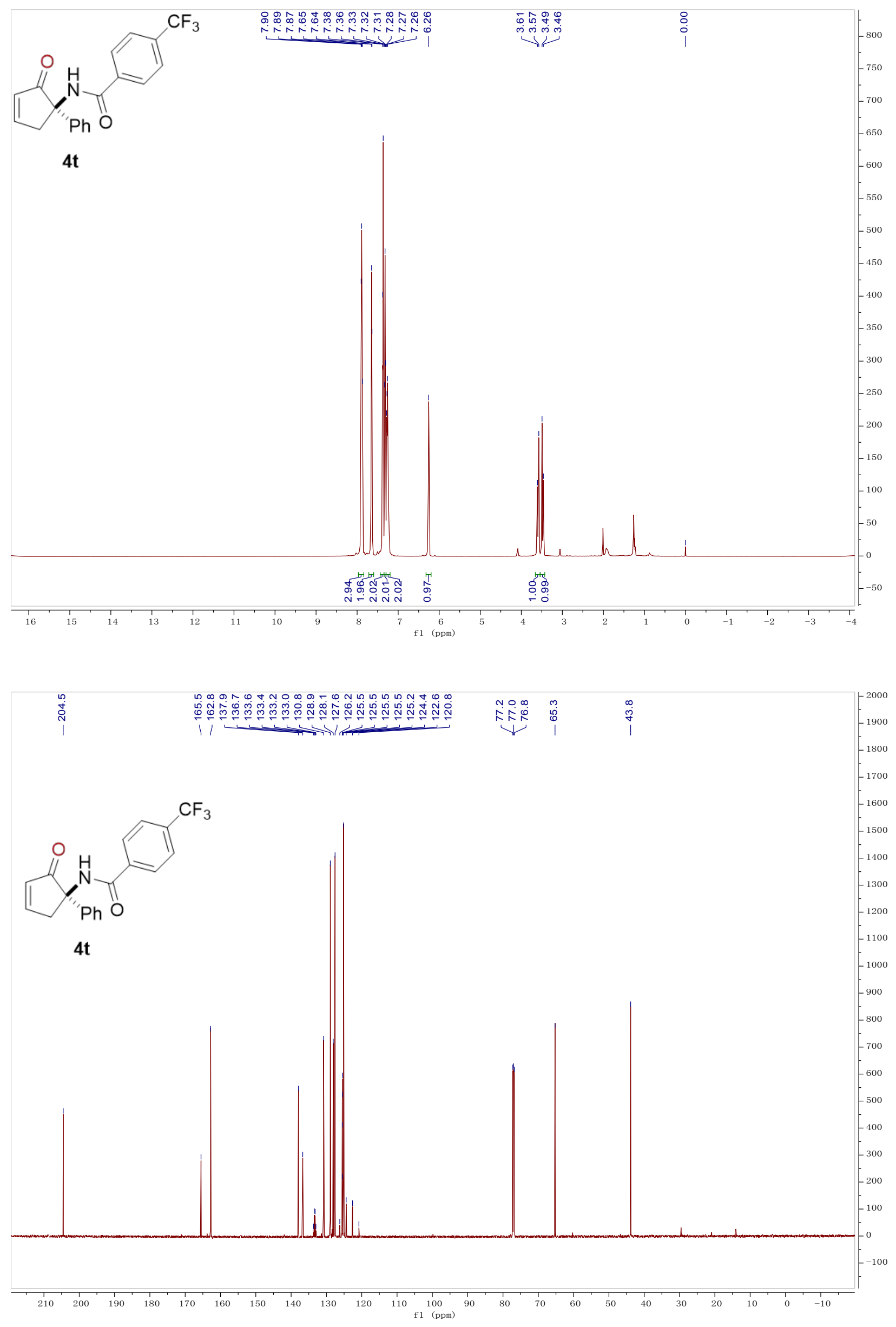

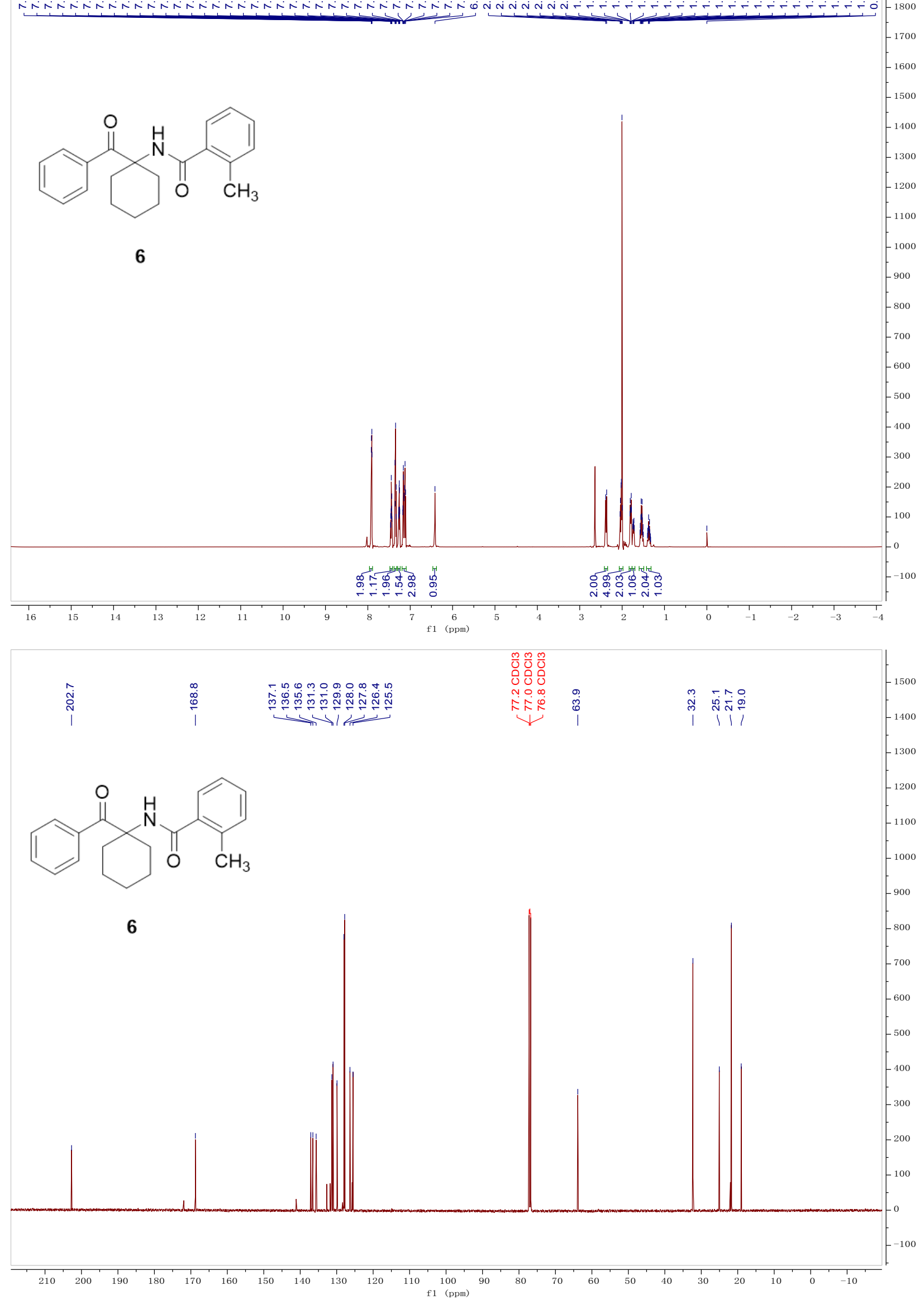

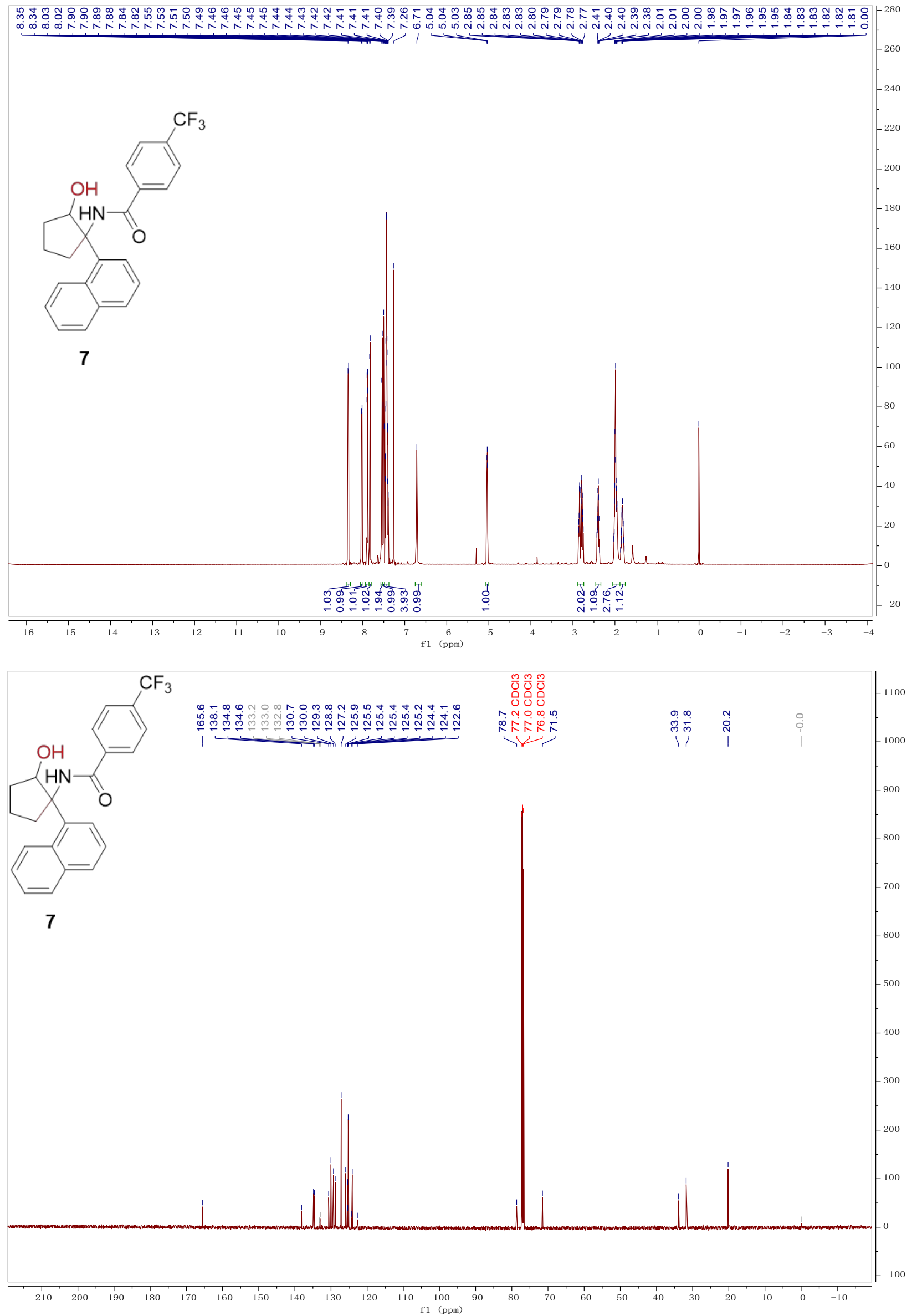